Engineer Research and

Development Center

\title{
Effects of Thermally Induced Microcracking on the Quasi-Static and Dynamic Response of Salem Limestone
}
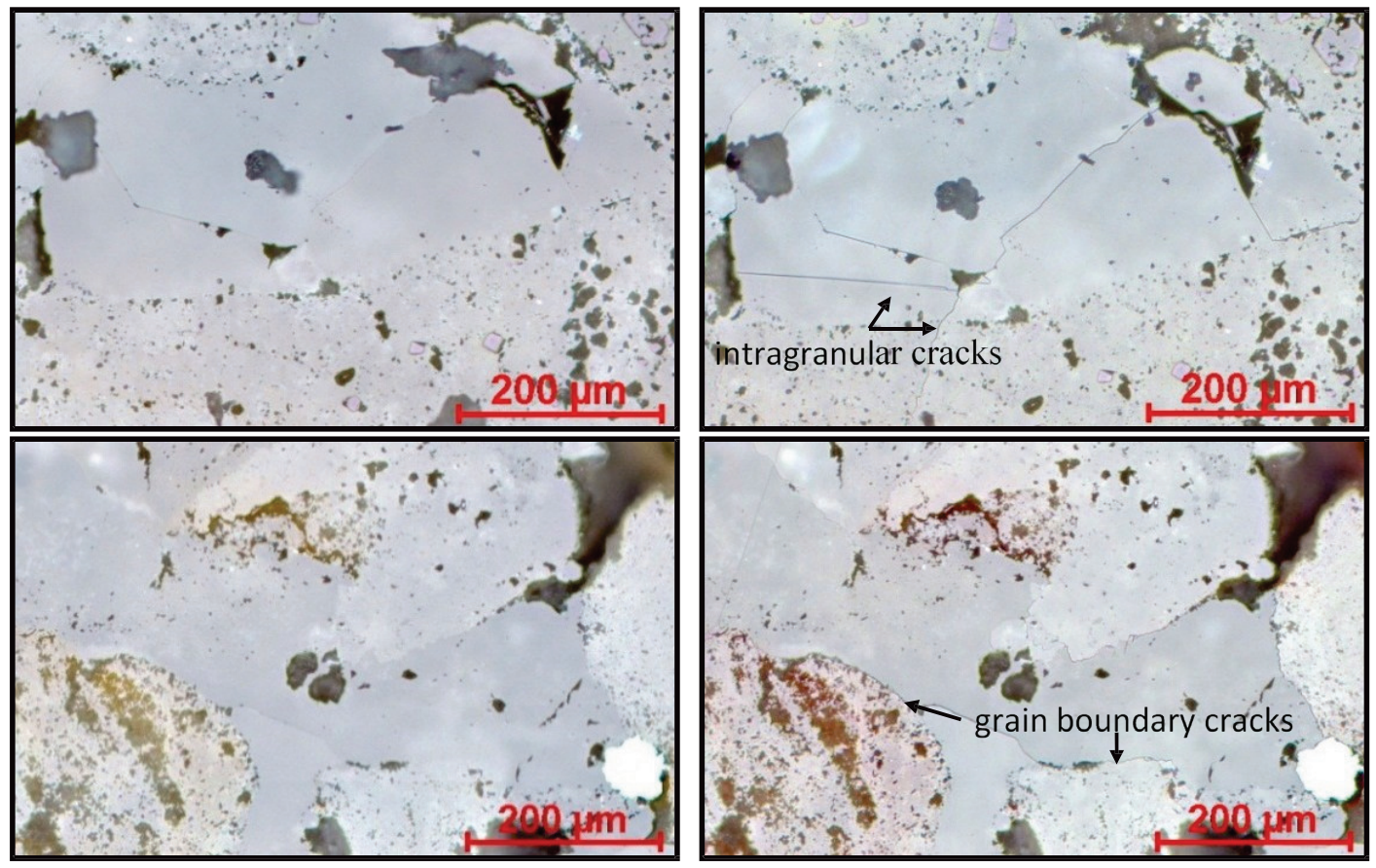
The U.S. Army Engineer Research and Development Center (ERDC) solves the nation's toughest engineering and environmental challenges. ERDC develops innovative solutions in civil and military engineering, geospatial sciences, water resources, and environmental sciences for the Army, the Department of Defense, civilian agencies, and our nation's public good. Find out more at www.erdc.usace.army.mil.

To search for other technical reports published by ERDC, visit the ERDC online library at http://acwc.sdp.sirsi.net/client/default. 


\title{
Effects of Thermally Induced Microcracking on the Quasi-Static and Dynamic Response of Salem Limestone
}

\author{
Z. Kyle Crosby \\ Geotechnical and Structures Laboratory \\ U.S. Army Engineer Research and Development Center \\ 3909 Halls Ferry Road \\ Vicksburg, MS 39180-6199
}

Final report

Approved for public release; distribution is unlimited.

Prepared for U.S. Army Engineer Research and Development Center

Vicksburg, MS

Under Project P2 331691, “Scalable Technology for Adaptive Response” 


\section{Abstract}

The effects of microcracking on the mechanical properties of Salem limestone were investigated in three phases: introduction of quantifiable levels of microcracks by thermal treating, mechanical testing of limestone samples with varying levels of microcracks, and modification of a numerical model to incorporate the measured effects. Computed tomography scanning, scanning electron microscopy, and optical microscopy (OM) were used to observe microstructural changes caused by the heat treatments. Mechanical testing was performed to characterize the mechanical response of the intact and damaged limestone. Quasi-static tests included uniaxial compression, triaxial compression, hydrostatic compression, and uniaxial strain / constant volume tests. Microcracking did not affect the limestone's strength at pressures greater than $10 \mathrm{MPa}$. Dynamic tests were performed using a modified split Hopkinson pressure bar.

The results of the mechanical tests were used to modify the HJC model. Modifications were made to account for shear modulus degradation and failure surface changes. The original and modified HJC models were used in a numerical analysis of the mechanical tests performed in this work. The modified HJC provided better results for damaged material when compared with the quasi-static and dynamic experiments. This work demonstrated that this approach is useful for examination of the effects of microcracking on quasi-brittle materials and can be used to improve the predictive capabilities of material models. 


\section{Contents}

Abstract.................................................................................................................................. if

Figures and Tables...............................................................................................................

Preface .........................................................................................................................vifi

Unit Conversion Factors.................................................................................................. ix

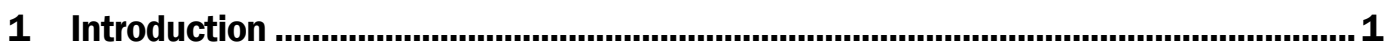

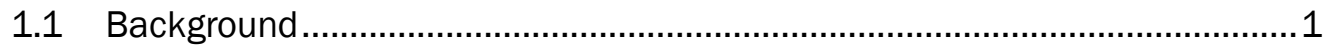

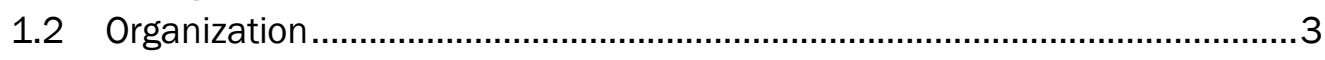

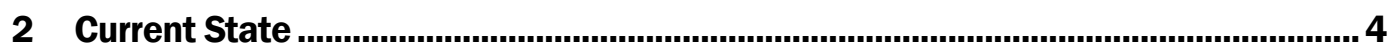

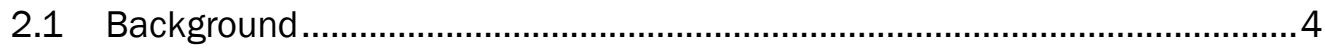

2.2 Mechanically induced microcracking ........................................................... 5

2.3 Thermally induced microcracking.............................................................. 8

2.4 Quasi-brittle material modeling ............................................................

2.4.1 Continuum damage mechanics models ............................................................ 11

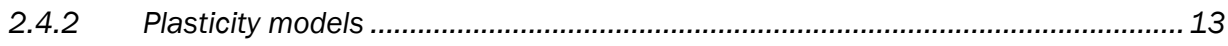

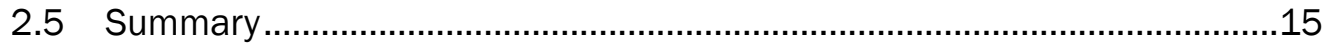

3 Inducing and Quantifying Damage .................................................................... 17

3.1 Overview ............................................................................................ 17

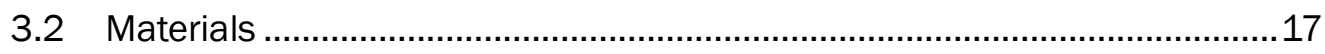

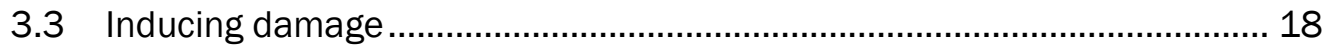

3.3.1 Thermal treating.................................................................................. 19

3.3.2 Wave velocities........................................................................................ 21

3.3.3 X-ray diffraction, thermogravimetric analysis, and differential scanning

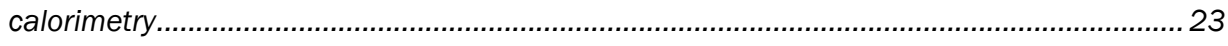

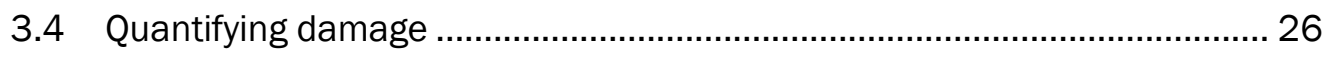

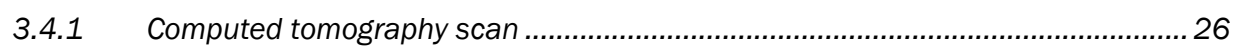

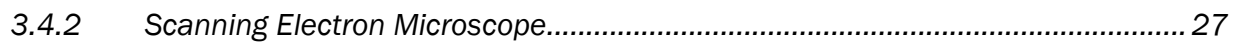

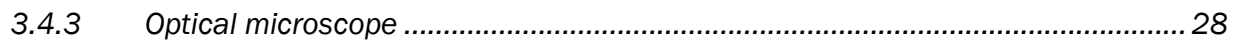

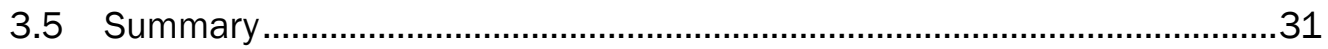

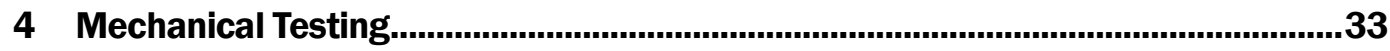

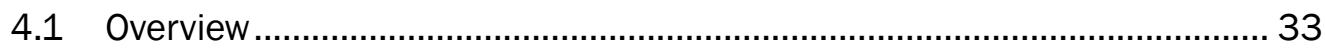

4.2 Quasi-static testing ....................................................................... 33

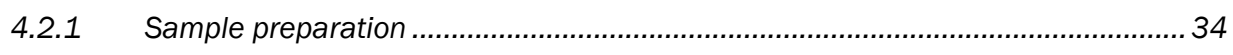

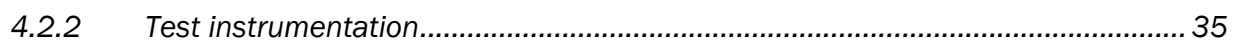

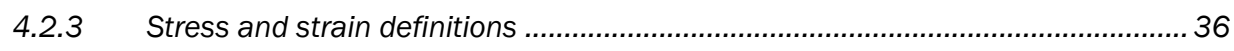

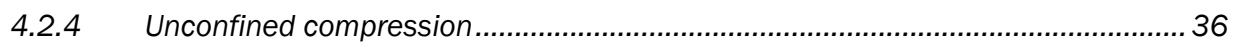

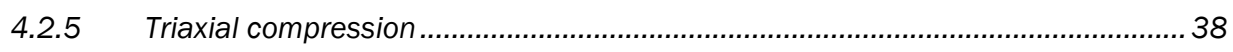

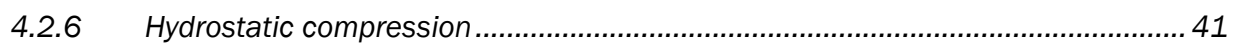


4.2.7 Uniaxial strain/constant volume strain path test............................................... 42

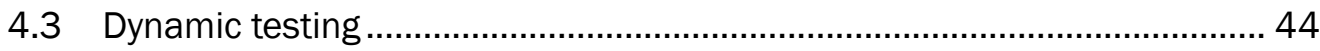

4.4 Summary ...................................................................................... 47

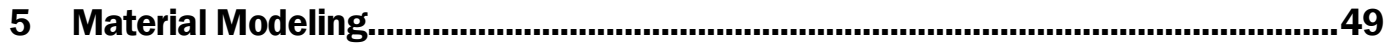

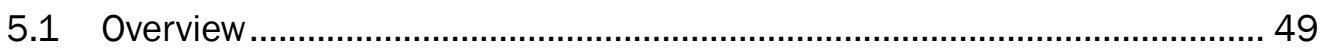

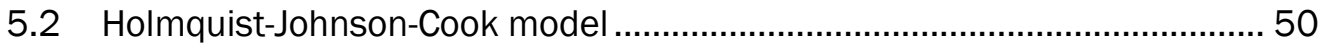

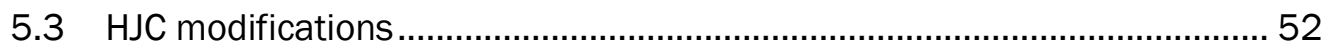

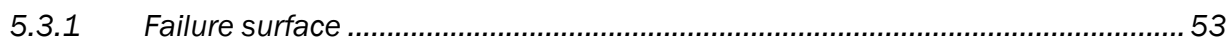

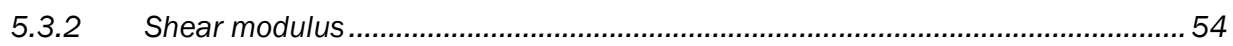

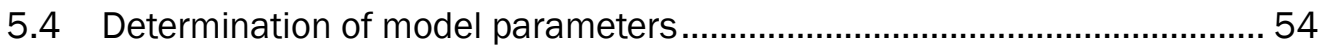

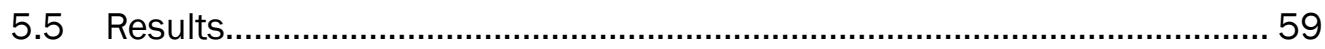

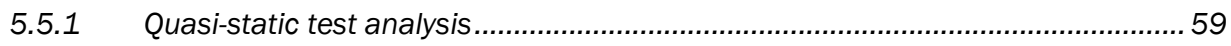

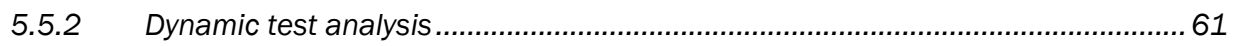

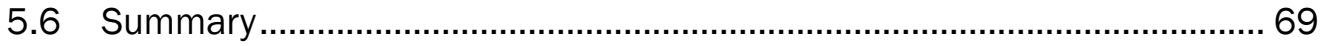

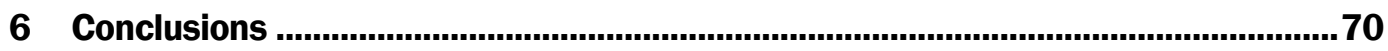

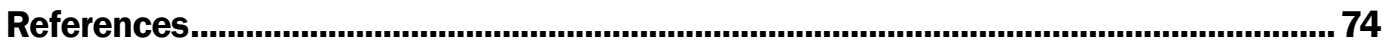

Appendix A: Quasi-Static Testing Results.................................................................... 78

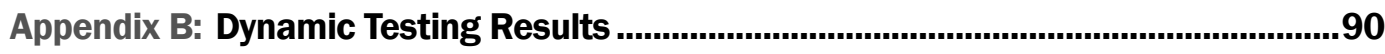

Appendix C: Mechanical Test Sample Properties ...................................................95

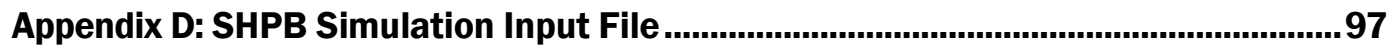

Report Documentation Page 


\section{Figures and Tables}

\section{Figures}

Figure 2-1. The shear limit surface of the HJC model. ......................................................14

Figure 3-1. Salem limestone blocks from Elliot Stone Company. .......................................17

Figure 3-2. Temperature vs. time for the heat treatments used for the mechanical

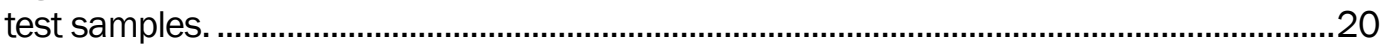

Figure 3-3. Percent volume change (left) and percent density change vs. maximum heat treatment temperature .................................................................................20

Figure 3-4. Sonic velocities for increasing maximum temperatures..................................21

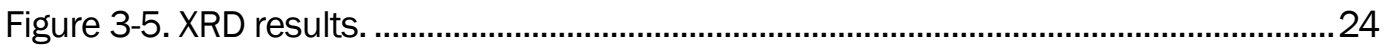

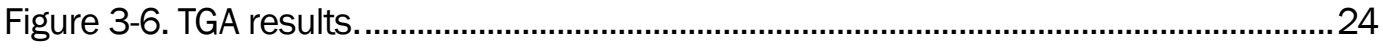

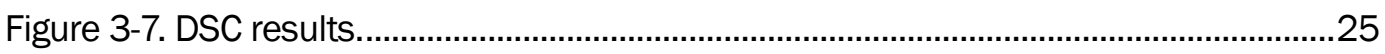

Figure 3-8. CT scan cross-section images from ( $L$ to $R$ ) untreated, $250^{\circ} \mathrm{C}$, and

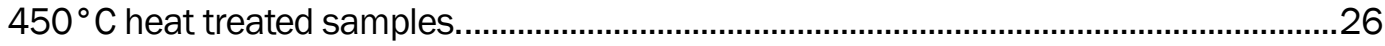

Figure 3-9. SEM images before $500^{\circ} \mathrm{C}$ heat treatment. ....................................................2

Figure 3-10. SEM images after $500^{\circ} \mathrm{C}$ heat treatment....................................................28

Figure 3-11. Salem limestone before (left) and after (right) $250^{\circ} \mathrm{C}$ heat treatment.

Figure 3-12. Salem limestone before (left) and after (right) $450^{\circ} \mathrm{C}$ heat

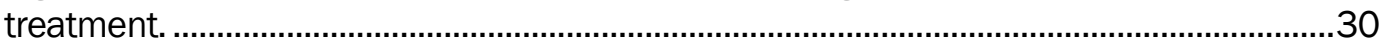

Figure 4-1. Typical test sample setup. ..............................................................................34

Figure 4-2. Lateral deformeters mounted on test specimen.............................................35

Figure 4-3. From left to right, principal stress difference vs. axial strain and principal stress difference vs. volumetric strain for undamaged and damaged samples during uniaxial compression.

Figure 4-4. 600-MPa pressure vessel details................................................................38

Figure 4-5. (L to R) Principal stress difference vs. axial strain and principal stress difference vs. volumetric strain for undamaged and damaged samples during triaxial compression with $10 \mathrm{MPa}$ confining pressure.

Figure 4-6. ( $L$ to R) Principal stress difference vs. axial strain and principal stress difference vs. volumetric strain for undamaged and damaged samples during triaxial compression with $20 \mathrm{MPa}$ confining pressure.

Figure 4-7. ( $L$ to R) Principal stress difference vs. axial strain and principal stress difference vs. volumetric strain for undamaged and damaged samples during triaxial compression with $100 \mathrm{MPa}$ confining pressure.

Figure 4-8. ( $L$ to R) Principal stress difference vs. axial strain and principal stress difference vs. volumetric strain for undamaged and damaged samples during triaxial compression with $400 \mathrm{MPa}$ confining pressure.

Figure 4-9. Pressure volume response for undamaged and damaged samples during hydrostatic compression to $400 \mathrm{MPa}$. 
Figure 4-10. Comparison of UX/CV and TXC tests with recommended failure surface.

Figure 4-11. (L to R) Mean Normal Stress vs. volumetric strain and principal stress difference vs. mean normal stress for undamaged and damaged samples during UX/CV tests.

Figure 4-12. Conventional SHPB setup.......................................................................44

Figure 4-13. Compression SHPB setup at MSU CAVS. .....................................................4

Figure 4-14. Modified SHPB Setup. .............................................................................45

Figure 4-15. Incident bar stress wave without (left) and with (right) a pulse shaper..

Figure 4-16. Interface stresses and strain rate from modified SHPB test on undamaged (top left), low damage (top right), and high damage samples (bottom left), and a comparison of the stress-strain responses for each damage level (bottom right). .46

Figure 5-1. Projectile penetration into concrete target. .......................................................49

Figure 5-2. The HJC failure surface showing the effects of damage..................................51

Figure 5-3. Pressure-Volume Response in HJC.

Figure 5-4. The original HJC failure surface (left) and proposed $\mathrm{HJC}$ failure surface (right). 53

Figure 5-5. Mackenzie damage parameter for various heat treatments. 55

Figure 5-6. (left) Model fit using HJC and (right) modified HJC for undamaged material ( $\mathrm{DO}=0)$ and (b) damaged material (D0=0.65). ....................................................56

Figure 5-7. Uniaxial compression data used to determine HJC damage constants...........57 Figure 5-8. Strain-time response for SHPB simulations with and without rate dependence...

Figure 5-9. Unconfined compression data compared with original HJC (left) and modified HJC model (right).

Figure 5-10. Triaxial compression data (10 MPa confining pressure) compared with original HJC (left) and modified HJC model (right).

Figure 5-11 Triaxial compression data (20 MPa confining pressure) compared with original HJC (left) and modified HJC model (right).

Figure 5-12. Triaxial compression data (100 MPa confining pressure) compared with original HJC (left) and modified HJC model (right).

Figure 5-13. SHPB geometry used in numerical analysis.

Figure 5-14. SHPB simulation of undamaged and damaged samples with (left) original $\mathrm{HJC}$ and (right) modified $\mathrm{HJC}$ model.

Figure 5-15. Stress-strain response from SHPB test showing stress levels for images in Figures 5.16 and 5.17.

Figure 5-16. Pressure in sample during SHPB test.

Figure 5-17. Effective confining pressure during SHPB test showing inertial effects on sample.

Figure 5-18. Pressure in the sample during the SHPB with a constant friction 
Figure 5-19. Effective confining pressure during SHPB test with a constant friction coefficient of 0.1 showing the effects of friction.

\section{Tables}

Table 3-1. Elastic moduli for samples with different heat treatments. ...............................22

Table 3-2. Stereological data from OM images for heat treated Salem limestone. ............31

Table 4-1. Mean peak principal stress difference during unconfined compression for undamaged and damaged samples.........................................................................37

Table 4-2. Mean peak PSD and volumetric strain for TXC tests on undamaged

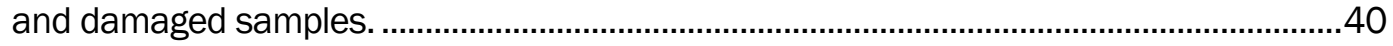

Table 5-1. Constants for the modified HJC model..............................................................58

Table 5-2. Energy comparison for SHPB tests with HJC and modified HJC models. ..........63

Table 5-3. Comparison of strengths from UC simulations and SHPB simulations with no friction and no rate dependency. . .64

Table 5-4. Variation in peak strength with various constant friction coefficients between bar-sample interfaces in SHPB simulation. 


\section{Preface}

This study was conducted for the U.S. Army Engineer Research and Development Center, Vicksburg, MS, under Project P2 331691, "Scalable Technology for Adaptive Response”. The technical monitor was Dr. Stephen A. Akers.

The work was performed by the Impact and Explosion Effects Branch (GMI) of the Engineering Systems and Materials Division (GM), U.S. Army Engineer Research and Development Center, Geotechnical and Structures Laboratory (ERDC-GSL). At the time of publication, Jeffrey G. Averett was Chief, CEERD-GMI; Dr. Gordon W. McMahon was Chief, CEERD-GM; and Pamela G. Kinnebrew, CEERD-GVT, was the Technical Director for Force Protection and Weapons Effects. The Deputy Director of ERDC-GSL was Dr. William P. Grogan, and the Director was Bartley P. Durst.

COL Bryan S. Green was the Commander of ERDC, and Dr. David W. Pittman was the Director. 


\section{Unit Conversion Factors}

\begin{tabular}{|c|c|c|}
\hline Multiply & By & To Obtain \\
\hline atmosphere (standard) & 101.325 & kilopascals \\
\hline bars & 100 & kilopascals \\
\hline cubic feet & 0.02831685 & cubic meters \\
\hline cubic inches & $1.6387064 \mathrm{E}-05$ & cubic meters \\
\hline cubic yards & 0.7645549 & cubic meters \\
\hline degrees (angle) & 0.01745329 & radians \\
\hline degrees Fahrenheit & $(\mathrm{F}-32) / 1.8$ & degrees Celsius \\
\hline feet & 0.3048 & meters \\
\hline foot-pounds force & 1.355818 & joules \\
\hline inches & 0.0254 & meters \\
\hline inch-pounds (force) & 0.1129848 & newton meters \\
\hline microns & $1.0 \mathrm{E}-06$ & meters \\
\hline miles per hour & 0.44704 & meters per second \\
\hline ounces (mass) & 0.02834952 & kilograms \\
\hline ounces (U.S. fluid) & $2.957353 \mathrm{E}-05$ & cubic meters \\
\hline pounds (force) & 4.448222 & newtons \\
\hline pounds (force) per foot & 14.59390 & newtons per meter \\
\hline pounds (force) per inch & 175.1268 & newtons per meter \\
\hline pounds (force) per square foot & 47.88026 & pascals \\
\hline pounds (force) per square inch & 6.894757 & kilopascals \\
\hline pounds (mass) & 0.45359237 & kilograms \\
\hline pounds (mass) per cubic foot & 16.01846 & kilograms per cubic meter \\
\hline pounds (mass) per cubic inch & $2.757990 \mathrm{E}+04$ & kilograms per cubic meter \\
\hline pounds (mass) per square foot & 4.882428 & kilograms per square meter \\
\hline pounds (mass) per square yard & 0.542492 & kilograms per square meter \\
\hline square feet & 0.09290304 & square meters \\
\hline square inches & $6.4516 \mathrm{E}-04$ & square meters \\
\hline square miles & $2.589998 \mathrm{E}+06$ & square meters \\
\hline square yards & 0.8361274 & square meters \\
\hline yards & 0.9144 & meters \\
\hline
\end{tabular}




\section{Introduction}

\subsection{Background}

This report examines three topics: the quantification of induced microcracking in Salem limestone, the effects of microcracks on its mechanical response, and the numerical modeling of that mechanical response. The first two topics deal with techniques to induce and quantify various levels of microcracking and determining changes in the mechanical response resulting from the microcracks. These topics are aimed at increasing the understanding of the effects of microscale properties on macroscale material response. The last topic introduces modifications to a commonly used numerical model intended to improve its predictive capabilities for materials containing defects such as microcracks. These studies demonstrate the importance of material characterization for varying levels of defects and how that characterization can be used to improve current predictive models.

The material used in this study is a quasi-brittle rock called Salem limestone. Salem limestone was chosen for this work mainly because it is a relatively homogeneous material and its quasi-brittle behavior should be analogous to other quasi-brittle materials such as concrete. Its relative homogeneity simplifies the microscale quantification and mechanical testing by reducing the number of microscale mechanisms involved in the material characterization and providing more consistent results to make the determination of microcrack effects more straightforward. Characterizing the effects of microcracking on this limestone should provide an easier transition to performing similar work on more complicated materials such as concrete, which have more complex chemistry and microstructure than limestone.

Understanding the mechanical behavior of quasi-brittle materials is the foundation of many civil engineering applications due to their wide use in civil and military structures. These materials include natural geological materials, such as limestone and granite, and engineered materials, such as concrete and ceramics. The evaluation of the mechanical properties of these materials has been largely based on their behavior in pristine condition, and that information is used when designing structures created from 
these materials. However, the mechanical behavior of these structures undergoes significant changes during their life cycle due to ordinary wear, vehicular impact (in civil applications), blast wave impact, and projectile penetration (in military applications) among other things. The changes that the structures undergo during these events should be taken into account if their continued use following these events is anticipated.

Vehicular and blast wave impact, projectile penetration, and even ordinary use causes microscopic damage in brittle materials, such as rock and concrete, in the form of microcracks. Furthermore, microcracks can be caused by stresses from mechanical or tectonic loading, differential expansion/contraction between grains from thermal loading, expansion of fluids in void space during freezing/thawing, or by various chemical processes. The nucleation and growth of microcracks significantly affect the macroscale behavior of the material by reducing the elastic properties, inducing material anisotropy, and causing irreversible strains due to crack openings. A better understanding of microstructural changes in brittle materials caused by these events and its effects on the macroscale mechanical response is needed to more accurately model the damaged response of a brittle material.

If a correlation between the microstructural changes in a material and its effects on the macroscale response is determined, it can be used in several ways:

1. Quantification of microscale changes following a loading event, such as a projectile impact, can be used to predict the material state, e.g. spatially varying microcrack densities, for similar events.

2. The correlation between the microstructural changes and macroscale response can be used in phenomenological models based on microscale phenomena to predict the material state following a loading event in lieu of actual experimental data.

3. The experimental data for the macroscale response of materials with varying levels of microcracks can be used to establish basic principles to guide the implementation of damage in empirical models.

This report addresses these issues by quantifying various levels of induced microcracks, determining the changes in mechanical behavior for various stress states and strain rates due to the microcracks, and applying the principles learned from these tests to a material model. 


\subsection{Organization}

This report covers the three main topics in five chapters: the quantification of induced microcracking in limestone (Chapter 3), the effects of microcracks on its mechanical response (Chapter 4), and the numerical modeling of that mechanical response (Chapter 5). Chapter 2 provides the current state of each of these topics and Chapter 6 summarizes the previous chapters and provides recommendations for future work.

In Chapter 2, the current state of microcrack characterization following mechanical and thermal loading will be reviewed. This review will concentrate on experimental work related to microcrack evolution instead of microcrack evolution theories. Following the microcrack evolution discussion, two types of phenomenological material models currently being used to predict the behavior of damaged brittle materials will be discussed. This discussion will provide details on how the models implement damage and its effects on the macroscale mechanical response.

Chapter 3 will provide the experimental techniques used in this work to quantify microcracking. The chapter is divided into four sections to provide information on the material used in this work, the experimental method used to induce damage, the experimental methods used to quantify the induced damage, and the results obtained from those experimental methods. The sample preparation methods for each experimental method used will also be given.

In Chapter 4, test methods to get the mechanical properties of the material will be discussed along with the results of those tests. Mechanical testing was performed to characterize the mechanical response of the material with varying amounts of microcracking at low and high strain rates for various loading states. The sample preparation methods are given along with the servo-hydraulic loading techniques used in quasi-static tests and the split Hopkinson pressure bar technique used in the dynamic tests. Chapter 5 presents a numerical analysis of the mechanical tests discussed in Chapter 4. The numerical analysis was performed using a commonly used concrete plasticity model. Modifications to the model are made to account for changes in the mechanical behavior due to the induced microcracking. The results from the original and modified model are compared to demonstrate the improvements due to the modifications.

Lastly, Chapter 6 is the conclusion to this report. This chapter summarizes the previous chapters and provides recommendations for future work. 


\section{Current State}

In this chapter, an overview is presented of the current state of the three topics examined in this report: the quantification of induced microcracking, the effects of microcracking on the mechanical response of quasi-brittle materials, and the numerical modeling of the mechanical response. Regarding the first two topics, the literature most relevant to this work will be discussed and how this work seeks to further the understanding of these topics. For the numerical modeling, the goal is not to give an exhaustive list of the available models for quasi-brittle materials but to give an overview of the different methods to simulate damaged mechanical behavior proposed in literature along with an in-depth description of a commonly used material model that is modified in Chapter 5 based on the experimental data found in this work.

\subsection{Background}

The quasi-brittle material used in this study is commonly referred to as Indiana, Salem, or Bedford limestone. This particular rock was chosen for this work because of its relative homogeneity, the availability of test data from other work (Cummins 1991; Frew 2001; Frew et al. 2001), and its mechanical behavior should be analogous to other quasi-brittle materials, e.g., concrete, ceramics, and other rocks. These materials are referred to as quasi-brittle because they exhibit moderate strain hardening prior to attaining their strength, followed by a strain softening behavior (Karihaloo 1995).

Generally, quasi-brittle materials are composed of a hard, solid material (grains, aggregates, crystals) and a softer matrix material, or bond system. The matrix material, even in intact samples, usually contains an abundance of defects including microcracks, pores, and weak interfacial zones. Additional microcracks nucleate and grow due to stresses induced by mechanical or tectonic loading, differential expansion/contraction between grains from thermal loading, expansion of fluids in void space during freezing/thawing, or by various chemical processes. The presence of microcracks in the material affects the macroscale behavior of a material by causing non-linearity of stress- strain relations, reducing the stiffness and strength, inducing material anisotropy, and causing irreversible strains due to cracks opening among other effects (Shao and Rudnicki 2000). Many studies have shown the effects of microcracking on quasi-brittle 
material properties. This review will focus on those showing the effects of microcracking caused by mechanical and thermal loading because those studies are most relevant to this work.

Microcrack properties cannot be used to determine the stress and deformation history of a material (Wawersik and Brace 1971). However, microcrack properties can be used to predict the mechanical properties of a material, and there remains a need to correlate microscale phenomena with the macroscale mechanical behavior. To meet that need, this work seeks to link the mechanical response of limestone to physical changes at the microstructural level with a view to improving the predictive capabilities of engineering material response models. This includes providing much needed mechanical test data for materials with varying levels of microcracks. One of the intentions of this work is to establish experimental methods that can be applied to all quasi-brittle materials; as such, this review will cover the effects of microcracking for a variety of quasi-static materials. For more detailed information and a review of microcracking, see Kranz (1983).

\subsection{Mechanically induced microcracking}

During the mechanical loading of quasi-brittle materials, microcracks nucleate, grow, and coalesce under deviatoric stresses (as opposed to hydrostatic stresses that mainly affect pores) to cause failure. Initially, microcracks increase in the weak interfacial zone between aggregates and matrix material or along grain boundaries. As loading increases, microcracks coalesce into continuous mesoscopic cracks, usually parallel to the major principal axis in compression. Approaching the failure stress, the micro- and mesoscale cracking leads to a localization of cracks composed of a system of bridging macrocracks. This localization continues to total failure by the development of a single macrocrack (Mertens 2009). For example, microcracking during uniaxial loading begins when the stress level is between 30 and 50 percent of the compressive strength in compression (Brace et al. 1966) and between 50 and 80 percent of the tensile strength in tension (Ockert 1997 in Riedel et al. 1999). Above that stress level, microcracks continue to develop and coalesce into a macroscale crack at failure.

Studies have examined the relationship between the mechanical loading process and microcracking during different stages of mechanical loading using optical microscopy (OM) and scanning electron microscopy (SEM). 
All of these studies analyzed microcracks from samples that had been created following mechanical loading, unloading, and sample preparation for the observational studies. The studies most relevant to this work are discussed next. The particular findings of these works are not the focus of the review, but rather the methods used to obtain the microscale properties after mechanical loading.

Hadley (1976) examined microcracks prior to failure for Westerly granite samples loaded in triaxial compression up to $80 \mathrm{MPa}$ confining pressure. The samples stressed from the triaxial tests were analyzed with SEM using a direct measurement approach.

The direct measurement approach consists of directly measuring crack lengths and orientations on a plane section (Wong 1985) and was used in this work to determine crack lengths, widths, and orientations.

Golshani et al. (2006) also used the direct measurement approach to determine microcrack lengths and densities of samples loaded in uniaxial and triaxial compression. Confining pressure of 20, 40, 60, and $80 \mathrm{MPa}$ were used and microcrack properties were measured at various deviatoric stresses for each confining pressure. The microcrack measurements were used to validate the material model presented in the paper.

Wawersik and Brace (1971) quantified microcracks from two rocks (Westerly granite and Frederick diabase) that had been loaded to different stages in the post-failure region in uniaxial and triaxial compression. A mechanical testing technique was used to load the samples at and beyond the ultimate strengths of the materials. The confining pressures used went up to approximately $150 \mathrm{MPa}$ for granite and $15 \mathrm{MPa}$ for diabase. Following the post-failure loading, polished sections were made for $\mathrm{OM}$ analysis using a geometric probability approach for crack measurements. The geometric probability approach involves counting the number of intersections between microcracks in a plane section with an array of parallel lines (Wong 1985). The microstructural analysis yielded information on crack densities, crack orientations, and their location relative to grain boundaries.

Homand et al. (2000) examined microcracks prior to failure for Vienne granite samples loaded in triaxial compression at $5 \mathrm{MPa}$ confining pressure. OM analyses were done on intact samples and samples loaded to 60, 
$80,90,99$, and 100 percent of the strength of the material. The geometric probability approach was used to measure crack densities and orientations from these tests.

Fredrich et al. (1989) also used the geometric probability approach to examine pre-failure samples of Carrarra marble. The samples were loaded in triaxial compression at various deviatoric stresses and at confining pressures up to $450 \mathrm{MPa}$. After samples had been loaded to the desired stress state and unloaded, crack densities in two orthogonal directions were measured using OM.

Tapponnier and Brace (1976) used the geometric probability approach to examine samples triaxially tested in the pre- and post-failure regions. For the pre-failure tests, samples were loaded to stresses at various increments of the peak strength of the material, unloaded, and observed using SEM. The post-failure samples were those created by Wawersik and Brace (1971).

Each of these six studies analyzed microcracks after loading to a particular stress state, unloading, and sample preparation for the microscale analyses. When analyzing samples created during this process, it is unclear whether the microscale properties taken after the load/unload cycle to a particular stress represents the actual microscale properties at that stress state. Before using this data to determine a correlation between the quantified microscale properties and its effects on the mechanical properties, this method should be validated to show that the microscale properties determined from this method represent the microstructural state of the stress state from which they were taken. Nonetheless, mechanical testing can be used to induce microcracking for the purpose of correlating microstructural properties with mechanical response as long as the mechanical response is tested following the microstructural characterization.

Zhao (1998) used real-time SEM during loading to observe microcracking in Fangshen marble. Microcrack lengths and orientations were directly measured during uniaxial loading using SEM on a $20 \mathrm{~mm} \times 5 \mathrm{~mm}$ × $2 \mathrm{~mm}$ sample (4 $\mathrm{mm} 2$ area of observation). The data from this method is preferred over that taken from samples that have been subjected to a load/unload cycle because the microcracking observed during loading is clearly correlated to a particular stress state. However, this method can only be used for uniaxial compression tests limiting its applicability. This method 
is also limited to small samples, and it may be difficult to test materials with large aggregates or grain sizes.

To link the mechanical response of limestone to physical changes at the microstructural level, this work induces various levels of microcracking prior to mechanical testing. This method avoids the uncertainty associated with the results obtained following a load/unload cycle. This method can also be used on relatively large samples and to test samples under multiaxial stress states, which cannot be done using real-time observation techniques. Though mechanical testing is a viable option to induce microcracking, thermal treating is used to induce various levels of microcracking in this work for reasons mentioned later.

\subsection{Thermally induced microcracking}

When quasi-brittle materials are subject to thermal loading (i.e., heating to a maximum temperature followed by cooling back to room temperature), microcracking is induced by slight differences in the coefficient of thermal expansion between grains, which cause differential expansion or contraction under sufficient thermal load. In rocks, new microcracks are formed after the previous maximum temperature has been exceeded (Johnson et al. 1978; Yong and Wang 1980). Slow, uniform heating above the previous maximum temperature cause grain boundary separation and intragranular cracking (Sprunt and Brace 1974; Simmons and Richter 1976; Friedman and Johnson 1978; Bauer and Johnson 1979; Kranz 1983) while large heating rates result in thermal gradients that can cause additional microcracking (Johnson and Gangi 1980).

To determine the effects of thermal loading on microstructural properties, studies have been performed to investigate microcracking using $\mathrm{OM}$ and SEM following thermal treating to various maximum temperatures. Some studies (Fredrich and Wong 1986; Lin 2002) quantified microcracks after various thermal treatments but did not perform mechanical tests to determine a correlation between the microcracking and changes in mechanical properties. Other studies (Friedman and Johnson 1978; Homand-Etienne and Troalen 1984; Yavuz et al. 2010) provided only qualitative changes in the materials following heat treatments and also did not perform mechanical tests. Because this work is investigating the correlation between microcracking and its effects on the mechanical response, only those studies that investigated microcracks with corresponding mechanical tests will be reviewed. 
Keshavarz et al. (2010) performed uniaxial compression tests on gabbro samples heated up to $1000^{\circ} \mathrm{C}$. The uniaxial compression data showed a steady decrease in strengths up to $600^{\circ} \mathrm{C}$ and a sharp decrease thereafter. The qualitative $\mathrm{OM}$ analysis showed that microcracks were the main source of strength reduction up to $600^{\circ} \mathrm{C}$, and phase transformations (in this case, oxidation of certain minerals) and bursting of fluid inclusions (there was no indication that materials were dried before heating) caused an increased strength reduction rate thereafter. However, microcracking was not quantified in this study so no correlation can be made between the microstructural changes and its effects on the mechanical properties.

Ferrero and Marini (2001) performed uniaxial compression tests on two marbles (Ormea black marble and Perlato Sicilia marble) heated up to $600^{\circ} \mathrm{C}$. The mechanical test data showed decreasing elastic moduli, tensile strengths, and sonic velocities with increasing maximum temperatures in the heat treatments. The OM analysis on each material also showed an increase in microcrack density for each material with increasing temperatures.

Homand-Etienne and Houpert (1989) performed uniaxial compression, hydrostatic compression, and uniaxial tension tests on two granites (Senones and Remiremont granite) heated up to $600^{\circ} \mathrm{C}$. The study showed that crack density increases and elastic moduli and strengths decrease as function of the maximum temperatures obtained in the heat treatments. The study also found the elastic moduli to be more sensitive to microcracks than the compressive strengths.

Lastly, Bauer and Johnson (1979) performed uniaxial and triaxial compression (confining pressures up to $60 \mathrm{MPa}$ ) and uniaxial tension tests on two granites (Westerly and Charcoal granite). The study found that below $500^{\circ} \mathrm{C}$ formation of new microcracks was the primary microstructural change; above $500^{\circ} \mathrm{C}$, cracks widened and the material went through a phase transformation. Regarding the mechanical testing, the tensile strengths of the granites did not decrease until maximum heat treatment temperatures exceeded $200^{\circ} \mathrm{C}$. The compression tests showed that confining pressure reduced the effects of microcracks on the compressive strength.

Each of these studies showed strength and elastic moduli decreases with increasing temperatures. Bauer and Johnson (1979) also observed that as 
confining pressures increased, the effects of microcracking on strength decreased. Bauer and Johnson (1979), Homand-Etienne and Houpert (1989), and Ferrero and Marini (2001) performed quantitative microcrack analyses along with their mechanical tests, so these studies could be used to correlate microcracking with macroscale material behavior.

Similar to these studies, this work characterizes microcracking in Salem limestone following thermal treating to various maximum temperatures. However, the focus of this work is to provide data on a material with varying levels of microcracks (and methods to test other quasi-brittle materials) with a view to improving predictive capabilities of engineering material response models. With this focus in mind, the thermal treatment was limited to maximum temperatures below which microcracking is the only microscale phenomenon occurring. This ensures that the quantified microcrack data and corresponding mechanical tests could also be correlated with mechanically induced microcracking. This work also provides additional mechanical tests than previous studies; the mechanical tests done in this work includes uniaxial compression (quasi-static and high strain rate), triaxial compression (confining pressures up to $400 \mathrm{MPa}$ ), hydrostatic compression, and uniaxial strain/constant volume strain path tests (explained in later chapters). This data set can be used to provide insight on quasi-brittle material behavior at multiple stress states and strain rates, which is vitally important when modeling these materials.

\subsection{Quasi-brittle material modeling}

The ability to model the behavior of structures consisting of quasi-brittle materials, such as concrete and rock, is important in many civil engineering applications due to their wide use in civil and military structures.

These models are necessary for the entire life cycle of the structure beginning at the design stage and extending throughout the life of structure, including renovations and repairs following damaging events.

Quasi-brittle materials exhibit complex behavior that is often non-linear and changes with varying stress states, strain rates, and damage. Each of these aspects must be taken into account in order to adequately design structures made from quasi-brittle materials.

Numerical models generally used to predict the behavior of quasi-brittle materials are categorized as either micromechanical models or phenomenological models. 
Micromechanical models attempt to model real physical mechanisms involved in inelastic deformation, such as microcrack nucleation and propagation, but are not suited for structural scale problems because representative volumes of the material are explicitly modeled (Hoxha and Homand 2000). Phenomenological models are developed in the irreversible thermodynamic framework with relatively simple macroscopic constitutive equations (Shao et al. 1999; Hoxha and Homand 2000; Shao and Rudnicki 2000) and do take into account the origin of the damage. These models comprise many different types of models including classical plasticity models, hypoelastic models, nonlinear elastic models, viscoplastic models, and continuum damage mechanics models among others (Bazant and Prat 1988).

Because this work is intended for use on the structural scale, this review will look at two types of phenomenological models, continuum damage mechanics models and plasticity models. The intent of this section is not to provide an exhaustive review of all phenomenological models but to provide an idea of how these two types of models handle damage and how they can be improved by the experimental data presented in this work.

To show how quantified microcrack data is used in brittle material models, the continuum damage mechanics models of Hoxha and Homand (2000), Shao and Rudnicki (2000), and Golshani et al. (2006) will be discussed first. Due to the inherent complexity of continuum damage mechanics models and the experimental focus of this work, a general description of these models is given without their theoretical basis. Then, the commonly used Holmquist-Johnson-Cook concrete model (Holmquist et al. 1993) will be discussed, which will give insight into damage formulations in a plasticity model.

\subsubsection{Continuum damage mechanics models}

In continuum damage mechanics models, microscopic events during loading such as microcrack initiation, growth, and kinetics are represented in the macroscopic response by scalar or tensor variables. Because the microscopic events are taken into account, these models can offer information on microcrack related quantities, e.g., microcrack density, length, and orientation, during loading (Golshani et al. 2006). However, it is difficult to quantify the microcracking and apply it to applications using these models (Zhou 2010). Of this type of model, three of the most relevant models to 
this work will be discussed further, Hoxha and Homand (2000), Shao and Rudnicki (2000), and Golshani et al. (2006).

Hoxha and Homand (2000) proposed a micromechanics-based damage model that uses a stereological parameter to capture the changes in crack geometry. The stereological parameter is the number per unit length of crack intersections with a test line defined for a given direction. They used the published results of previously mentioned microscopic analyses (Hadley 1976; Wong 1985; Zhao 1998; Homand et al. 2000) to formulate their microcrack evolution equations. The evolution of the crack geometry is used to predict the effective properties of the material during compressive loading. This model can provide good agreement with laboratory tests until the last stage of testing when crack coalescence begins. At that point, the simulations deviate from the test data. This model was only used for compressive stress states.

Shao and Rudnicki (2000) have also proposed a micromechanics-based damage model, which uses an internal variable to represent the density and orientation of microcracks. They performed their own tests to induce damage for their proposed microcrack evolution that consisted of confined compression tests at different confining pressures. This macroscale data and various assumptions about the microcrack growth are used to correlate the macroscale data with microscale events. No efforts were made to verify whether the assumed microscale events were actually occurring. As with Hoxha and Homand (2000), the model works well until the samples are near failure. At this point, the model is not in agreement with experimental data.

The proposed model of Golshani et al. (2006) predicts changes in microcrack lengths and density and compares those microcrack changes with experimental data.

They performed their own tests to induce and quantify damage, which consisted of confined compression tests at different confining pressures. During mechanical testing, the deviatoric stresses were varied in order to monitor crack property changes at the various deviatoric stresses. As with the other two models, the final stages of testing do not compare well with experimental data, but the model was able to predict the overall trend of changes in microcrack length and density under triaxial loading. 
The models by Hoxha and Homand (2000) and Shao and Rudnicki (2000) account for measurable microcrack properties and their evolution, but they do not provide evidence that the models predict the actual microcrack evolution during loading. Only the effects on the macroscale response are given in the form of stress-strain relationships. The model of Golshani et al. (2006) showed how microcracks evolved with stress along with the macroscale stress-strain relationships. Golshani stated, 'any micromechanical model is not fully justified even if the predictions, on a macroscale, agree well with experimental results.' Though the initial damage state may be correctly implemented, the damage evolution should be compared with experimental results to ensure the model is capturing the damage evolution correctly.

\subsubsection{Plasticity models}

The complexity of continuum damage mechanics has mostly limited their use to research endeavors. In constrast, the relative simplicity of plasticity models has resulted in more widespread use. The simplicity of the plasticity models comes from their implementation of relatively simple macroscopic constitutive equations that do not take into account the origin of damage. To show how the experimental data obtained in this work can be used to improve material models in general, the Holmquist-Johnson-Cook (HJC) model (1993), a popular material model for impact problems, has been chosen for modification based on the material response observed in this work.

The HJC model is an elastic-viscoplastic model with isotropic damage for concrete subjected to large strains and high strain rates and pressures. This model is included because it has been widely used, modified (Riedel et al. 1999; Gebbeken and Ruppert 2000; Polanco-Loria et al. 2008), and takes into account the most important issues of brittle material behavior, such as pressure dependency, rate dependency, pressure-volume changes, and damage.

In the HJC model, the material is linear elastic until the failure surface, or shear limit surface, is reached and damage is accumulated by inelastic deformations. Damage then affects the material by reducing the cohesive strength value, A, in the failure surface given in Eqs. 2.1 and 2.2. 


$$
\begin{gathered}
\sigma^{*}=\left[A(1-D)+B P^{* N}\right]\left[1+C \ln \dot{\varepsilon}^{*}\right] \text { for } \sigma^{*} \leq S M A X \\
\sigma^{*}=S M A X \text { for } \sigma^{*}>S M A X
\end{gathered}
$$

In Eqs. 2.1 and 2.2, $\sigma^{*}$ and $P^{*}$ are the deviatoric stress and pressure normalized with respect to the unconfined compressive strength of the material, $f^{\prime}{ }_{c}$, respectively, and $\varepsilon^{*}$ is the strain rate normalized to a reference strain rate (usually $1 \mathrm{~s}^{-1}$ ). A, B, N, and C are material constants, and SMAX is the maximum strength. $\mathrm{D}$ represents damage and is given by

$$
D=\sum \frac{\left(\Delta \varepsilon_{p}+\Delta \mu_{p}\right)}{\left(\varepsilon_{p}^{f}+\mu_{p}^{f}\right)}
$$

where $\Delta \varepsilon_{p}$ and $\Delta \mu_{p}$ are the equivalent plastic strain increment and equivalent volumetric strain increment, respectively, and $\varepsilon_{p}$ and $\mu_{p}$ those strains at failure. The failure surface and the effect of damage on it are shown in Figure 2-1.

Figure 2-1. The shear limit surface of the HJC model.

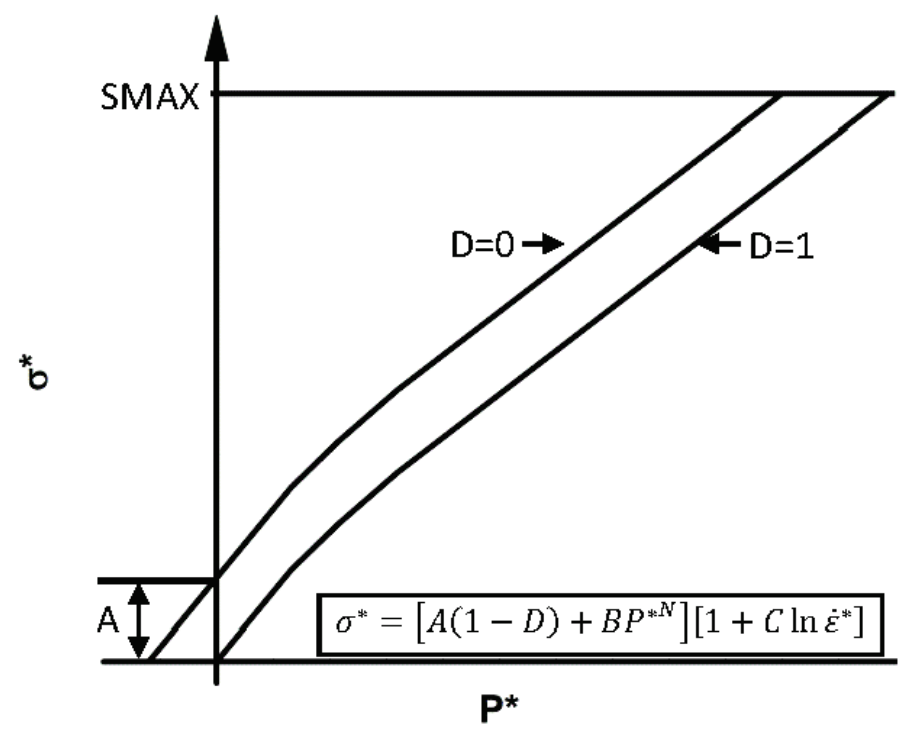

Though this model takes into account some important aspects of concrete behavior, some behavior is not accounted for such as the non-linearity before peak load, stiffness degradation and recovery, induced anisotropy, and shear strength differences between tension and compression (Polanco-Loria et al. 2008). There is no evidence to support that the damage 
effects implemented in the HJC model, given in Eqs. 1 and 2 and shown in Figure 1, reflect what actually occurs when the material is damaged.

To improve the implementation of damage in the HJC model, basic principles determined from the experimental data performed in this work were used to make modifications to the model. The goal of these modifications was to improve the prediction capabilities for damaged materials under varying stress states and strain rates. For comparison, results from the original HJC model and the modified version are compared to the experimental data.

\subsection{Summary}

The first portion of this review covered microcracking, the primary damage mechanism in quasi-brittle materials. The effects of both mechanically and thermally induced microcracking were discussed, which included studies that correlated quantified microcracks with changes in macroscale mechanical behavior. The studies using mechanical loading to induce microcracking performed their microstructural analysis after a loading/unloading cycle, which leads to some uncertainty about how the microstructural characterization is related to the stress state from which it was taken.

Regarding the studies on thermally induced microcracking, the effects of microcracking on a limited number of stress states were investigated.

To address these issues, this work induced various levels of microcracking prior to mechanical testing that included uniaxial compression (quasistatic and high strain rate), triaxial compression (confining pressures up to $400 \mathrm{MPa}$ ), hydrostatic compression, and uniaxial strain/constant volume strain path tests. This data set can be used to provide insight on microand macroscale quasi-brittle material behavior at multiple stress states and strain rates, which is necessary when modeling these materials.

Four phenomenological material models have been discussed including three continuum damage mechanics models and a plasticity model. The recent development of micromechanical-based damage models have allowed for internal variables based on physical mechanisms such as microcrack densities and orientations. However, there is still much work before these can be used in a predictive capacity. They work well for predicting overall effective stiffness but cannot predict failure because it is 
usually due to the growth of cracks of one orientation (Hoxha and Homand 2000) or frictional-dilatant slip in a particular direction (Bazant and $\mathrm{Zi} \mathrm{2003).} \mathrm{The} \mathrm{HJC} \mathrm{plasticity} \mathrm{model} \mathrm{was} \mathrm{also} \mathrm{discussed} \mathrm{because} \mathrm{of} \mathrm{its} \mathrm{wide-}$ spread use and simplicity of its constitutive equations.

Though the HJC model captures important aspects of concrete behavior, there are still other important aspects that should be considered. Strength and stiffness degradation due to damage are the aspects addressed in this work.

There is a very limited amount of experimental data with which to calibrate and validate any of the material models mentioned. The micro- and macroscale data provided by this work will aid in the development of continuum damage mechanics models by providing additional data sets for use in model validation and calibration. The data in this work should also aid in the development of plasticity models by providing basic principles with which to formulate the macroscale response of a damaged material. To show how this work can be used to improve phenomenological plasticity models, the effects of damage characterized in this work are used to modify the damage implementation in the HJC concrete plasticity model. 


\section{Inducing and Quantifying Damage}

\subsection{Overview}

This chapter is divided into three sections: Indiana limestone description; the experimental method used to induce damage; and the experimental methods used to quantify the induced damage. After the material description, the thermal treating method used to induce damage in the samples will be discussed. Then, the methods used to quantify that damage will be given along with the results of the quantification.

\subsection{Materials}

The material used in this study is commonly referred to as Indiana, Salem, or Bedford limestone. The material is of Mississippian age and is a commonly used building stone material. It was quarried and cut by the Elliot Stone Company of Bedford, IN, into 18-in. by 18 -in. by 12 -in. blocks (see Figure 3-1). Indiana limestone is composed primarily of calcium carbonate $\left(\mathrm{CaCO}_{3}\right)$, or calcite, that forms the grains and the cementing material that binds the grains. The limestone is uniform in composition, texture, and structure and is practically non-crystalline in character (ILI Handbook 2007).

Figure 3-1. Salem limestone blocks from Elliot Stone Company.
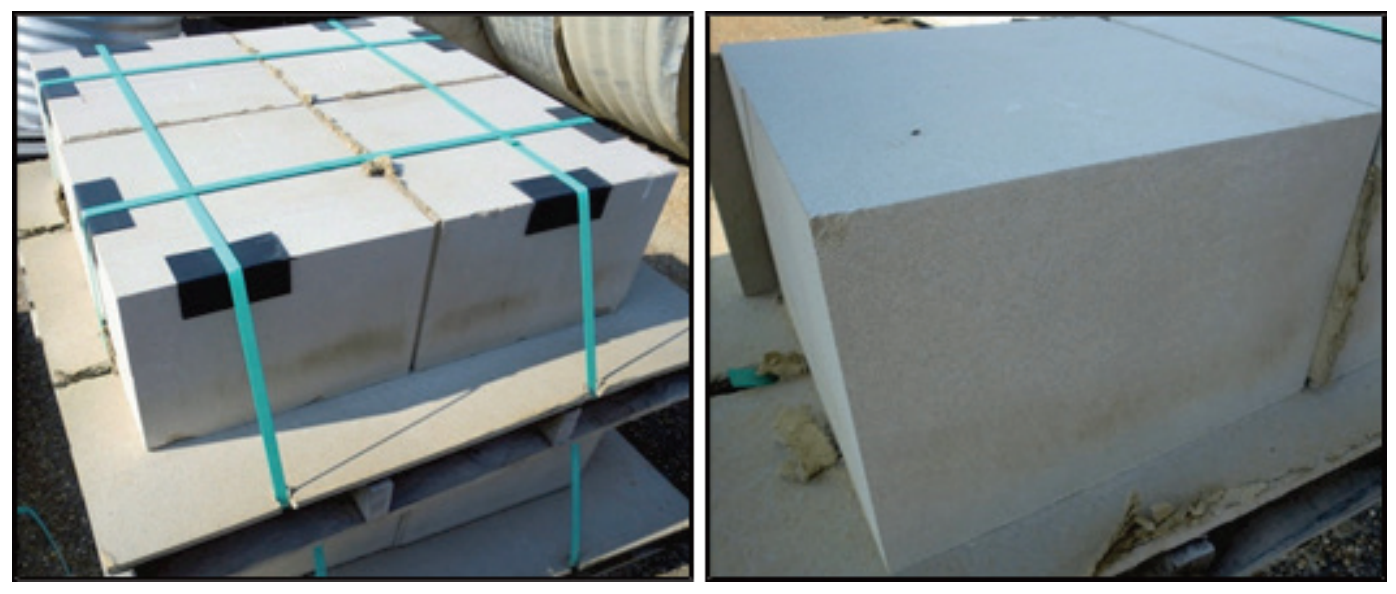

The minimum compressive strength of Indiana limestone (ILI Handbook 2007) is approximately 27.6 MPa (4000 psi). Frew et al. (2010) found the unconfined compressive strength to be approximately $65 \mathrm{MPa}$ (9400 psi). Porosity varies between 12 and 21 percent, depending on quarry location (Churcher et al. 1991; Fossum et al. 1995). The ILI Handbook (2007) also 
gives a range for bulk specific gravity between 2.1 and 2.75, and modulus of elasticity between 22,750 and $37250 \mathrm{MPa}(3,300,000-5,400,000 \mathrm{psi})$. The material used in this work had an unconfined compressive strength of $72 \mathrm{MPa}$ (10400 psi).

This particular material was chosen for this work for three reasons: (1) There have been several other studies done on Salem limestone that provide additional test data (Cummins 1991; Frew 2001; Frew et al. 2010); (2) Its mechanical behavior should be analogous to other quasi-brittle materials, e.g., concrete, ceramics, and other rocks; and

(3) This limestone is relatively homogeneous compared to other quasibrittle materials, which was desired when developing the test method used in this work.

\subsection{Inducing damage}

In order to study the effects of microcracking on the mechanical properties of limestone, a method of inducing consistent levels of damage in the limestone samples is needed. Mechanical loading, thermal treating, freezing/thawing, and chemical treating have been used to investigate the processes involved in mechanical or tectonic loading, thermal loading, weathering, and corrosion, respectively. However, thermal treating was chosen for the reasons discussed next.

Thermal treating is the process of heating a material to a maximum temperature and cooling the sample back to room temperature. This process induces microcracks because slight differences in the coefficient of thermal expansion between grains cause local stresses. If the maximum temperature is kept below that which causes changes in the material composition, the microstructural changes caused by the heat treatments should be comparable with that caused by mechanical loading and freezing/thawing.

Chemical treating of the samples was not chosen to induce microcracking because it may cause changes that are not related to the damage mechanisms found in mechanical loading, thermal treating, and freezing/thawing.

Thermal treating was chosen to induce microcracking rather than mechanical loading and freezing/thawing because it is less complicated and less expensive to perform. When using thermal treatment, heating/cooling rate 
and maximum temperature need to be considered, and a low heating/cooling rate is usually chosen to reduce thermal shock (Homand-Etienne and Houpert 1989; Homand-Etienne and Troalen 1984). If freezing/thawing is used to induce damage, the degree of saturation, freezing/thawing rate, and minimum temperature are the major variables concerned. Constant saturation throughout the sample also needs to be carefully handled or localized damage could occur. Regarding the costs associated with thermal treating, an oven with controllable heating cooling/rate is all that is needed, and the samples can be treated simultaneously in about 24 hours. For mechanical testing (e.g., triaxial testing at $400 \mathrm{MPa}$ confining pressures), two samples can be tested a day for approximately $\$ 1500$ in labor alone.

Lastly, thermal treating can be used to induce various levels of microcracking by simply varying the maximum temperature reached during the thermal treatment. To get consistent levels of damage while running mechanical tests, the sample strengths must be fairly reproducible and the samples must be closely monitored when nearing peak stress. Most mechanical tests also introduce anisotropic microcracking, whereas heat treating induces relatively isotropic microcracking (David et al. 1999).

\subsubsection{Thermal treating}

To induce microcracks in the limestone, the samples were heated in a muffle furnace at a low heating rate $\left(1^{\circ} \mathrm{C} / \mathrm{min}\right.$ to $300^{\circ} \mathrm{C}, 2^{\circ} \mathrm{C} / \mathrm{min}$ thereafter $)$. The maximum temperature was then held for five hours and cooled down at approximately $1{ }^{\circ} \mathrm{C} / \mathrm{min}$. This heat treatment was chosen because it is similar to heat treatments used in previous studies (Homand-Etienne and Houpert 1989; Homand-Etienne and Troalen 1984). All samples were kept in a $60^{\circ} \mathrm{C}$ oven before and after all mechanical tests and heat treatments to reduce their moisture content. Figure 3-2 shows the temperature vs. time for the $250^{\circ} \mathrm{C}$ and $450^{\circ} \mathrm{C}$ heat treatments. 
Figure 3-2. Temperature vs. time for the heat treatments used for the mechanical test samples.

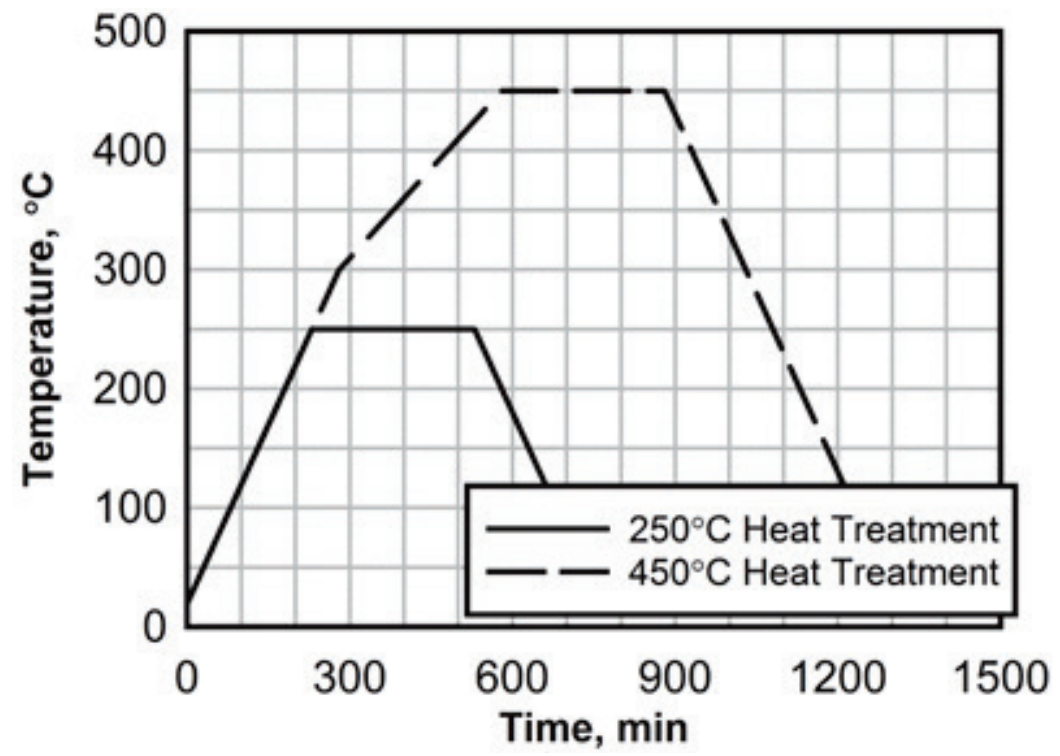

Sample lengths, diameters, and weights were measured before and after each heat treatment to determine volume and density changes as a function of the maximum temperatures used in the heat treatments (see Figure 3-3). These measurements were taken as a rough estimate of the induced microcrack volume and to give an initial indication of other changes that may be occurring besides microcracking. For the $250^{\circ} \mathrm{C}$ and $450^{\circ} \mathrm{C}$ heat treatments, the average percent volume changes were 0.06 and 1.24 percent, and the average percent density changes were -0.17 and -1.48 percent, respectively. The $800^{\circ} \mathrm{C}$ heat treatment resulted in a drastic increase in volume and decrease in density, which indicated that changes other than microcracking were occurring around that maximum temperature.

Figure 3-3. Percent volume change (left) and percent density change vs. maximum heat treatment temperature.
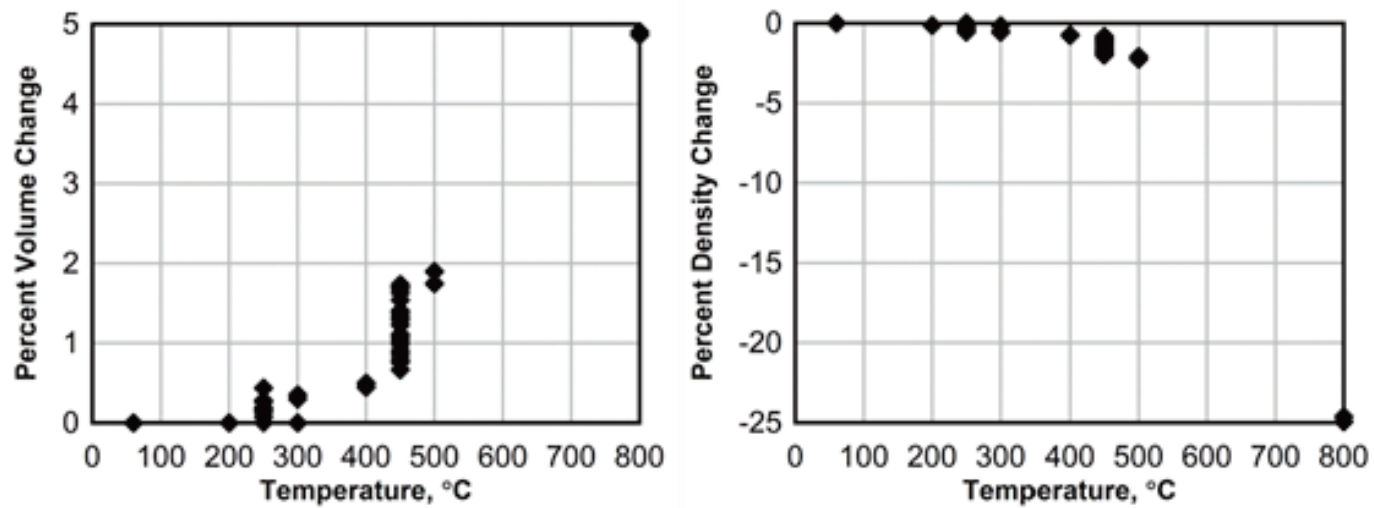


\subsubsection{Wave velocities}

P-wave (or compressional wave) velocities and S-wave (or shear wave) velocities were measured using the ultrasonic pulse transmission technique before and after heat treatments. This technique is a non-destructive means of evaluating damage in a material because the waves passed through the material are influenced by the elastic properties and discontinuities such as pores and microcracks. The velocities were taken to give an initial indication of the effects of microcracks induced by the heat treatments and to determine if heat treatments reliably induce a consistent amount of microcracks.

For the sonic velocity tests, limestone samples were created using a conventional rock coring barrel to core the original blocks. Then, the samples were cut to their approximate final length with a slabbing saw and later ground flat. The final samples were right cylinders with a length and a diameter of $50.8 \mathrm{~mm}$ (2.0 in.). The experimental setup included a pair of 1$\mathrm{MHz}$ piezoelectric transducers to transmit and receive the $\mathrm{P}$-waves, a pair of 2.25 MHz transducers for the S-waves, and a $100 \mathrm{MHz}$ oscilloscope to measure the wave travel times. Velocities were calculated by dividing the length of the samples, measured from digital micrometers, by the wave travel time. The P- and S-wave velocities were measured along three orthogonal directions in the cylindrical samples: one in the axial direction and two in orthogonal radial directions. This was done to check for uniformity throughout the samples. All of the velocity measurements were taken under atmospheric conditions in accordance with ASTM C 597 (ASTM 2005c).

Figure 3-4. Sonic velocities for increasing maximum temperatures.

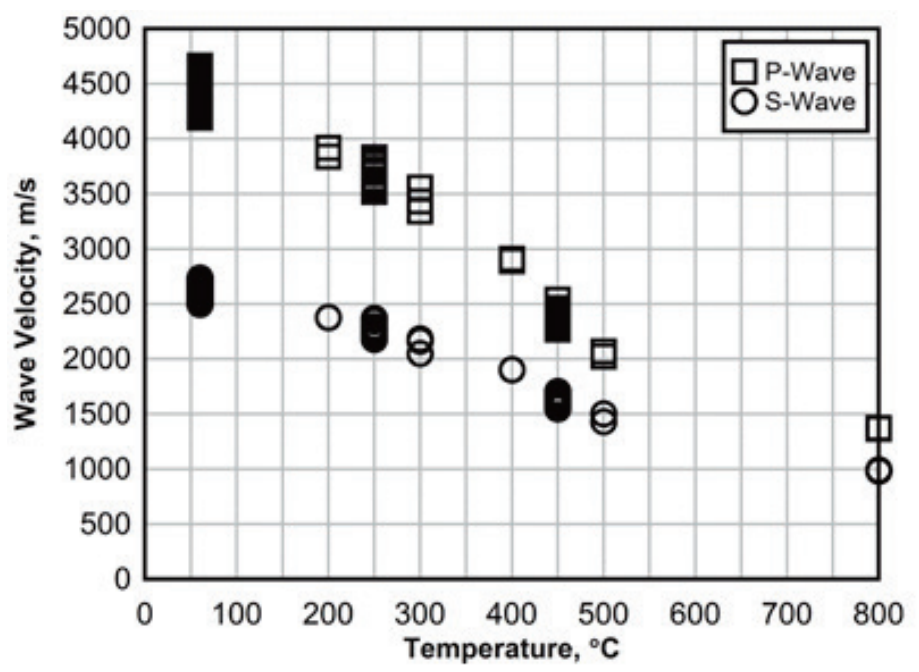


Wave velocity measurements, a total of 142 , were taken on the untreated, $200^{\circ} \mathrm{C}, 250^{\circ} \mathrm{C}, 300^{\circ} \mathrm{C}, 400^{\circ} \mathrm{C}, 450^{\circ} \mathrm{C}, 500^{\circ} \mathrm{C}$, and $800^{\circ} \mathrm{C}$ heat-treated limestone samples. The velocity data in the axial direction are shown in Figure 3.3. The data show a clear correlation between the heat-treatment temperatures and the reduced wave velocities caused by induced microcracking. P-wave velocities of untreated samples ranged from approximately $4200 \mathrm{~m} / \mathrm{s}$ to $4700 \mathrm{~m} / \mathrm{s}$, and S-wave velocities of untreated samples ranged from approximately $2500 \mathrm{~m} / \mathrm{s}$ to $2700 \mathrm{~m} / \mathrm{s}$. P-wave velocities were reduced by approximately $17 \%, 47 \%$, and $69 \%$, at $250^{\circ} \mathrm{C}, 450^{\circ} \mathrm{C}$, and $800^{\circ} \mathrm{C}$, respectively; and $\mathrm{S}$ - wave velocities were reduced by approximately $13 \%, 38 \%$, and $62 \%$, at $250^{\circ} \mathrm{C}, 450^{\circ} \mathrm{C}$, and $800^{\circ} \mathrm{C}$, respectively.

Wave velocity measurements can also be used to approximately calculate elastic moduli. The bulk modulus and shear modulus were determined from wave velocity measurements on undamaged and damaged samples using Eqs. 3.1 and 3.2.

$$
\begin{gathered}
K=\rho\left(V_{p}^{2}-\frac{4}{3} V_{s}^{2}\right) \\
G=\rho V_{s}^{2}
\end{gathered}
$$

$\mathrm{V}_{\mathrm{p}}$ and $\mathrm{V}_{\mathrm{s}}$ are the P-wave and S-wave velocities of the material, respectively.Table 3-1 shows the elastic moduli for the untreated and treated samples calculated from the wave velocities.

Table 3-1. Elastic moduli for samples with different heat treatments.

\begin{tabular}{|c|c|c|}
\hline $\begin{array}{c}\text { Maximum } \\
\text { Temperature, }{ }^{\circ} \mathrm{C}\end{array}$ & $\begin{array}{c}\text { Average Bulk } \\
\text { Modulus, MPa }\end{array}$ & $\begin{array}{c}\text { Average Shear } \\
\text { Modulus, MPa }\end{array}$ \\
\hline 60 & 10500 & 16000 \\
\hline 200 & 7500 & 13400 \\
\hline 250 & 6500 & 12000 \\
\hline 300 & 5800 & 10700 \\
\hline 400 & 3600 & 8500 \\
\hline 450 & 2100 & 6000 \\
\hline 500 & 1300 & 5000 \\
\hline 800 & 600 & 1700 \\
\hline
\end{tabular}

Because these values are calculated directly from the wave velocity values, they follow the same trend as the wave velocity, which is a steady decrease in elastic moduli as maximum thermal treatment temperatures increase. 
These results verified the initial assumptions made when choosing heat treatments for this work: The heat treatments induced microcracking as a function of the maximum temperature, and consistent levels of induced microcracking can be obtained.

\subsubsection{X-ray diffraction, thermogravimetric analysis, and differential scanning calorimetry}

To exclude the possibility that the effects of the heat treatments on the mechanical response were due to changes in material composition (e.g., phase changes), specimens were examined using x-ray diffraction (XRD), thermogravimetric analysis (TGA), and differential scanning calorimetry (DSC). These tests were performed to ensure no changes were occurring for the temperature range of interest, ambient temperature to $500^{\circ} \mathrm{C}$.

$\mathrm{XRD}$ is a nondestructive technique of determining the chemical composition and crystallographic structure of a material. This method was used to detect material composition changes in ground powder samples of the untreated, $200^{\circ} \mathrm{C}, 300^{\circ} \mathrm{C}, 400^{\circ} \mathrm{C}, 500^{\circ} \mathrm{C}$, and $800^{\circ} \mathrm{C}$ heat-treated limestone samples. The XRD analysis was performed using a Panalytical X'Pert Pro Materials Research Diffractometer.

Figure 3-5 shows the XRD patterns from the limestone samples compared to reference patterns for calcite $\left(\mathrm{CaCO}_{3}\right)$ and portlandite $\left(\mathrm{Ca}(\mathrm{OH})_{2}\right)$. The $800^{\circ} \mathrm{C}$ heat treatment resulted in calcite that was partially transformed to portlandite. During the $800^{\circ} \mathrm{C}$ heat treatment, the calcite went through a thermal decomposition to form calcium oxide according to the reaction in Eq. 3.3.

$$
\mathrm{CaCO}_{3} \rightarrow \mathrm{CaO}+\mathrm{CO}_{2}
$$

Upon removal of the samples from the oven and before the XRD test, the calcium oxide reacted with water in the atmosphere to form portlandite according the reaction in Eq. 3.4.

$$
\mathrm{CaO}+\mathrm{H}_{2} \mathrm{O} \rightarrow \mathrm{Ca}(\mathrm{OH})_{2}
$$

Samples undergoing heat treatments of $500^{\circ} \mathrm{C}$ or less show no phase changes or decomposition of the calcite, which provides evidence that microcracking is the main microstructural change for that temperature range. 
Figure 3-5. XRD results.

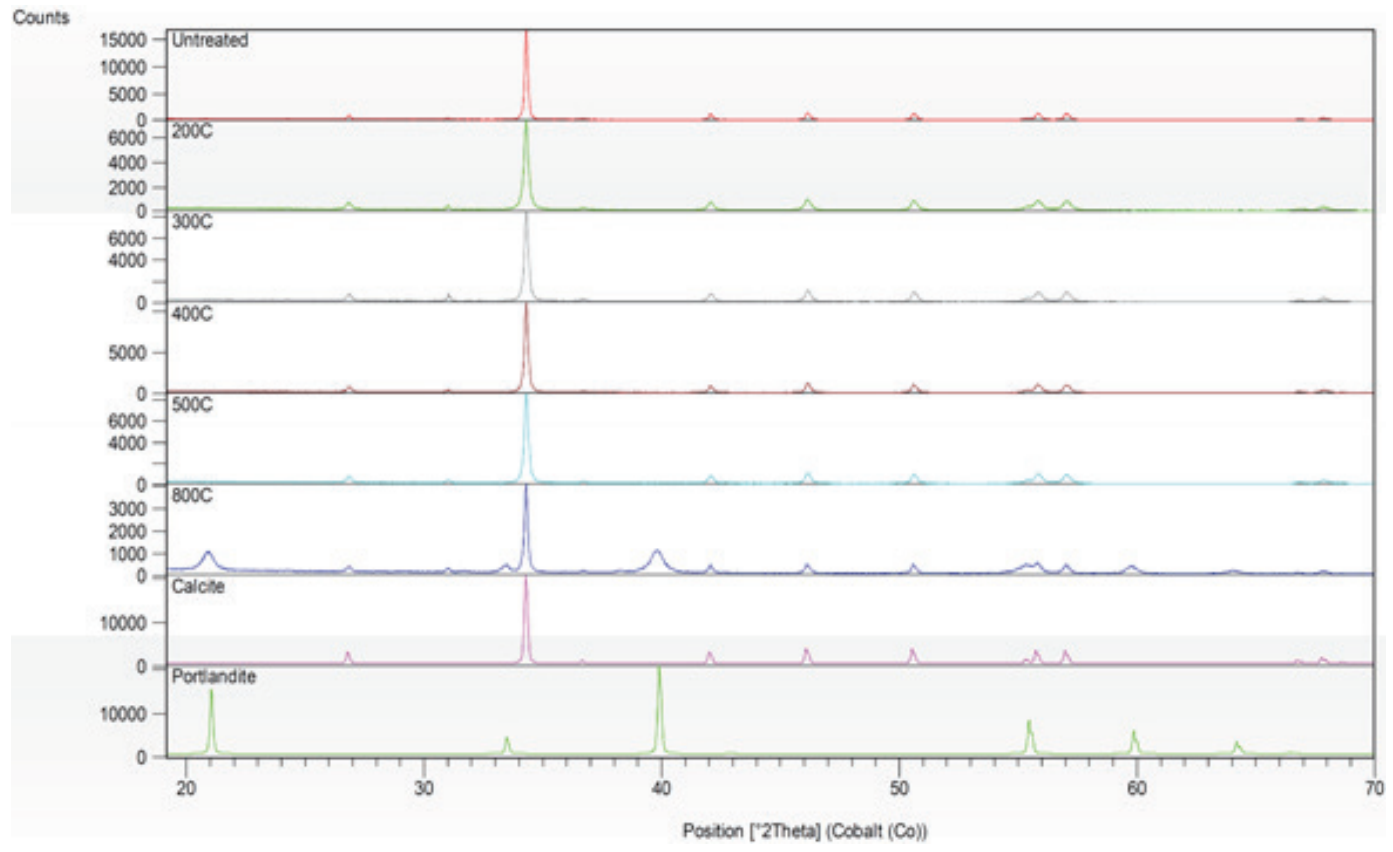

TGA is another technique to detect material composition changes. This method allows for the determination of phases present in the material based on the mass loss over a range of temperatures. For this test, an untreated sample was analyzed in a nitrogen atmosphere (to prevent oxidation and hydration) during a $500^{\circ} \mathrm{C}$ heat treatment using the same heating rates and hold times for all tests $\left(1^{\circ} \mathrm{C} / \mathrm{min}\right.$ to $300^{\circ} \mathrm{C}$, and $2^{\circ} \mathrm{C} / \mathrm{min}$ thereafter with a $5 \mathrm{hr}$ hold time at max temp). This test was performed with a Netzsch Jupiter Thermal Analyzer. Figure 3-6 shows the results of this test.

Figure 3-6. TGA results.

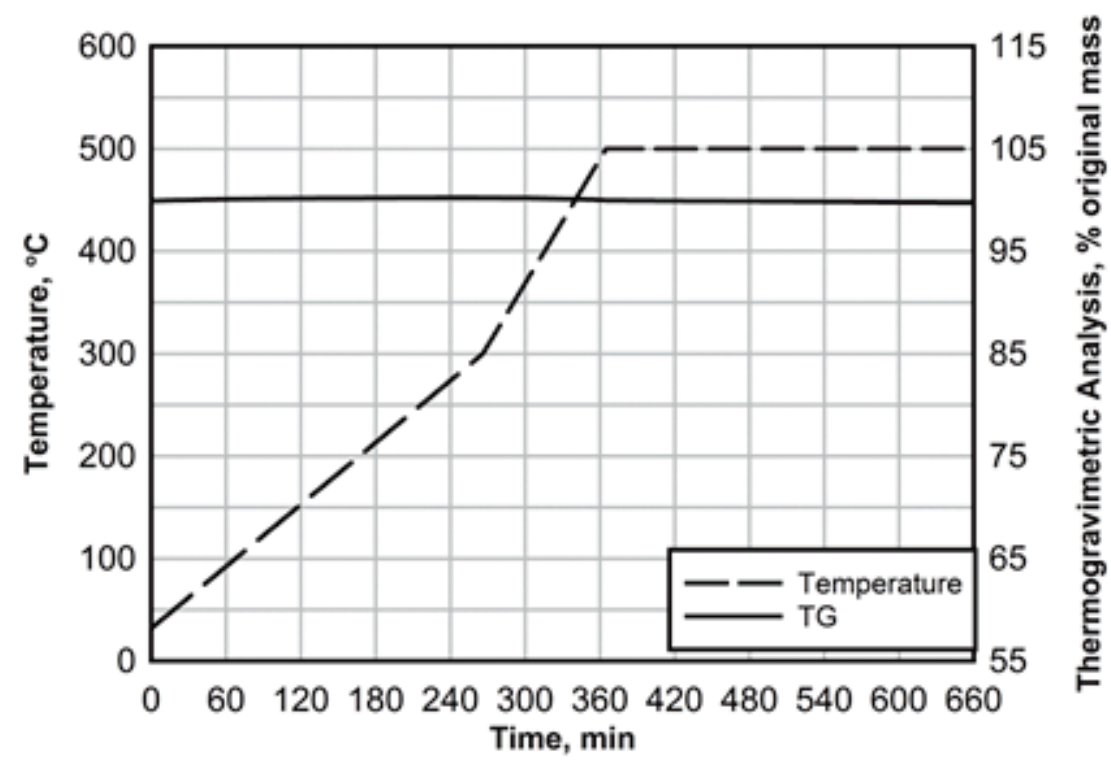


Negligible changes in mass were observed, indicating no phase changes or decomposition at temperatures up to $500^{\circ} \mathrm{C}$. Significant changes in material composition, as detected by TGA, occur at temperatures between $700^{\circ} \mathrm{C}$ and $1000^{\circ} \mathrm{C}$ and can cause mass losses of approximately 45 percent.

DSC was the last test performed to detect phase changes in the material. Material composition changes, such as phase changes, cause variations in the amount of heat needed to maintain the temperature of the sample. These variations in heat energy transfer, or heat flux, are measured in a DSC analysis and can be used to determine material composition changes as a function of temperature. This test was also performed on a limestone sample in a nitrogen atmosphere during a $500^{\circ} \mathrm{C}$ heat treatment with a Netzch Jupiter Thermal Analyzer. Figure 3-7 shows the DSC results.

Figure 3-7. DSC results.

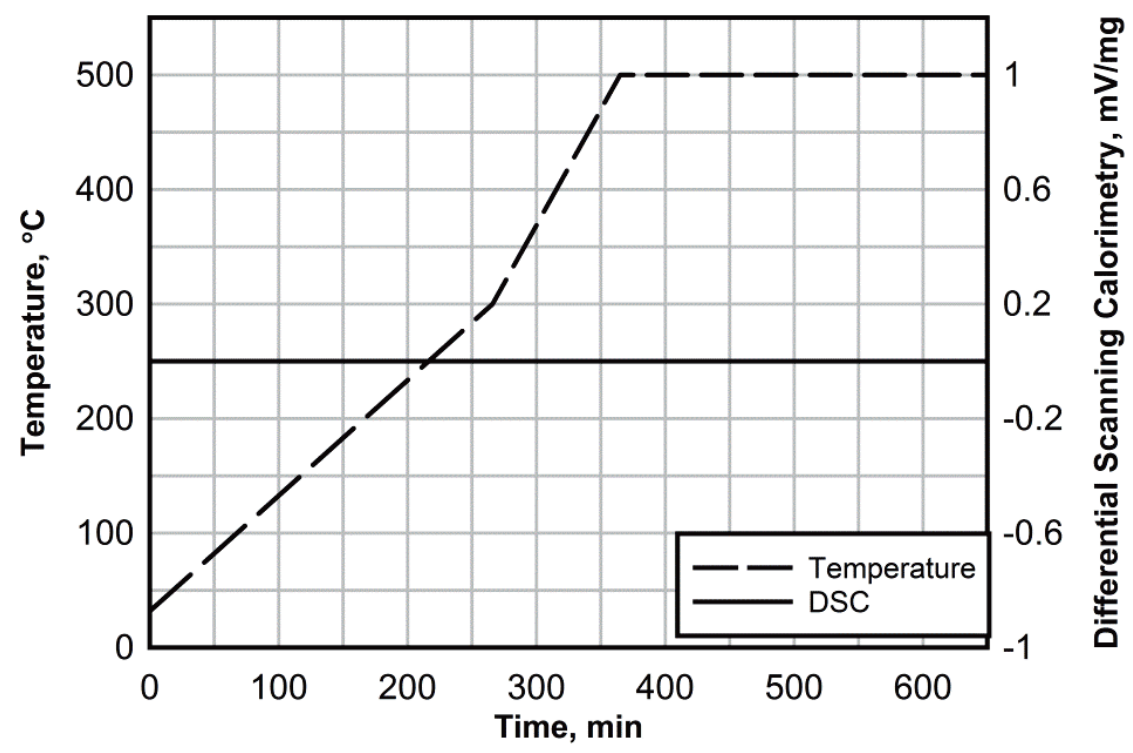

Negligible changes in heat flux were observed that indicated no phase changes or decomposition at temperatures up to $500 \mathrm{C}$. Significant changes in material composition, as detected by DSC, occur at temperatures between $700^{\circ} \mathrm{C}$ and $1000^{\circ} \mathrm{C}$ and can cause heat flux variations of approximately $3 \mathrm{~mW} / \mathrm{mg}$. These results along with those from DSC and TGA indicate that no chemical changes are happening for the temperature range of interest. Thus, thermal treating is a viable option for inducing microcracks for evaluation with mechanical testing. 


\subsection{Quantifying damage}

Several methods were used to quantify the damage from the heat treatments including computed tomography (CT) scanning, scanning electron microscopy (SEM), and optical microscopy (OM). Each of these techniques will be discussed in this section.

\subsubsection{Computed tomography scan}

CT scanning is a 3-D imaging technique that uses $\mathrm{x}$-rays to produce tomographic images of samples. This technique was performed on untreated, $250^{\circ} \mathrm{C}$, and $450^{\circ} \mathrm{C}$ heat treated samples to determine if it can be used to quantify microstructural changes caused by heat treating. The CT scan was performed using the SkyScan 1173 high energy spiral scan micro-CT with a maximum resolution of approximately 7 microns. The samples used in this study were from Frew (2001) and were cylinders with a diameter and length of $12.7 \mathrm{~mm}$ ( $0.5 \mathrm{in}$.) These smaller samples were used to obtain an image resolution of approximately 8 microns; larger samples could only be scanned at lower resolutions.

The CT scans did not have the resolution needed to capture microcracking, so the images were used to determine percent void increases between untreated, $250^{\circ} \mathrm{C}$, and $450^{\circ} \mathrm{C}$ heat treated samples. Figure $3-8$ shows $\mathrm{CT}$ cross-section images for each sample type. For the percent voids calculation, the void area was determined by setting the grey threshold such that the undamaged void area matched the porosity of the virgin material (approximately 14.0 percent). The same threshold was used for the $250^{\circ} \mathrm{C}$ and $450^{\circ} \mathrm{C}$ treated samples and the void percentage was calculated. The CT results show the $250^{\circ} \mathrm{C}$ and $450^{\circ} \mathrm{C}$ treated samples had void area increases to 16.8 percent and 17.7 percent, respectively.

Figure 3-8. CT scan cross-section images from ( $L$ to $R$ ) untreated, $250^{\circ} \mathrm{C}$, and $450^{\circ} \mathrm{C}$ heat treated samples.
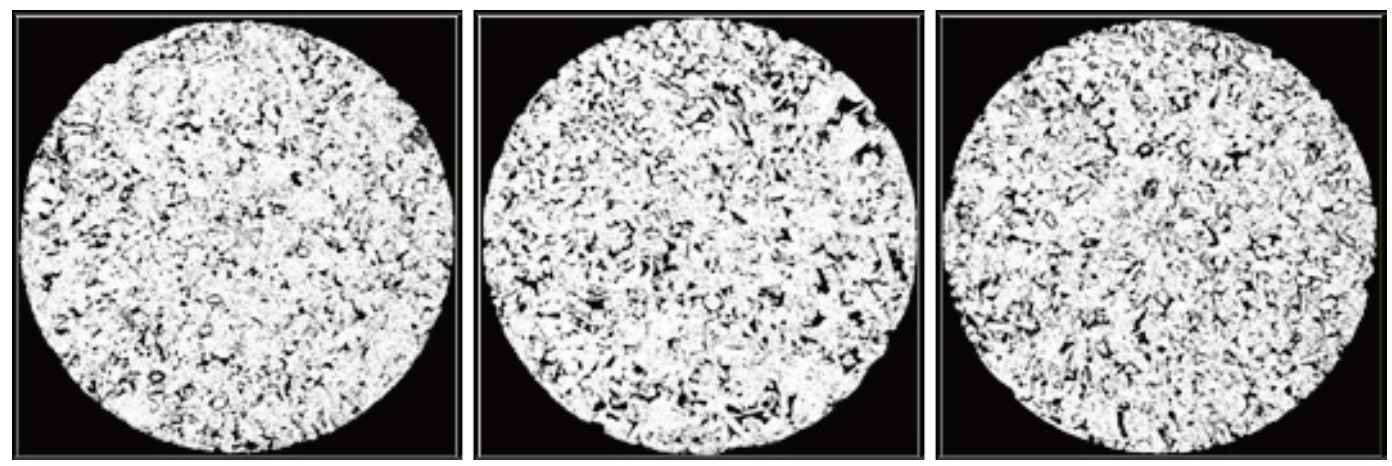
The increase in void area with higher temperature heat treatments seen in the CT scan results do not seem reasonable because the resolution of the CT scans is larger than the cracks, which should be the major contributor to the increase in void area. The image analysis is highly sensitive to the chosen threshold value, which may account for the increases. Until CT scan resolutions of 1-2 microns can be obtained and proper threshold values are determined, CT scanning is not recommended for use when determining crack properties and void areas for damage quantification purposes.

\subsubsection{Scanning Electron Microscope}

SEM was used in the initial stages of the microcrack characterization to provide images for a qualitative analysis of the changes induced by the heat treatments. For the observations, 2-in.-diameter samples (same as samples used in sonic velocity tests) were heat treated to $500^{\circ} \mathrm{C}$. The surfaces were polished with diamond paste and coated with gold-palladium. The backscattered SEM images were taken using the FEI Nova NanoSEM 630. The SEM images, shown in Figure 3-9 and Figure 3-10, show no significantcracking in the untreated material. Following the $500^{\circ} \mathrm{C}$ heat treatment, extensive microcracking along grain boundaries and inside grains can be observed.

Figure 3-9. SEM images before $500^{\circ} \mathrm{C}$ heat treatment.
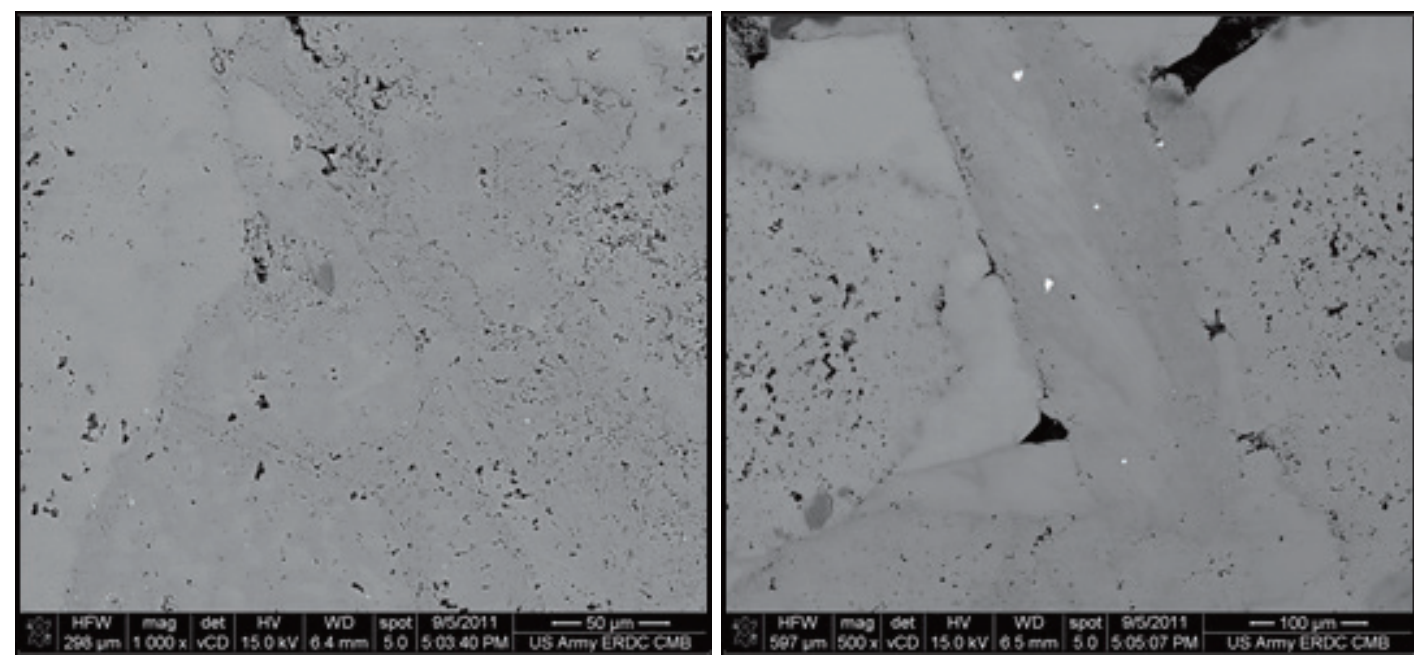
Figure 3-10. SEM images after $500^{\circ} \mathrm{C}$ heat treatment.
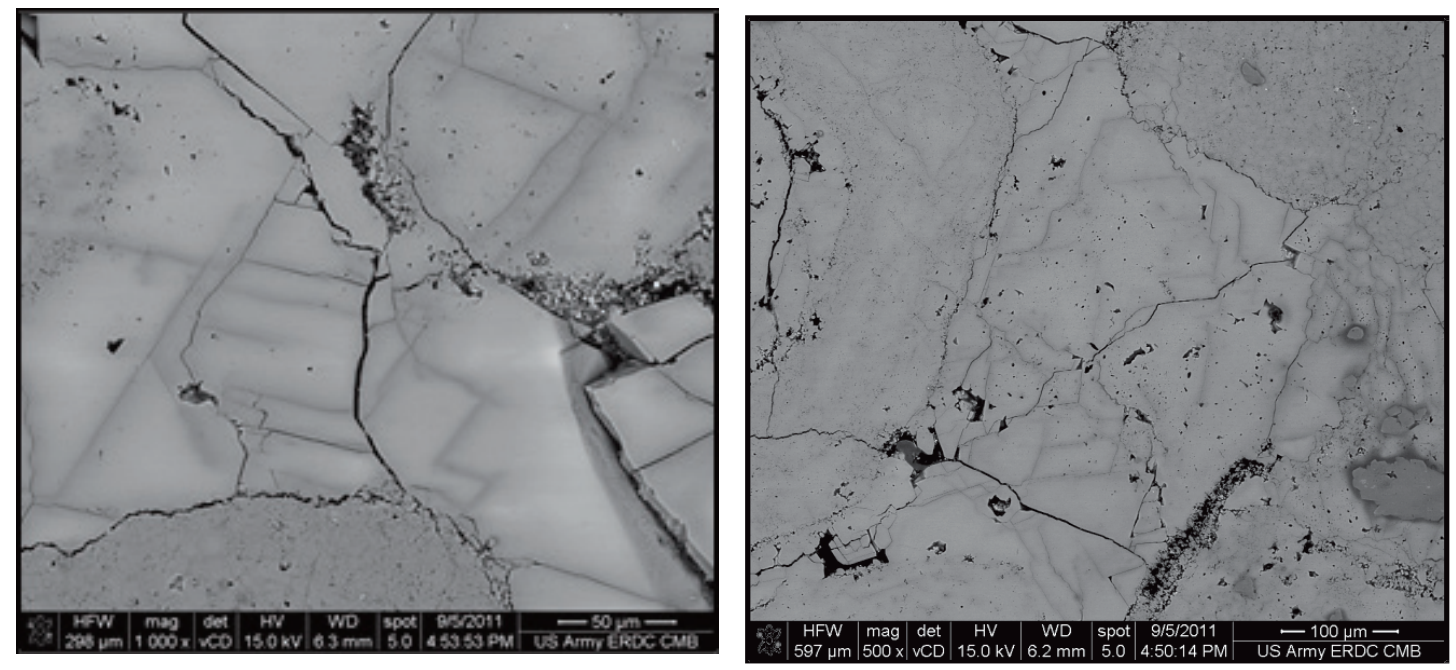

For the microstructural characterization in this work, images of the same locations before and after heat treating were desired. Though SEM images provide sufficient contrast to use for damage quantification purposes, it was unclear how the gold- palladium coating used for SEM would be affected by the heat treatment and subsequent characterization. So, optical microscopy was chosen as the means of obtaining images for microcrack quantification.

\subsubsection{Optical microscope}

Optical microscopy was performed on untreated and heat treated limestone samples to provide qualitative and quantitative data on the microstructural changes as a function of the maximum temperatures from the heat treatments. OM samples were created by coring the original blocks with a conventional rock coring barrel and were cut to their approximate final length with a slabbing saw. The samples were then polished to one micron with diamond paste. Samples were right cylinders with a length and a diameter of $38.1 \mathrm{~mm}$ (1.5 in.). These samples were slightly smaller than other tests samples to allow them to fit inside the polisher. After polishing, a reference mark was etched in each sample to orient the microscope in the same locations for the images taken before and after heat treatments. Only surface cracks were observed because crack patterns formed on the surface show only minor differences from interior crack patterns (Nolen-Hoeksema and Gordon 1987). The samples were examined using a Zeiss Axiovert 200 optical microscope with a magnification range of 50-2500 equipped with a camera. For this study, images were 
taken at 100x magnification. This magnification range should allow cracks of approximately 1 micron in width to be observed.

Figure 3-11 shows the limestone before and after $250^{\circ} \mathrm{C}$ heat treatment, and Figure 3-12 shows the limestone before and after $450^{\circ} \mathrm{C}$ heat treatment. The figures show that the primary effect of heat treatment in this temperature range is the formation of new microcracks. The samples heated to $250^{\circ} \mathrm{C}$ introduced cracks into the sample that were mostly along grain boundaries with few intragranular cracks. The $450^{\circ} \mathrm{C}$ heat treatment lengthened some existing grain boundary cracks and introduced many intragranular cracks into the limestone samples. The intragranular cracks appear to develop along planes of crystallographic weakness, such as cleavage planes and pre-existing flaws. The increasing number of cracks with increasing temperature results in the decrease in the measured wave velocities.

Figure 3-11. Salem limestone before (left) and after (right) $250^{\circ} \mathrm{C}$ heat treatment.
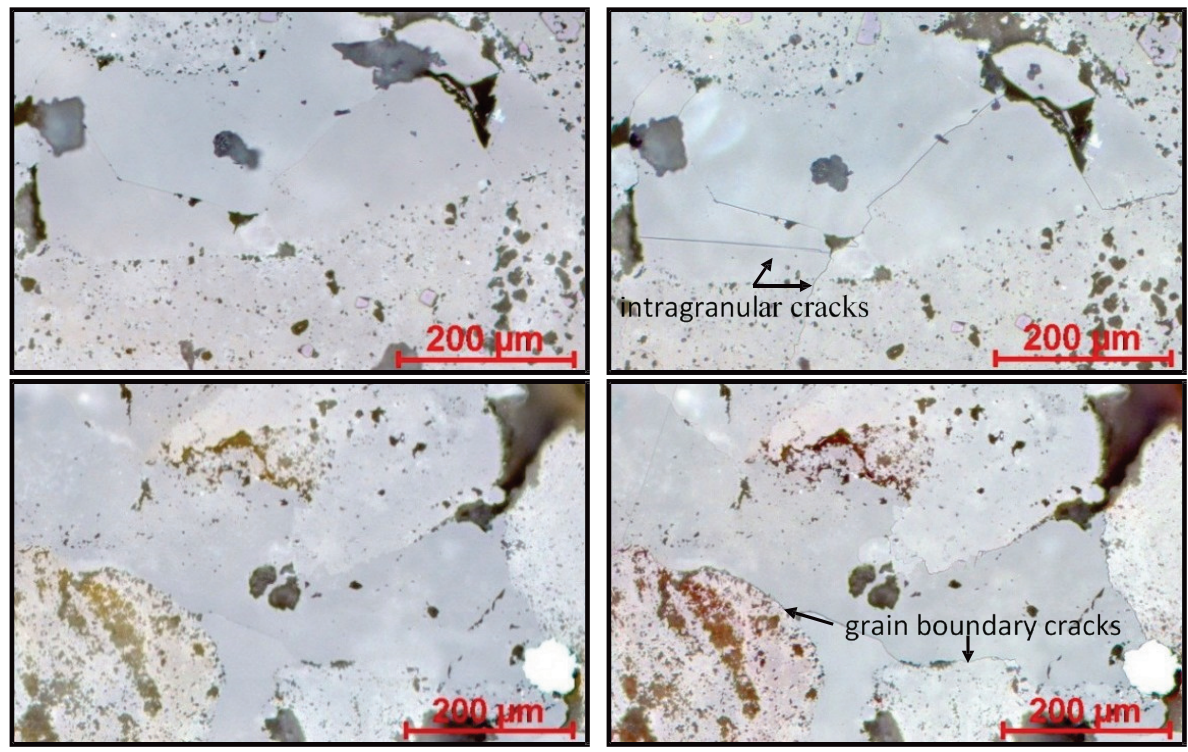
Figure 3-12. Salem limestone before (left) and after (right) $450^{\circ} \mathrm{C}$ heat treatment.
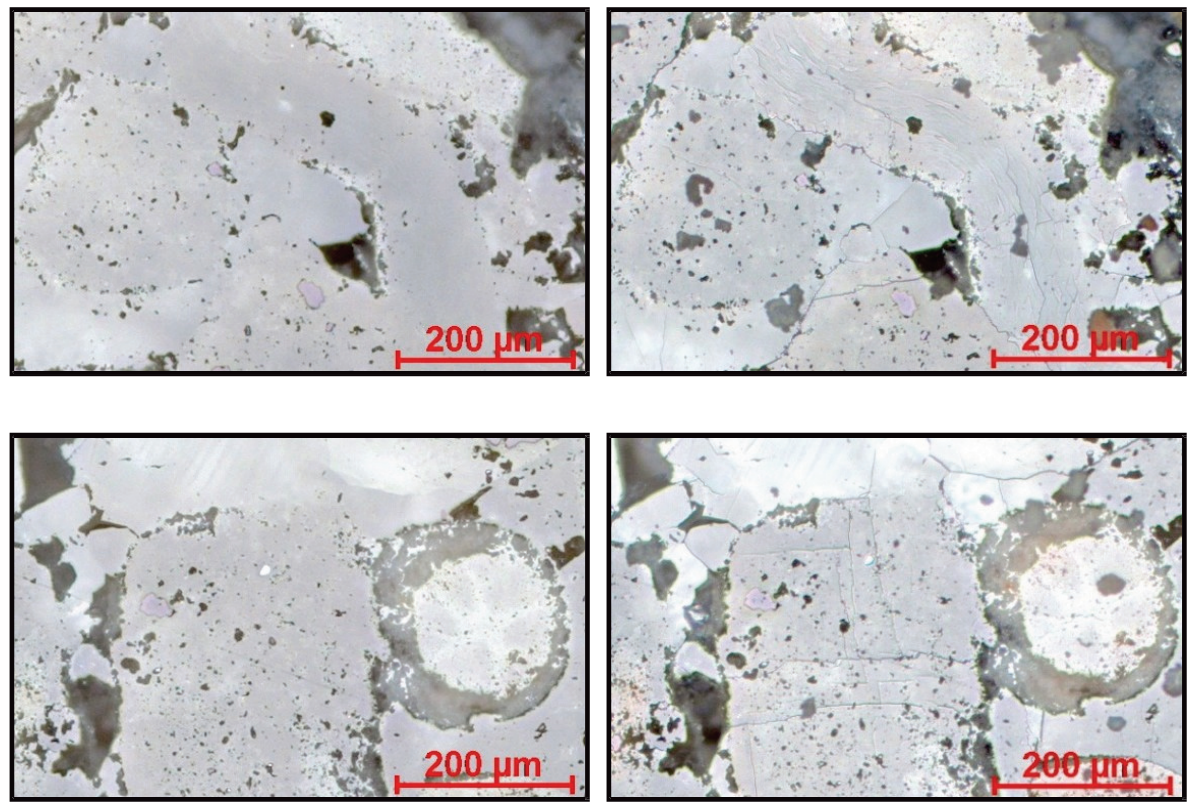

Quantification of the induced damage with $\mathrm{OM}$ consisted of measuring the microcrack densities for the $250^{\circ} \mathrm{C}$ and $450^{\circ} \mathrm{C}$ heat treatments. The quantification was performed for the $250^{\circ} \mathrm{C}$ and $450^{\circ} \mathrm{C}$ heat treated samples, because these are the heat treatments used on the mechanical test samples discussed in the next chapter. A stereological technique, or geometric probability approach (Fredrich and Wong 1986; Wong 1985), was used to quantify the microcrack density. The approach consists of counting the number of crack intersections with a parallel array of equally spaced lines. For this work, an array of 10 parallel lines of $1 \mathrm{~mm}$ length spaced $0.1 \mathrm{~mm}$ apart was overlaid on the OM images. Thus, a test area of $10 \mathrm{~mm}^{2}$ was covered for each image. A total of 128 images were analyzed resulting in a total test area of $1280 \mathrm{~mm}^{2}$. The OM images were taken in two locations on the sample, the center and midway between the center and edge of the sample. The criterion for a crack was that it has to be visible at 100x magnification and that it has an aspect ratio greater than about 1:10 to restrict the inclusion of pores.

The stereological data for Salem limestone heat treated to $250^{\circ} \mathrm{C}$ and $450^{\circ} \mathrm{C}$ is shown in Table $3^{-2}$, where the stereological parameter, $\mathrm{P}_{\mathrm{L}}$, is the average number of cracks per unit length. The undamaged material had a negligible amount of cracks (about 1 crack per $10 \mathrm{~mm}^{2}$ test array area that usually did not intersect a test array line). The microcrack density increased with increasing temperatures with the $450^{\circ} \mathrm{C}$ heat treated samples having more than three times the microcrack density than the $250^{\circ} \mathrm{C}$ heat treated samples. 
Table 3-2. Stereological data from OM images for heat treated Salem limestone.

\begin{tabular}{|c|c|c|}
\hline Sample Type & Test Area, $\mathrm{mm}^{2}$ & PL Total, $/ \mathrm{mm}$ \\
\hline Untreated & 640 & Negligible \\
\hline $250^{\circ} \mathrm{C}$ Heat Treatment & 320 & 0.94 \\
\hline $450^{\circ} \mathrm{C}$ Heat Treatment & 320 & 3.14 \\
\hline
\end{tabular}

\subsection{Summary}

This chapter described the limestone material used in this work and the experimental methods used to induce and quantify microstructural changes in the material. Thermal treating was chosen to induce microcracks in the material rather than freezing/thawing or mechanical testing because it is inexpensive and has less variables to consider. Wave velocities were measured as a non-destructive means of evaluating the effects of damage. Wave velocities decreased with increasing maximum temperatures used in the heat treatments indicating that the induced microstructural changes were a function of that maximum temperature. The wave velocities also showed little variability for a particular heat treatment, which showed that the heat treatments could induce consistent levels of microcracking. XRD, DSC, and TGA were performed to provide a range of temperatures in which to heat the samples without changing the material composition. The results of those three analyses confirmed that no composition changes occurred at $500^{\circ} \mathrm{C}$ or below; therefore, room temperature to $500^{\circ} \mathrm{C}$ became the temperature range of interest for the microcrack characterization and mechanical testing.

CT scanning, SEM, and OM were used to observe microstructural changes caused by the $250^{\circ} \mathrm{C}$ and $450^{\circ} \mathrm{C}$ heat treatments. CT scans were able to provide $3 \mathrm{D}$ images of the untreated and treated samples. However, the resolution of the CT scan was too large, $\sim 7$ microns, to provide microcrack information, which requires a resolution of around 1-2 microns. An SEM analysis was also performed to give an initial indication of microcracking caused by the heat treatments. For the microcrack characterization, images in the same locations before and after heat treating were preferred. Because SEM requires a gold-palladium coating in order to obtain images, $\mathrm{OM}$ analysis was chosen for the microstructural characterization to avoid any effects the coating may have on the sample during heating. The OM analysis yielded both qualitative and quantitative data on the microstructural changes associated with the heat treatments. OM images showed an 
increase in grain boundary and intragranular cracks with increasing maximum temperatures in the heat treatments. A stereological technique provided microcrack densities for the corresponding heat treatments. The microcrack density, as given by a stereological parameter, increased as a function of the maximum temperature in the heat treatments. 


\section{Mechanical Testing}

\subsection{Overview}

Mechanical tests were performed to characterize the mechanical response of the intact and damaged limestone at low strain rates for various stress states and high strain rates for uniaxial compression. This section describes the test methods and results. The quasi-static tests using servo-hydraulic loading will be discussed followed by the dynamic tests using the split Hopkinson pressure bar (SHPB). In this chapter, the samples heat treated to a maximum temperature of $250^{\circ} \mathrm{C}$ and $450^{\circ} \mathrm{C}$ will be referred to as low damage and high damage samples, respectively. Low damage and high damage are also considered synonymous with low and high levels of microcracking.

\subsection{Quasi-static testing}

Quasi-static tests were performed on undamaged and damaged samples to determine how damage affects various mechanical properties. A total of 45 compression tests were successfully performed including 9 unconfined compression (UC) tests, 24 triaxial compression (TXC) tests, 3 hydrostatic compression (HC) tests, and 9 uniaxial strain/constant volume (UX/CV) strain path tests. All of the tests were performed quasi-statically with strain rates ranging from $10^{-5}$ to $10^{-4} \mathrm{~S}^{-1}$. At these rates, times to reach peak load varied from 5 to 30 minutes.

Prior to performing the mechanical tests, the height, diameter, and weight of each sample was measured and used to compute the wet density of material. Following the test, post-test water contents were measured according to ASTM D 2216 (ASTM 2005d). Using the post-test water content, wet density, and grain density (determined to be $2.75 \mathrm{Mg} / \mathrm{m} 3$ ), porosity, degree of saturation, and air, water, and solid volumes were calculated. The average values for the limestone samples for wet density (which equals the dry density because the samples were dried before testing) and porosity were $2.34 \mathrm{Mg} / \mathrm{m}^{3}$ and 14.9 percent, respectively. Values for each sample can be found in the Appendix. 


\subsubsection{Sample preparation}

Samples for the quasi-static mechanical tests were cored using a $50.8 \mathrm{~mm}$ (2 in.) diameter, diamond-bit core barrel following the procedures provided in ASTM C 42 (ASTM 2005b). The samples were cut to the correct length, and the ends were ground flat and parallel to each other (within $\pm 0.025 \mathrm{~mm}$ ) and perpendicular to the core side following the procedures provided in ASTM D 4543 (ASTM 2005e). The finished samples had a nominal diameter and length of $50.8 \mathrm{~mm}$ (2 in.) and $114.0 \mathrm{~mm}$ (4.5 in.), respectively.

Hardened steel caps were placed on the ends of each sample before testing.

Except for the unconfined compression tests, two $0.6 \mathrm{~mm}$ thick latex membranes were placed around the samples (see Figure 4-1), and the exterior of the outer membrane was coated with liquid synthetic rubber to prevent deterioration from the confining fluid, a mixture of kerosene and hydraulic oil. After the membrane and coating were applied, the samples were placed on the testing device and the instrumentation was attached.

Figure 4-1. Typical test sample setup.

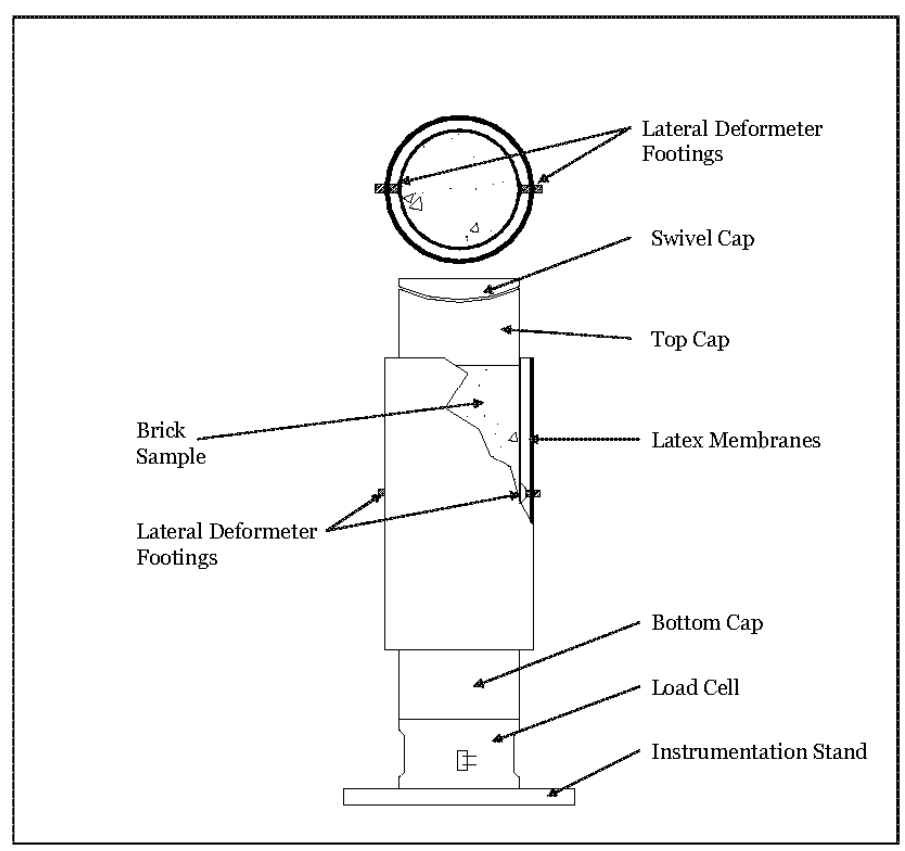




\subsubsection{Test instrumentation}

A vertical deflection measurement system, consisting of two linear variable differential transformers (LVDTs), was used for all tests to measure the axial deformation of the samples. These were placed between the top and base caps of the sample. For confined tests, a linear potentiometer was mounted to the outside of the pressure vessel to measure the displacement of the piston applying the axial load. This provided an additional measurement of the axial displacement in case the LVDTs malfunctioned or exceeded their calibrated range.

A radial deflection measurement system, consisting of lateral deformeters, was used to measure the radial deflection in the samples. On the sides of each sample, two small, steel footings were attached (see Figure 4-1). Each footing had a threaded post that extended through the latex membrane on which steel caps were screwed to seal the membranes to the footing. The lateral deformeters were attached to these steel caps with set screws (see Figure 4-2).

Figure 4-2. Lateral deformeters mounted on test specimen.

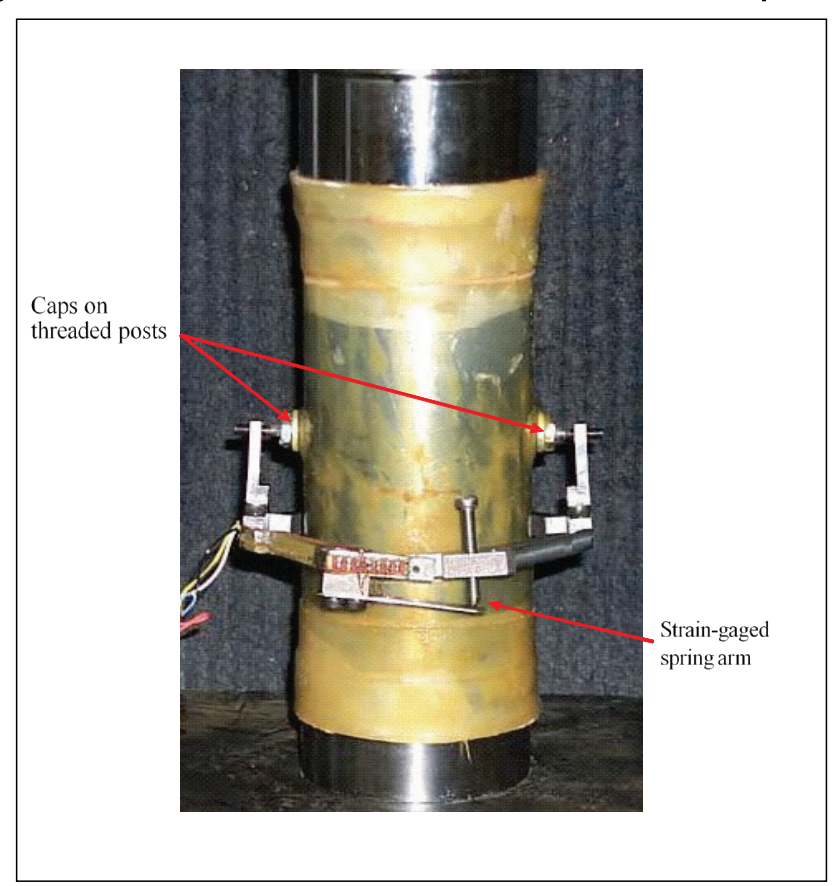

Outputs from the instrumentation were electronically amplified and filtered, and the signals were recorded by computer-controlled, 16-bit, analog-to-digital converters. The data acquisition system, sampling at a rate of 
0.2 to $1 \mathrm{~Hz}$, converted the voltage to engineering units (displacement, load, and pressure) and stored the data for further processing.

\subsubsection{Stress and strain definitions}

During the mechanical tests, the axial and radial deformations, the axial load, and the confining pressures (except for UC) were recorded. These measurements and the pretest height and diameter of the samples were used to calculate the true stresses and engineering strains. Compressive stresses and strains are considered positive for these tests.

Axial strain, $\varepsilon$ a, was calculated by dividing the axial deformation, $\Delta \mathrm{h}$, by the original height, ho. Radial strain was calculated by dividing the radial deformation, $\Delta \mathrm{d}$, by the original diameter, $\mathrm{d}_{\mathrm{o}}$. Volumetric strain, $\varepsilon_{\mathrm{v}}$, was assumed to be the sum of the axial strain and two times the radial strain, as given in Eq. 4.1.

$$
\varepsilon_{\mathrm{v}}=\varepsilon_{\mathrm{a}}+2 \varepsilon_{r}
$$

The principal stress difference (PSD), $q$, is determined by dividing the axial load by the cross-sectional area of the sample, $\mathrm{A}$, which is equal to the original cross-sectional area, $A_{0}$, multiplied by $\left(1-\varepsilon_{r}\right)^{2}$ as given in Eq. 4.2.

$$
q=\left(\sigma_{a}-\sigma_{r}\right)=\frac{\text { Axial Load }}{A_{0}\left(1-\varepsilon_{r}\right)^{2}}
$$

Here, $\sigma_{\mathrm{a}}$ is the axial stress and $\sigma_{\mathrm{r}}$ is the radial stress. For uniaxial compression, the principal stress difference is simply the axial stress. The mean normal stress (MNS), p, is the average of the applied principal stresses, given in Eq. 4.3 for cylindrical samples.

$$
p=\frac{\sigma_{a}+2 \sigma_{r}}{3}
$$

\subsubsection{Unconfined compression}

Nine UC tests ( 3 undamaged, 3 low damage, and 3 high damage) were performed to provide shear and failure data on the undamaged and damaged limestone samples. For the unconfined compression tests, the axial load 
was applied using a 3.3 MN (750,00o lb-force) loader. The load application was manually controlled. Only top and base caps, a load cell, and vertical and radial deformeters were needed for these tests.

Figure 4-3 shows the typical PSD-axial strain curves for the unconfined compression tests performed on undamaged, low damage, and high damage samples (see appendix for all mechanical test results). Table 4-1 shows the mean peak PSD's and the percentage of the PSD's compared to the undamaged materials. At the beginning of the unconfined compression tests on the treated samples (up to approximately 0.07 percent axial strain for low damage and 0.23 percent for $450^{\circ} \mathrm{C}$ high damage samples), cracks were closing perpendicular to the loading axis causing an apparent ductility. That apparent ductility correlated to an increase in volume caused by the induced microcracks.

Figure 4-3. From left to right, principal stress difference vs. axial strain and principal stress difference vs. volumetric strain for undamaged and damaged samples during uniaxial compression.
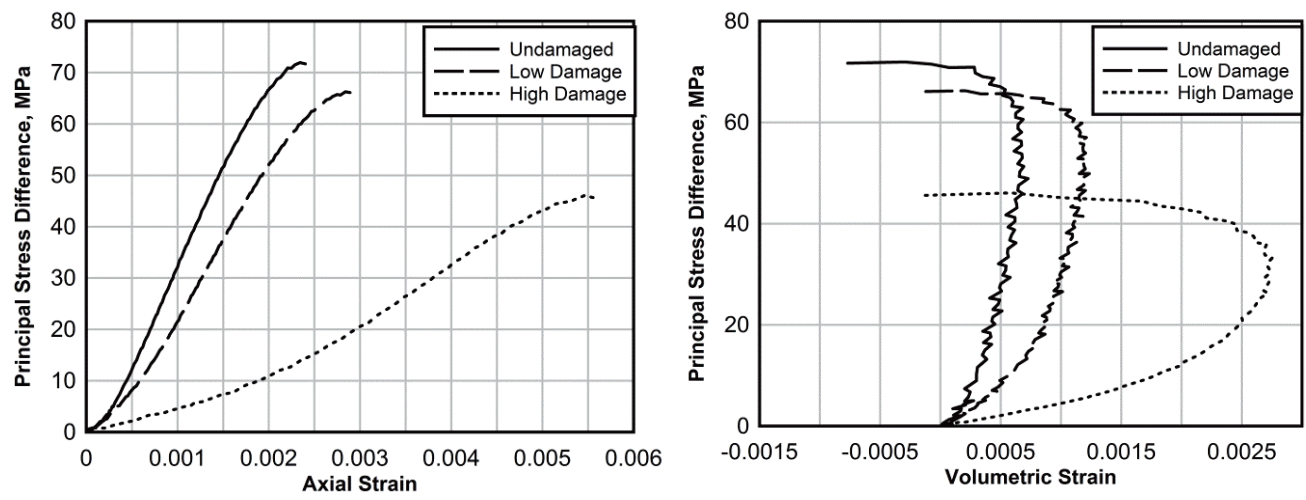

Table 4-1. Mean peak principal stress difference during unconfined compression for undamaged and damaged samples.

\begin{tabular}{|c|c|c|}
\hline Sample Type & Mean Peak PSD, MPa & Percent of Undamaged PSD \\
\hline Undamaged & 72.3 & 100 \\
\hline Low Damage & 65.3 & 90.3 \\
\hline High Damage & 45.7 & 63.2 \\
\hline
\end{tabular}

Figure 4-3 also shows the PSD-volumetric strain curves. Initially the volumetric strains were positive, indicating compression. The mean peak volumetric strains for the undamaged, low damage, and high damage samples were $0.08 \%, 0.12 \%$, and $0.27 \%$, respectively. Once the peak volumetric strains were reached, negative volumetric strains were produced, because the samples were expanding more quickly in the radial direction than the 
axial direction. This radial expansion was due to crack coalescence and dilation. Because the heat treated samples had a larger crack density initially, the cracks coalesced and expanded more quickly, which led to the onset of dilatation at lower stresses.

\subsubsection{Triaxial compression}

Twenty-four triaxial compression tests were performed to provide additional shear and failure data. Six tests each were performed at $10 \mathrm{MPa}, 20$ $\mathrm{MPa}, 100 \mathrm{MPa}$, and $400 \mathrm{MPa}$ confining pressures. For each set of six tests at each confining pressure, two were performed on undamaged, two on low damage, and two on high damage samples. In these tests, the axial load was applied using an 8.9 MN (2,000,00o lb-force) loader, and the confining pressures were applied with a $600 \mathrm{MPa}$ capacity pressure vessel (see Figure 4-4. The application of load, pressure, and axial displacement were controlled by a servo-controlled data acquisition system.

Figure 4-4. 600-MPa pressure vessel details.

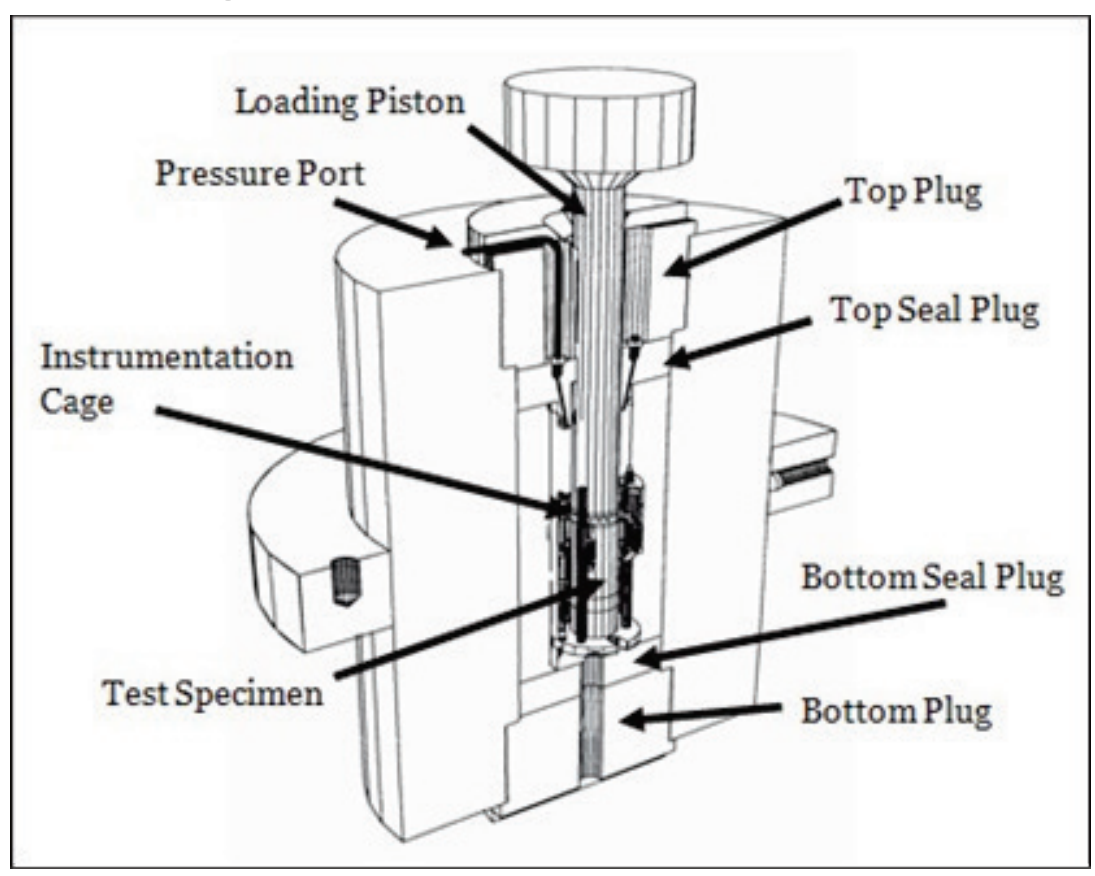

The TXC tests were performed in two stages, hydrostatic loading followed by shear loading. In the initial stage, the samples are subjected to a hydrostatic loading up to the desired pressure, e.g. $10 \mathrm{MPa}, 20 \mathrm{MPa}, 100 \mathrm{MPa}$, and $400 \mathrm{MPa}$ for this work. This stage of loading measures the pressurevolume response of the material, which can be used to calculate the material's bulk modulus. Following the hydrostatic loading stage, shear loading 
is applied by holding the confining pressure constant while increasing the axial load. For this work, the peak strength of the material is defined as the maximum PSD that a sample can support or the PSD at 15 percent axial strain during shear (whichever comes first). This stage of loading provides the PSD-axial strain response, which can be used to calculate the elastic moduli.

Figure 4-5 to Figure 4-8 show the PSD-axial strain curves for the TXC tests at the various confining pressures. Table 4.2 shows the mean peak PSD for the TXC tests. Note that the axial strains are given minus the axial strains induced during the hydrostatic loading. These results show that for the range of confining pressures tested the strengths did not change significantly. This shows that for some confining pressure less than $10 \mathrm{MPa}$, there exists a threshold pressure after which damage does not lower the strength of the material.

Figure 4-5. ( $L$ to $R$ ) Principal stress difference vs. axial strain and principal stress difference vs. volumetric strain for undamaged and damaged samples during triaxial compression with $10 \mathrm{MPa}$ confining pressure.
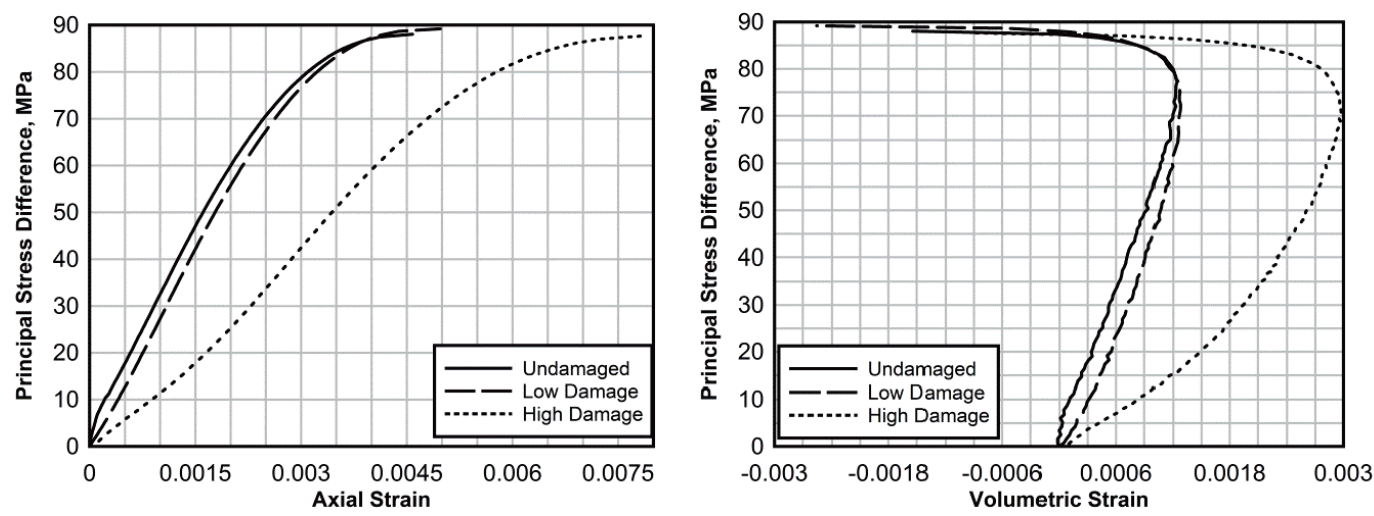

Figure 4-6. ( $L$ to $R$ ) Principal stress difference vs. axial strain and principal stress difference vs. volumetric strain for undamaged and damaged samples during triaxial compression with $20 \mathrm{MPa}$ confining pressure.
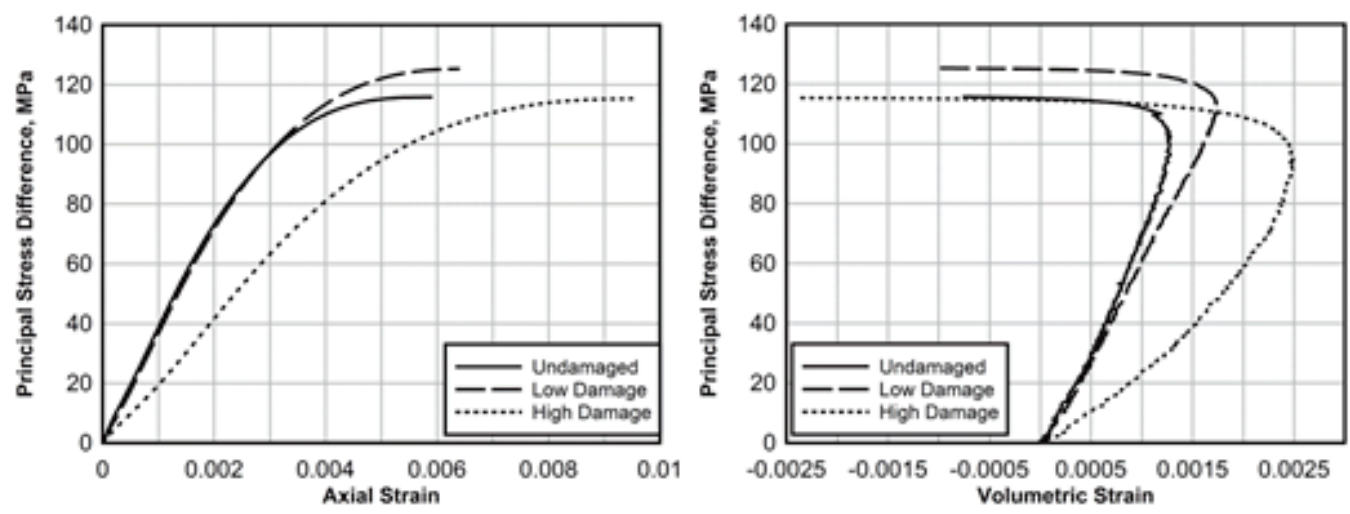
Figure 4-7. ( $L$ to $R$ ) Principal stress difference vs. axial strain and principal stress difference vs. volumetric strain for undamaged and damaged samples during triaxial compression with $100 \mathrm{MPa}$ confining pressure.
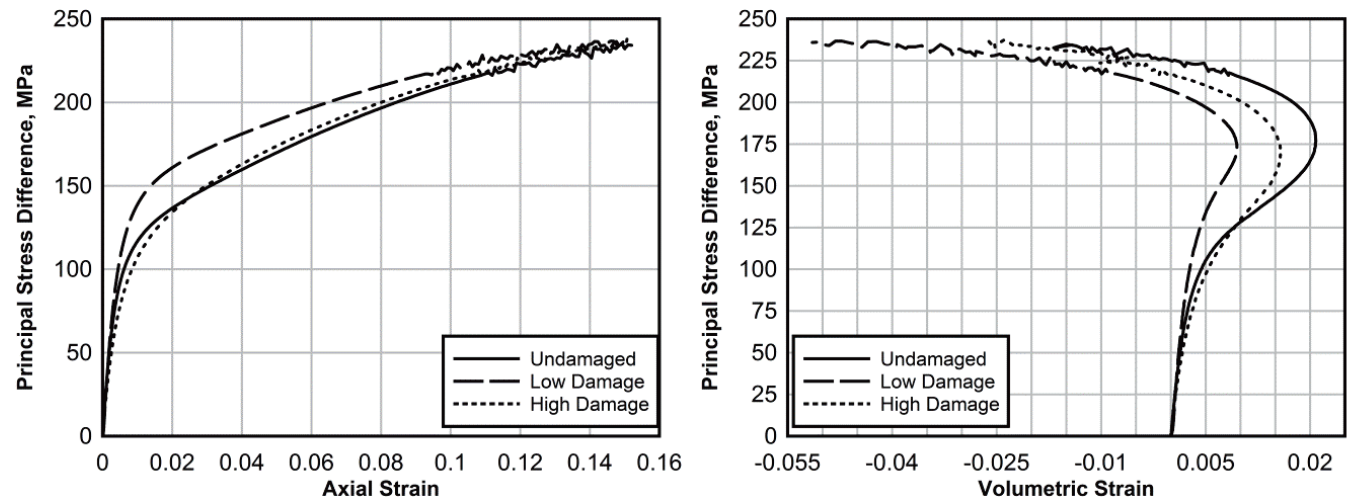

Figure 4-8. ( $L$ to $R$ ) Principal stress difference vs. axial strain and principal stress difference vs. volumetric strain for undamaged and damaged samples during triaxial compression with $400 \mathrm{MPa}$ confining pressure.
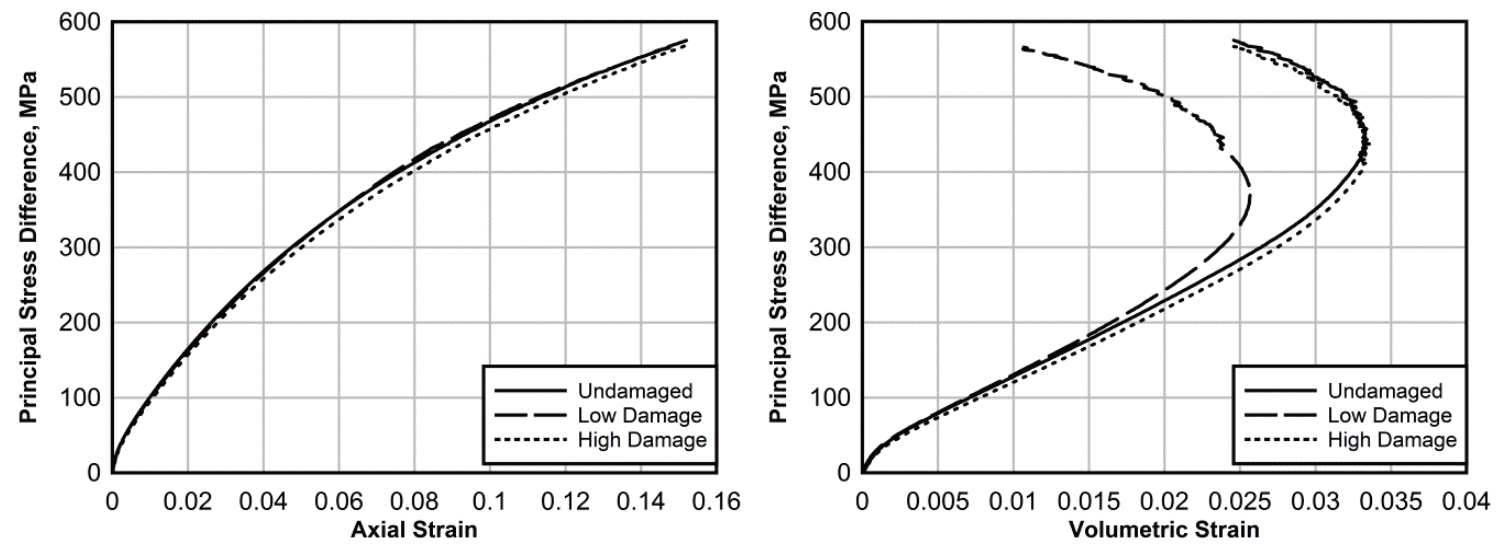

Figure 4-5 to Figure 4-8 also show the PSD-volumetric strain curves for the TXC tests at the various confining pressures. Initially, the volumetric strains were compressive and remain positive until dilation occurs in the samples. Table 4-2 shows the mean peak volumetric strain during shear for the TXC tests.

Table 4-2. Mean peak PSD and volumetric strain for TXC tests on undamaged and damaged samples.

\begin{tabular}{|c|c|c|}
\hline Sample Type & Mean Peak PSD, MPa & Mean Peak Volumetric Strain, Percent \\
\hline \multicolumn{3}{|c|}{ TXC at $10 \mathrm{MPa}$} \\
\hline Undamaged & 87.0 & 0.122 \\
\hline Low Damage & 89.2 & 0.128 \\
\hline High Damage & 85.5 & 0.289 \\
\hline
\end{tabular}




\begin{tabular}{|c|c|l|}
\hline Sample Type & Mean Peak PSD, MPa & Mean Peak Volumetric Strain, Percent \\
\hline \multicolumn{3}{|c|}{ TXC at 20 MPa } \\
\hline Undamaged & 113.0 & 0.128 \\
\hline Low Damage & 124.6 & 0.162 \\
\hline High Damage & 106.8 & 0.240 \\
\hline \multicolumn{2}{|c|}{ TXC at 100 MPa } \\
\hline Undamaged & 240.8 & 1.64 \\
\hline Low Damage & 234.3 & 1.07 \\
\hline High Damage & 241.7 & 1.43 \\
\hline \multicolumn{2}{|c|}{ TXC at 400 MPa } \\
\hline Undamaged & 572.9 & 3.32 \\
\hline Low Damage & 567.2 & 2.63 \\
\hline High Damage & 570.3 & 3.56 \\
\hline
\end{tabular}

\subsubsection{Hydrostatic compression}

Three hydrostatic compression tests were performed up to a pressure of $400 \mathrm{MPa}$ to provide undrained compressibility data for the limestone samples. One test was performed each on the undamaged, low damage, and high damage samples. The test setup was the same as that used in the initial stage of the TXC tests.

The pressure-volume response of the undamaged and damaged samples can be seen in Figure 4-9. During the tests, the pressure was intentionally held constant for a brief period (approximately $4 \mathrm{~min}$.) before unloading. During this time the strains continued to increase, which indicated that the material is susceptible to creep at high pressures. For each material, yield occurs and plastic strains begin to accumulate at a pressure of approximately $175 \mathrm{MPa}$. The high damage sample initially had a lower bulk modulus ( 2000 MPa) but began to stiffen with increased strain. After that initial stiffening, the damaged material had a bulk response similar to that of the undamaged material ( $14000 \mathrm{MPa})$. 
Figure 4-9. Pressure volume response for undamaged and damaged samples during hydrostatic compression to $400 \mathrm{MPa}$.

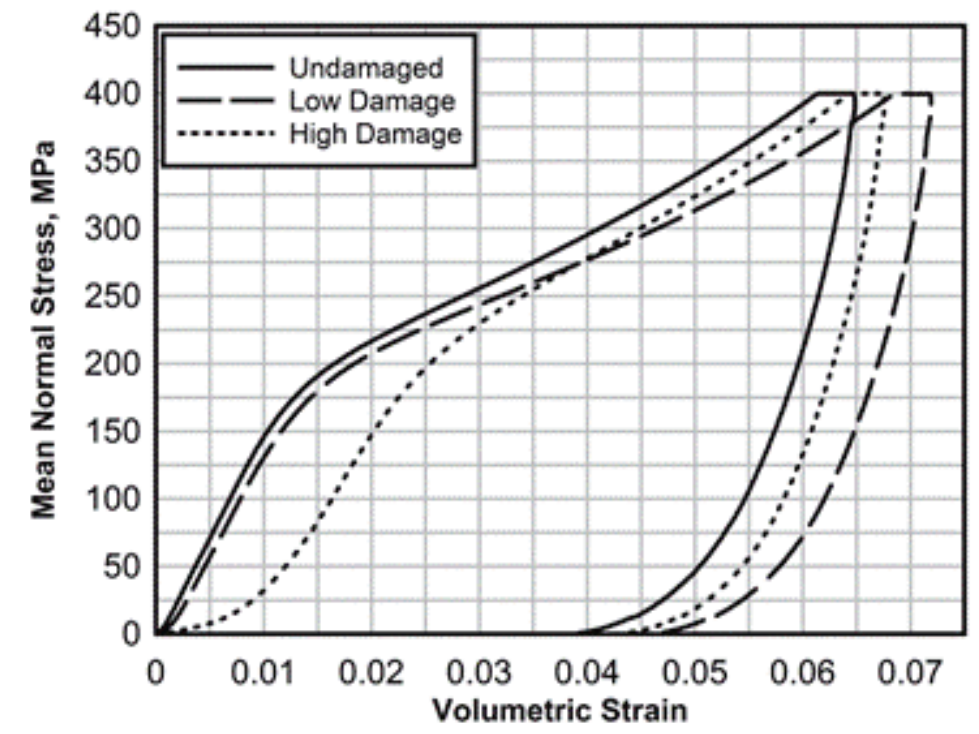

\subsubsection{Uniaxial strain/constant volume strain path test}

Nine UX/CV tests were performed on the samples to obtain failure and one- dimensional compressibility data. The axial load was applied using an 8.9 $\mathrm{MN}$ (2,000,000 lb-force) loader, and the confining pressures were applied with a $600 \mathrm{MPa}$ capacity pressure vessel. Three tests were performed (one for each damage level) to $100 \mathrm{MPa}$ confining pressure during the UX portion of the test, three to $150 \mathrm{MPa}$ confining pressure, and three to $200 \mathrm{MPa}$ confining pressure. These tests were performed in two stages, uniaxial strain loading and loading that maintains constant sample volume. The UX portion of the test was conducted by applying an axial load and confining pressure simultaneously so that the diameter of the sample remains unchanged as the axial load is applied. Following the UX loading, a constant axial-to-radial strain ratio (ARSR) of -2.0 was applied. The ARSR of -2.o insures a constant volumetric strain as the sample is loaded. $\mathrm{UX} / \mathrm{CV}$ tests are useful for confirming results obtained from the TXC because the data approximately follows the recommended failure surface of the material, as seen in Figure 4-10. 
Figure 4-10. Comparison of UX/CV and TXC tests with recommended failure surface.

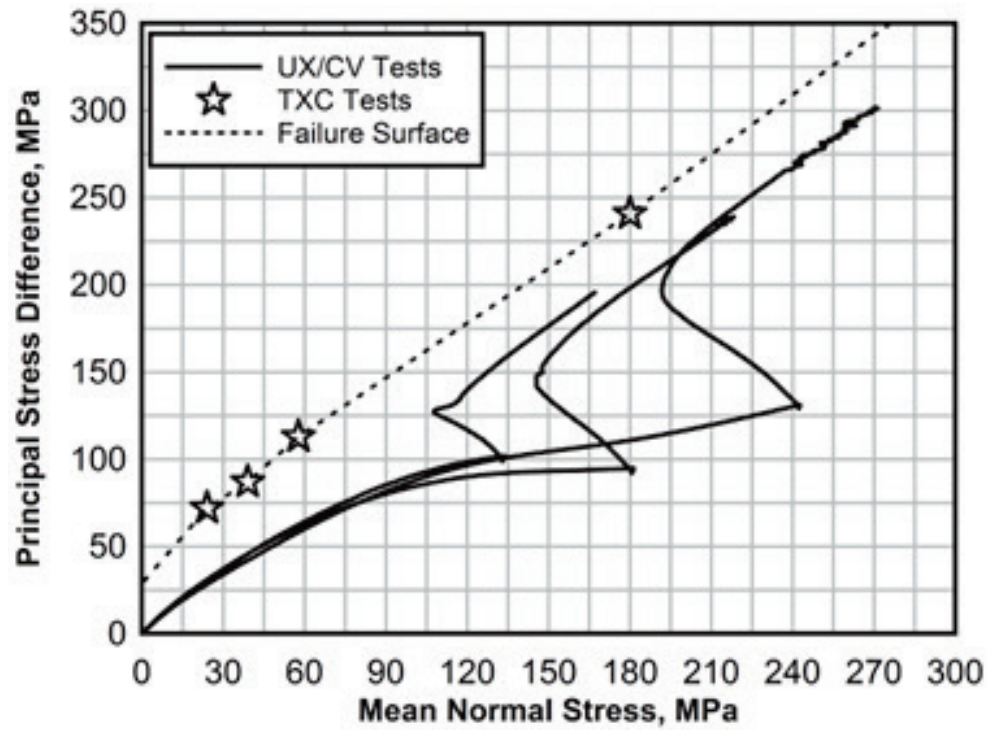

Figure 4-11 shows the pressure-volume response and PSD vs. MNS for the $\mathrm{UX} / \mathrm{CV}$ tests to $150 \mathrm{MPa}$ confining pressure. The pressure-volume response shows that high damage samples accumulate more strain before reaching the same pressures as the less damaged samples. This response is due to crack closure with increased loading. The vertical records following the UX portion indicate the CV portion of the test where volumetric strain remains constant. The PSD-MNS response follows the failure surface of the material and is slightly lower than the TXC results. The PSD-MNS response also shows that increasing levels of damage requires higher axial loading to increase the pressure during UX. For the CV portions of these tests, there is not a significant change in the failure surface between the undamaged and damaged material.

Figure 4-11. ( $L$ to R) Mean Normal Stress vs. volumetric strain and principal stress difference vs. mean normal stress for undamaged and damaged samples during UX/CV tests.
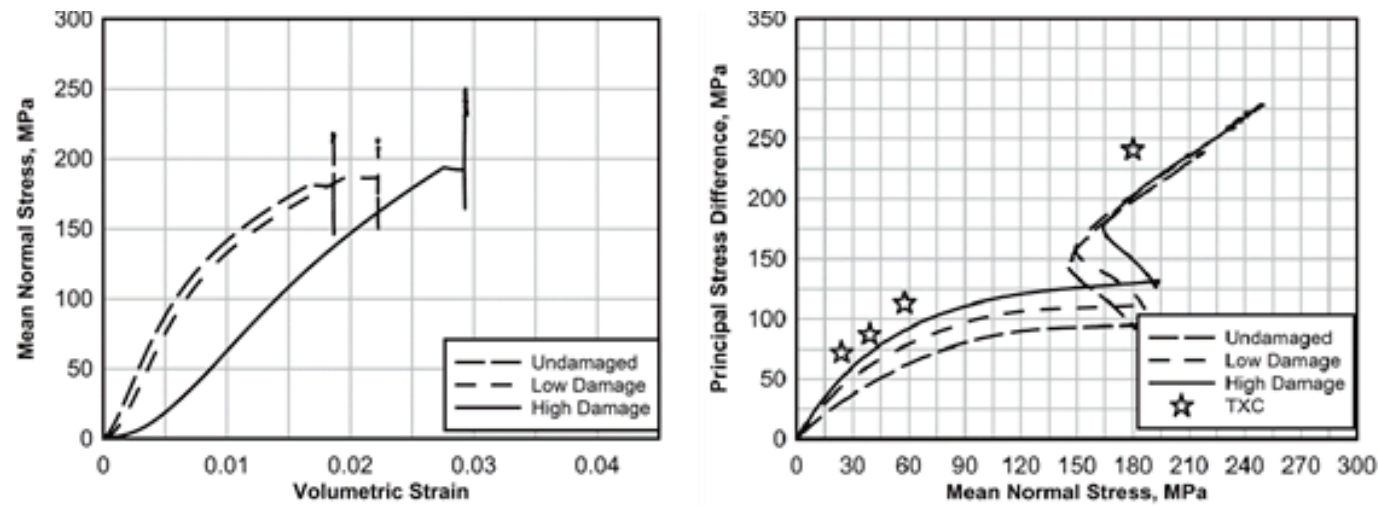


\subsection{Dynamic testing}

Dynamic testing was performed using a modified split Hopkinson pressure bar (SHPB). For a conventional compression SHPB (see Figure 4-12), a sample is placed between two bars, an incident (input) and transmitted (output) bar, made of an elastic material, e.g., a high strength steel. A third bar, the striker bar, is propelled (typically by a gas gun) into the end of the incident bar generating a longitudinal compressive incident wave. When the wave reaches the sample, part of it passes through the sample and the remainder is reflected back into the incident bar. The elastic displacements caused by the compressive waves, measured by strain gages, are used to determine the stress-strain response of the sample. Figure 4-13 shows the compression SHPB at the Center for Advanced Vehicular Systems (CAVS) at Mississippi State University (MSU) used for this work.

Figure 4-12. Conventional SHPB setup.

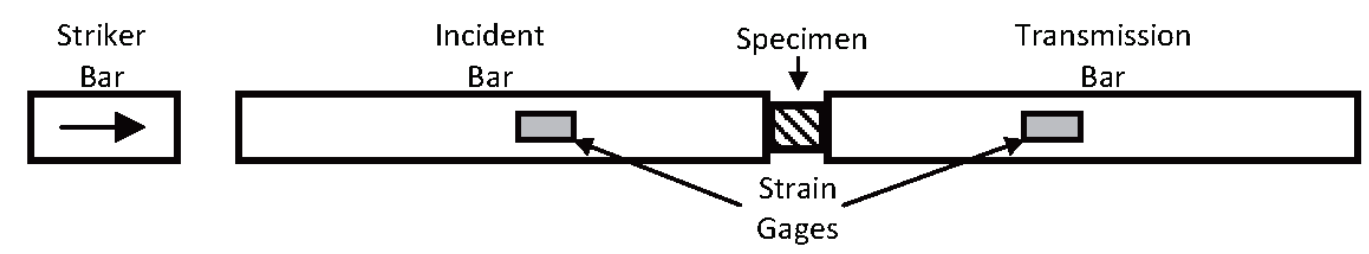

Figure 4-13. Compression SHPB setup at MSU CAVS.

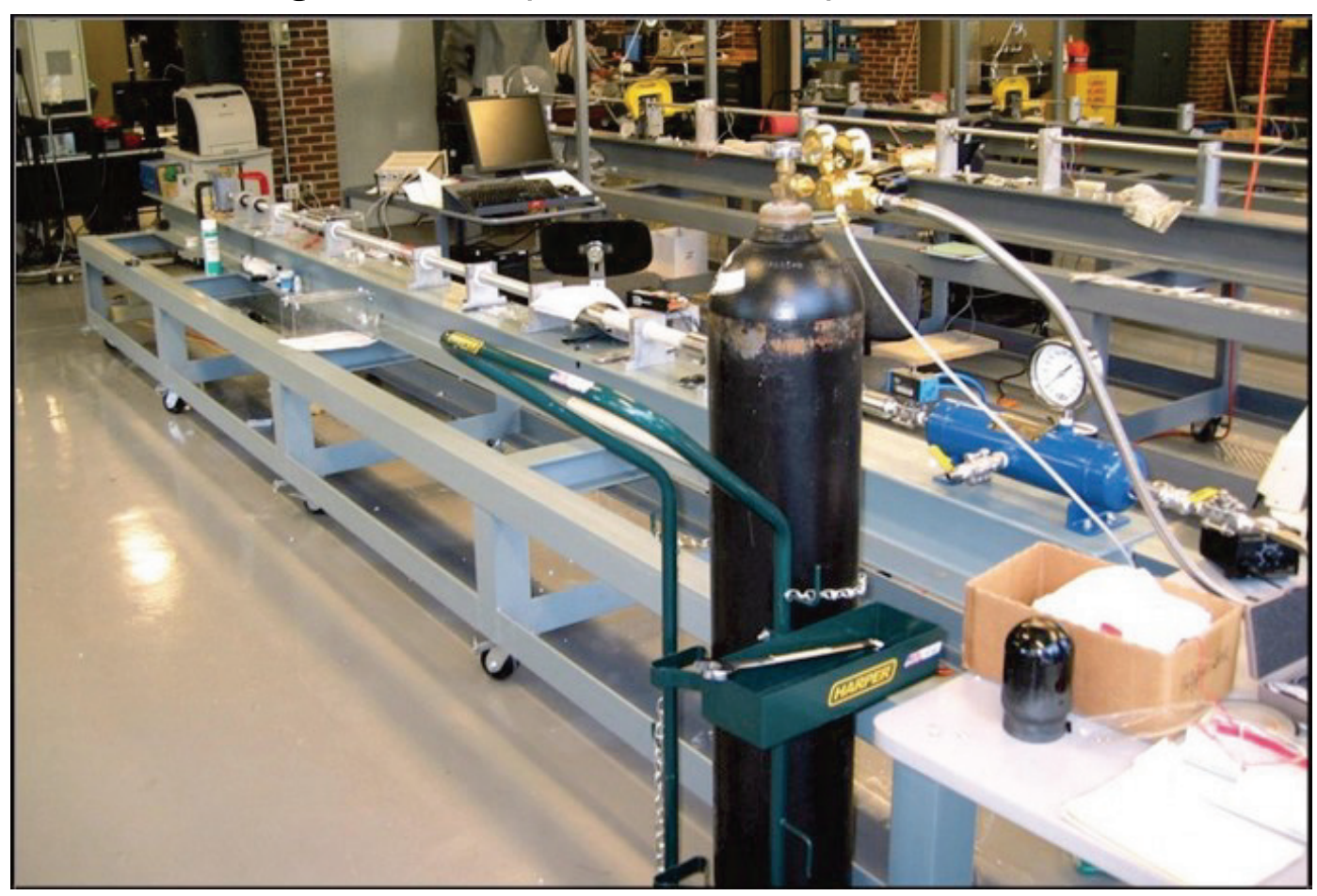


For brittle materials such as limestone, a nondispersive ramp pulse is required to maintain dynamic stress equilibrium and a constant strain rate for the duration of the SHPB tests needed for valid results (Frew 2001). A modified SHPB technique that uses a thin copper pulse shaper is used in this work to obtain the required ramp pulse (see Figure 4-14). Figure 4-15 shows the incident wave for a test without a pulse shaper and the incident wave obtained in this work. The tests with the pulse shaper provide a nearly linear ramp in the loading up to $100 \mu$ s and eliminate the high frequency oscillations that appear in a conventional SHPB test.

Figure 4-14. Modified SHPB Setup.

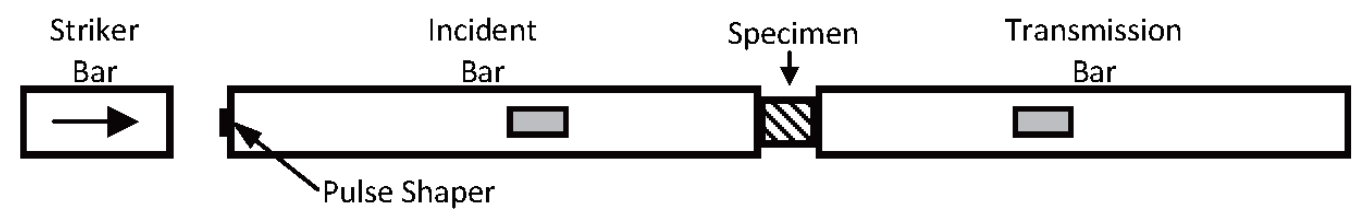

Figure 4-15. Incident bar stress wave without (left) and with (right) a pulse shaper.
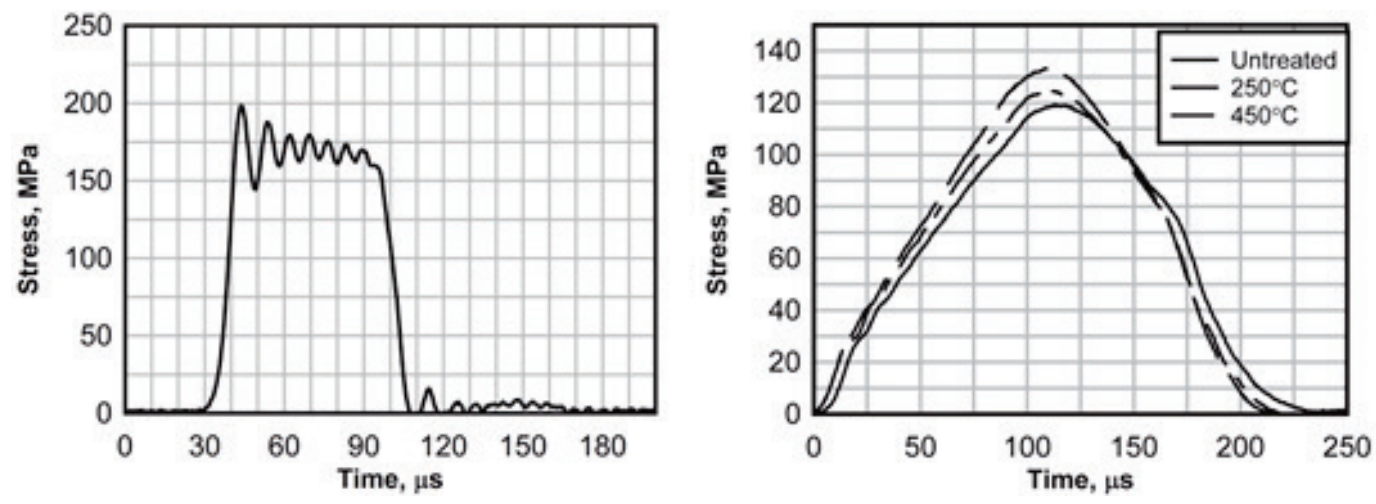

The bars used in this work were made of high-strength steel and had diameters of $12.8 \mathrm{~mm}$. The striker, incident, and transmitted bars had lengths of $203.2 \mathrm{~mm}, 2438.4 \mathrm{~mm}$, and $1219.2 \mathrm{~mm}$, respectively. The strain gage on the incident bar was located $1219 \mathrm{~mm}$ from the sample, and the transmitted bar gage was $381 \mathrm{~mm}$ from the sample. A $3.97 \mathrm{~mm}$ diameter, $0.79 \mathrm{~mm}$ thick annealed copper, C1100o (Lewis 1979 in Frew et al. 2001), disk was placed on the impact surface of the incident bar as a pulse shaper. The samples used in the work were prepared by Frew (2001) and a limited amount was available.

Figure 4-16 shows the stresses in the samples at the incident bar-sample interface and the transmission bar-sample interface for the undamaged, 
low damage, and high damage samples. Because the incident and transmission bar interface stresses are in good agreement, the samples are approximately in a state of dynamic equilibrium. If the interface stresses were not in agreement (e.g., the transmission bar stress diverges and significantly exceeds the incident bar stress), that would indicate that the sample was not in stress equilibrium resulting in invalid results. For the undamaged sample, the strain rate is relatively constant until the sample begins to fail at approximately $90 \mu \mathrm{s}$. As the damage increases, a greater variation in the measured strain rate can be seen. There is also a larger variation in the incident- and transmission-bar interface stresses at the initial portion of the test data. This most likely occurs because a greater number of cracks perpendicular to the applied stresses are being closed in the samples with induced damage. The results from all of the SHPB tests can be seen in the appendix.

Figure 4-16. Interface stresses and strain rate from modified SHPB test on undamaged (top left), low damage (top right), and high damage samples (bottom left), and a comparison of the stress-strain responses for each damage level (bottom right).
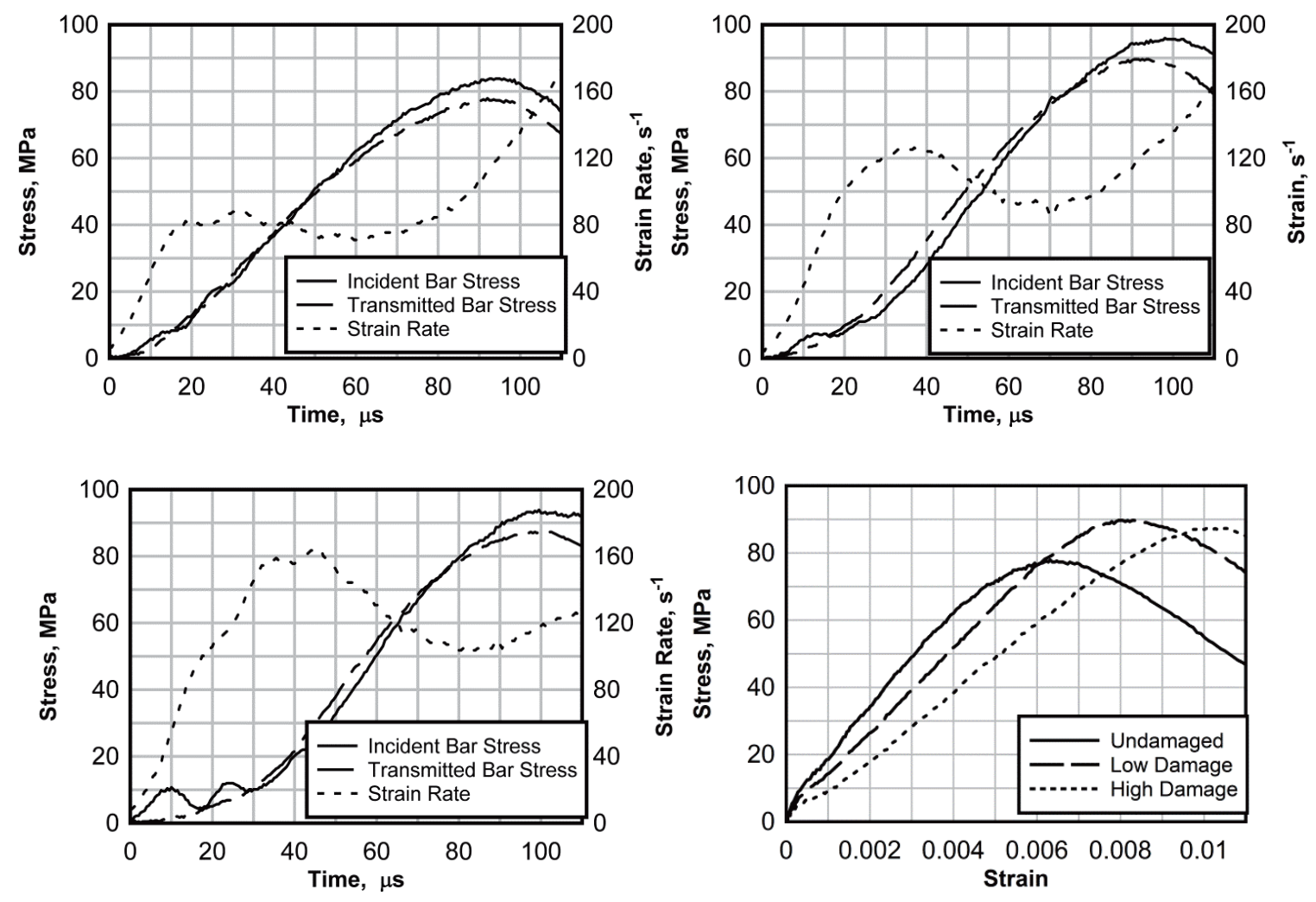
The undamaged limestone sample had a failure stress of about $80 \mathrm{MPa}$ at a strain rate of $8 \mathrm{o} \mathrm{s}^{-1}$, which is lower than the failure stress of the low and high damage samples of about $90 \mathrm{MPa}$. This is probably due to strength variations between the individual samples. Because of the small sample sizes ( 0.5 inch length and diameter), density changes between samples also play a large role. This strength is also significantly lower than the dynamic strength determined by Frew (2001) of about $120 \mathrm{MPa}$ for a strain rate between 100 and $120 \mathrm{~s}^{-1}$. This could be explained by several factors including differences in strain rates used ( $\left.80 \mathrm{o} \mathrm{s}^{-1} \mathrm{vs} .100-120 \mathrm{~s}^{-1}\right)$, differences in equipment (Frew's tests were done at the U.S. Army Engineering Research and Development Center), or simply differences between samples

The damaged and the undamaged samples had failure stresses of about 90 MPa for strain rates between 100 and $130 \mathrm{~s}^{-1}$. Though similar incident stress pulses were imparted to the samples, higher strain rates were observed for increasing levels of damage. This is most likely due to an initial lower stiffness in the samples (similar to that seen in the quasi-static tests) during crack closure offering little resistance initially that allows the strain rate to increase at a higher rate. This same behavior could also be responsible for undamaged and damage samples having the same dynamic strengths.

Though the overall stiffness of the damaged samples is lower, the failure stresses are consistent regardless of the damage levels, as seen in Figure 4.16 (bottom right). More dynamic tests are needed to confirm if these trends remain for a larger sample size.

\subsection{Summary}

Quasi-static and dynamic testing was performed to characterize the mechanical response of the intact and damaged limestone. The quasi-static tests provided results for tests generating several stress states including uniaxial compression, triaxial compression, hydrostatic compression, and uniaxial strain / constant volume. These tests provided evidence that microcracking affected limestone by lowering peak strengths at confining pressures lower than $10 \mathrm{MPa}$ and lowering the stiffness regardless of the stress state (though greater effects can be seen at lower pressures). Microcracking did not affect the limestone's strength at pressures greater than $10 \mathrm{MPa}$. 
Modified SHPB tests were also performed to determine the effects of microcracking on the dynamic response of the limestone. These tests showed that microcracks lower the stiffness of the material even at higher strain rates. Microcracking did not seem to have an effect on the dynamic strength of the limestone. However, a limited number of samples were available for SHPB tests, and more dynamic tests are needed to confirm if these trends remain for a larger sample size. 


\section{Material Modeling}

\subsection{Overview}

The ability to predict the response of damaged quasi-brittle materials has many applications in civil and military engineering problems, including penetration and blast resistant design in defense structures and structural integrity assessment for public infrastructure. In addition to damage effects, these applications commonly involve large strains, high local pressures, and high strain rates, which require consideration when modeling these types of events. For example, Figure 5 -1 shows a typical projectile penetration problem where pressures around the tip exceed $400 \mathrm{MPa}$ and large areas exceed pressures of $200 \mathrm{MPa}$.

Figure 5-1. Projectile penetration into concrete target.

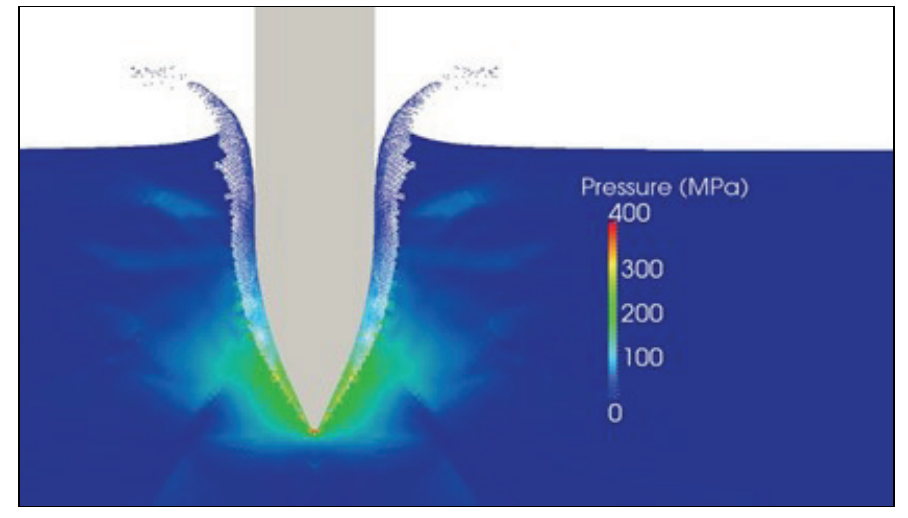

To show how the experimental data obtained in this work can be used to improve quasi-brittle material models, the Holmquist-Johnson-Cook (HJC) model (1993) has been examined and modified based on the damaged material response observed in the previous chapter. The HJC model was chosen because it is widely used for blast and impact problems and it is a relatively simple model that takes into account the most important issues of brittle material behavior, such as pressure dependency, rate dependency, pressure-volume changes, and damage. Some aspects of quasibrittle material behavior are not implemented in the HJC model such as stiffness degradation and stress-state dependency and have been addressed in other studies (Riedel et al. 1999; Gebbeken and Ruppert 2000; Polanco-Loria et al. 2008). For this work, modifications were made to account for shear modulus degradation and failure surface changes, which were the main effects of microcracking on the material behavior observed in the experimental data. 


\subsection{Holmquist-Johnson-Cook model}

The HJC model is an elastic-viscoplastic model with isotropic damage for concrete subjected to large strains and high strain rates and pressures. In the HJC model, the deviatoric response of the material is determined by the constitutive relation given in Eqs. 5.1 and 5.2. The material is linear elastic until the failure surface, or shear limit surface, is reached. It includes a scalar damage term that affects the material by reducing the cohesive strength value, $\mathrm{A}$, in the failure surface.

$$
\begin{gathered}
\sigma^{*}=\left[A(1-D)+B P^{* N}\right]\left[1+C \ln \dot{\varepsilon}^{*}\right] \text { for } \sigma^{*} \leq S M A X \\
\sigma^{*}=S M A X \text { for } \sigma^{*}>S M A X
\end{gathered}
$$

In Eq. (1), $\sigma^{*}$ and $P^{*}$ are the deviatoric stress and pressure normalized with respect to the compressive strength of the material, $f_{c}$, respectively, and $\varepsilon^{*}$ is the strain rate normalized to a reference strain rate (usually $1 \mathrm{~s}^{-}$ ${ }^{1)}$. Using normalized pressure and tensile hydrostatic pressure values allows for the same values to be used for different unit systems. B, N, and C are material constants, where $\mathrm{B}$ and $\mathrm{N}$ affect the pressure dependency, and $\mathrm{C}$ affects the strain rate dependency. SMAX is the maximum strength and acts as a limiting surface. $\mathrm{D}$ represents damage.

A scalar damage formulation is used in the HJC model and is defined as the accumulation of equivalent plastic strain and plastic volumetric strain, given in Eq. 5.3.

$$
D=\sum \frac{\left(\Delta \varepsilon_{p}+\Delta \mu_{p}\right)}{\left(\varepsilon_{p}^{f}+\mu_{p}^{f}\right)}
$$

In Eq. $2, \Delta \varepsilon_{p}$ and $\Delta \mu_{p}$ are the equivalent plastic strain increment and equivalent volumetric strain increment, respectively, and $\varepsilon_{p} p_{p}$ and $\mu_{p}$ those strains at failure. The plastic strains at failure, $\varepsilon_{p}^{f}$ and $\mu_{p}^{f}$, are expressed as

$$
\varepsilon_{p}^{f}+\mu_{p}^{f}=D 1\left(P^{*}+T^{*}\right)^{D 2} \geq E F M I N
$$

where $\mathrm{D} 1$ and $\mathrm{D} 2$ are constants and $\mathrm{P}^{*}$ and $\mathrm{T}^{*}$ are the normalized pressure and normalized tensile hydrostatic pressure, respectively. EFMIN is used 
as a lower limit on the failure strain to prevent fracture from low magnitude tensile waves. Figure 5-2 illustrates the failure surface used in the HJC model. The effect of damage in this formulation is to translate the failure surface down, and no shape change is possible.

Figure 5-2. The HJC failure surface showing the effects of damage.

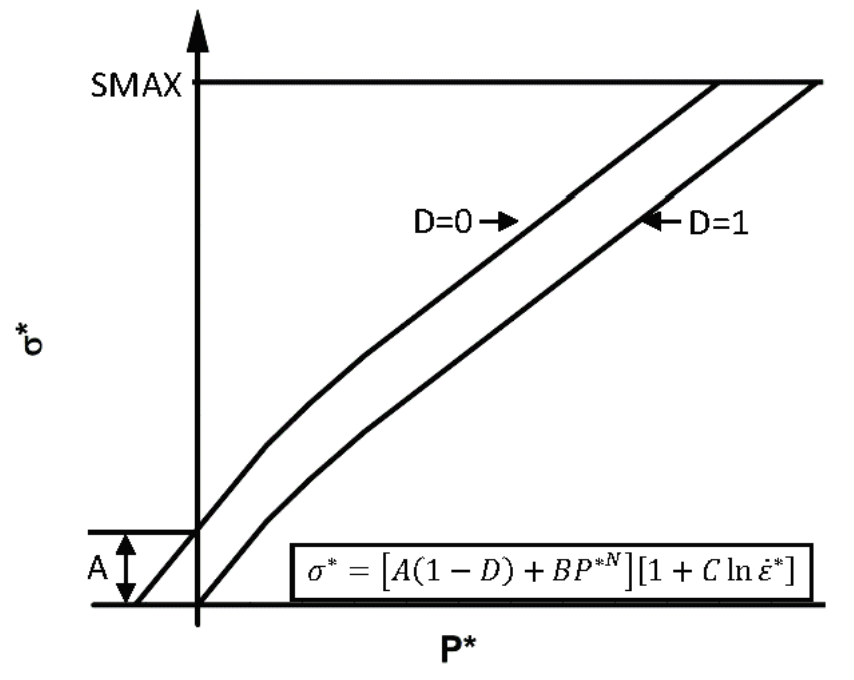

The HJC model describes the pressure-volume response of the material with three distinct regions. In the first region (at pressures lower than the crush pressure), the material is linear elastic. The bulk modulus in this region is given by

$$
K_{\text {elastic }}=P_{\text {crush }} / \mu_{\text {crush }}
$$

where $\mathrm{P}_{\text {crush }}$ is the crush pressure and $\mu_{\text {crush }}$ is the volumetric strain at the crush pressure. The second region occurs at pressures higher than the crush pressure and lower than the locking pressure. The bulk response in this region is determined by interpolating the responses of the first and third region. The third region describes the relationship for fully dense material, where all of the air voids are compressed out of the material. In this region, pressure is a non-linear function of volumetric strain, given in Eq. 5.6.

$$
P=K 1 \bar{\mu}+K 2 \bar{\mu}^{2}+K 3 \bar{\mu}^{3}
$$

In Eq. 5.6, the modified volumetric strain, $\bar{\mu}$, is given instead of the volumetric strain to provide a relationship to the volumetric strain at locking, 
$\mu_{\text {lock }}$ (the beginning of the third region in the pressure-volume response). The modified volumetric strain is given in Eq. 5.7.

$$
\bar{\mu}=\frac{\mu-\mu_{\text {lock }}}{1+\mu_{\text {lock }}}
$$

Because all of the voids are gone, large pressure increases occur for very small changes in volumetric strain. Figure 5-3 illustrates the pressure-volume response used in the HJC model.

Figure 5-3. Pressure-Volume Response in HJC.

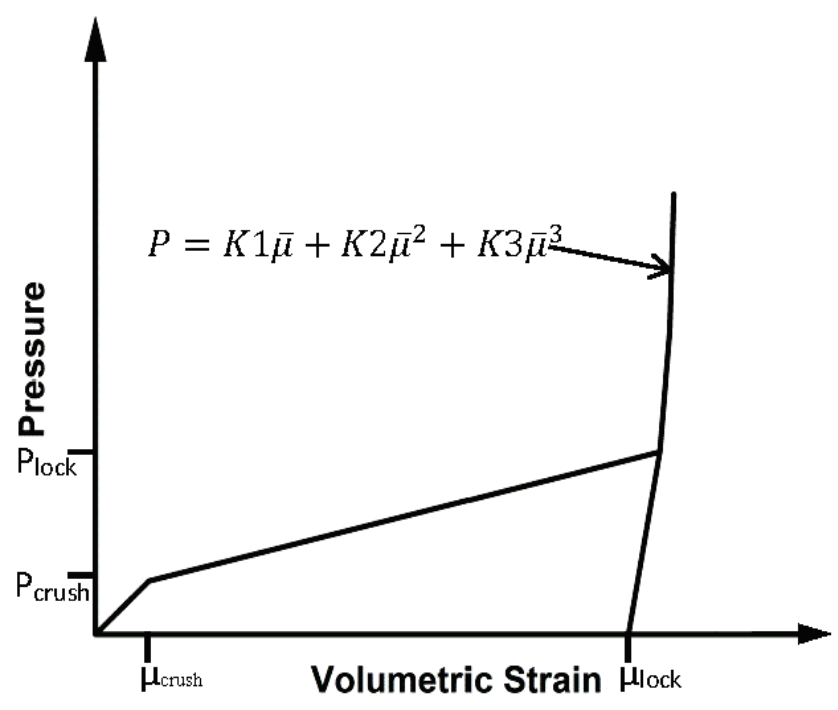

\subsection{HJC modifications}

The experiments performed in this work show that damage affects the strength of the material only at low confining pressures ( $<10 \mathrm{MPa})$. As pressure increases, the strength of the damaged material increases until it is equal to that of the undamaged material (see Table 4.2). It also shows the elastic moduli are affected by damage at confining pressures less than $100 \mathrm{MPa}$. Modifications were made to the $\mathrm{HJC}$ model to incorporate these damage effects on the failure surface and shear modulus, which provides a more realistic material response for various levels of damage. The modifications to the HJC failure surface will be discussed next followed by the changes to the shear modulus formulation. 


\subsubsection{Failure surface}

In the first term of the HJC failure surface (Eq. 5.1), damage reduces the cohesive strength, A, which shifts the failure surface of the material to a damaged state as shown in Figure 5.2. Once the material has accumulated any amount of damage, it cannot return to the undamaged failure surface. The experiments performed in this work indicate that damage affects the shear strength of the material in a pressure dependent manner. At low confining pressures (less than $10 \mathrm{MPa}$ ), the effects are significant; as pressure increases, damage effects on the shear strength diminish. To incorporate this pressure dependency, a modification was made to the yield surface formulation that allows damage to reduce the strength of the material only at low pressures. Eqs. 5.8 and 5.9 show the new failure surface formulation, which resembles the original formulation with an additional multiplier on the damage constant.

$$
\begin{gathered}
\sigma^{*}=\left[A\left(1-D^{*}\right)+B P^{* N}\right]\left[1+C \ln \dot{\varepsilon}^{*}\right] \text { for } \sigma^{*} \leq S M A X \\
D^{*}=D\left(1-\frac{P^{*}}{P_{\text {Threshold }}^{*}}\right)^{D C}
\end{gathered}
$$

$D^{*}$ is the new pressure dependent damage term, $P^{*}$ Threshold is the pressure after which damage does not affect the shear strength, and DC is a damage constant that determines how quickly the effect of damage decreases with pressure. Figure 5-4 illustrates the failure surface of the original HJC and the failure surface proposed in this work.

Figure 5-4. The original HJC failure surface (left) and proposed $\mathrm{HJC}$ failure surface (right).

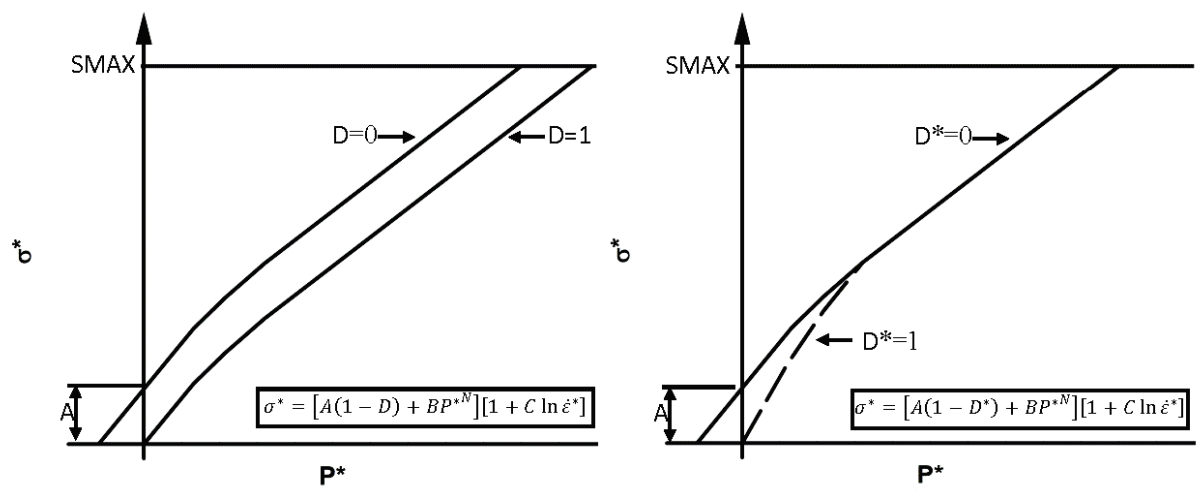




\subsubsection{Shear modulus}

The experimental results indicate that damage affects the elastic moduli of the material, and that behavior is not captured by the original HJC formulation. As shown in the hydrostatic compression tests (discussed in Chapter 4), the initial bulk modulus of the damaged material was lower than the undamaged material, but the bulk modulus increased with increasing pressure to match the bulk response of the undamaged material.

Therefore, no damage effects on the bulk moduli are considered here. However, damage effects on the shear modulus were persistent to high pressures so those affects were included in the modifications to the HJC model in this work.

To incorporate the effects of damage in the shear modulus formulation, a linear interpolation scheme (Gebbeken and Ruppert 2000; Polanco-Loria et al. 2008) shown in Eq. 5.10 was used.

$$
G=G_{O}\left(1-D^{*}\right)+G_{D} D^{*}
$$

$G, G_{O}$, and $G_{D}$ represent the current, initial, and completely damaged shear modulus, respectively. $D^{*}$ was used instead of $D$ because the experimental results also showed a pressure dependence on the shear modulus.

\subsection{Determination of model parameters}

The modified HJC model was implemented in the solid mechanics code Sierra (SAND2011-7597). The Sierra implementation of the original HJC model requires the identification of 20 parameters: the initial density; two elastic constants (bulk and shear modulus); six strength constants including the unconfined compressive and tensile strength, cohesive strength A, pressure hardening coefficient $\mathrm{B}$, pressure hardening exponent $\mathrm{N}$, and maximum shear strength SMAX; one rate sensitivity parameter $\mathrm{C}$; three damage constants (D1, D2, and EFMIN); and seven constants to describe the pressure- volume response including those defining the elastic region (Pcrush and Ucrush), the crushing region (Plock and Ulock), and the locking region ( $\mathrm{K} 1, \mathrm{~K} 2$, and $\left.\mathrm{K}_{3}\right)$. The modifications to the $\mathrm{HJC}$ model require three additional parameters: the normalized threshold pressure $P^{*}$ Threshold, another damage constant DC, and a fully damaged shear modulus $G_{D}$. 
Simulations were performed to compare with the undamaged and damaged material data. For the undamaged material, the initial damage was set to zero. For the highly damaged material (heated to $450^{\circ} \mathrm{C}$ ), the initial damage was set to 0.65 . This value was determined using the damage parameter proposed by MacKenzie [25] because it relates damage to the shear and bulk modulus of the material. The MacKenzie damage parameter, $\psi_{D}$, is shown in Eq. (5.11).

$$
\Psi_{D}=\frac{4 G(K-\widetilde{K})}{K(4 G+3 \widetilde{K})}
$$

The parameters $K$ and $G$ in Eq. 5.11 are the elastic bulk modulus and shear modulus of the undamaged material, respectively. The parameter $K$ is the bulk modulus of the damaged material. For all problems, the damage parameter is between 0 and 1 , or $0 \leq . \psi_{D} \leq 1$. When the material is undamaged, $K=K, \psi_{D}=0$, and for completely damage materials, $K=0, \psi_{D}=1$. For this work, the bulk modulus and shear modulus were determined from wave velocity measurements on undamaged and damaged samples. Figure 5-5 shows the MacKenzie parameter for the various heat treatments.

Figure 5-5. MacKenzie damage parameter for various heat treatments.

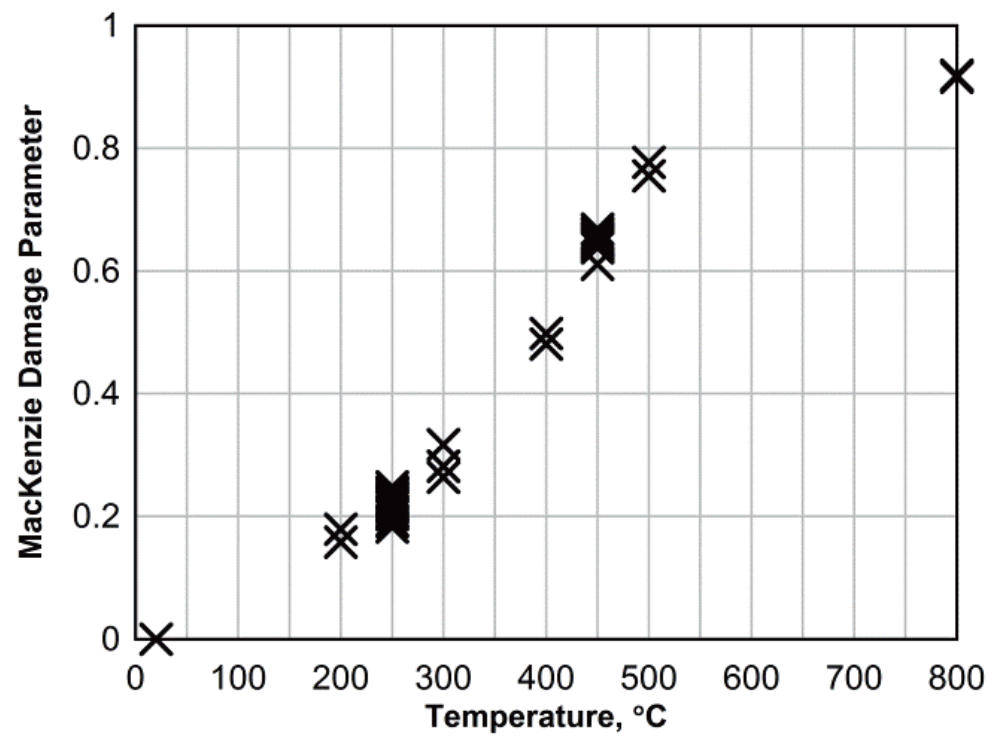

For the strength parameters, data from the unconfined and confined compression tests were used to find the find the values of A, B, and N. Because no tension tests were performed, the tensile strength was assumed to be related to the compressive strength, i.e., $f t^{\prime}=6.7 / f_{C}$ (ACI 318,2011 ). With no initial damage, the original and modified HJC results are identical 
(see Figure 5-6). With high initial damage $\left(D_{0}=0.65\right)$, the original HJC failure surface is shifted down because of the reduction in the cohesive strength. The modified HJC matches the failure surface at both lower pressure, where the strength is reduced, and higher pressures. SMAX was simply set to a high number because the experiments indicate that the material will continue to pressure harden for the range of pressures tested.

Figure 5-6. (left) Model fit using HJC and (right) modified HJC for undamaged material $(\mathrm{DO}=0)$ and $(\mathrm{b})$ damaged material $(\mathrm{DO}=0.65)$.
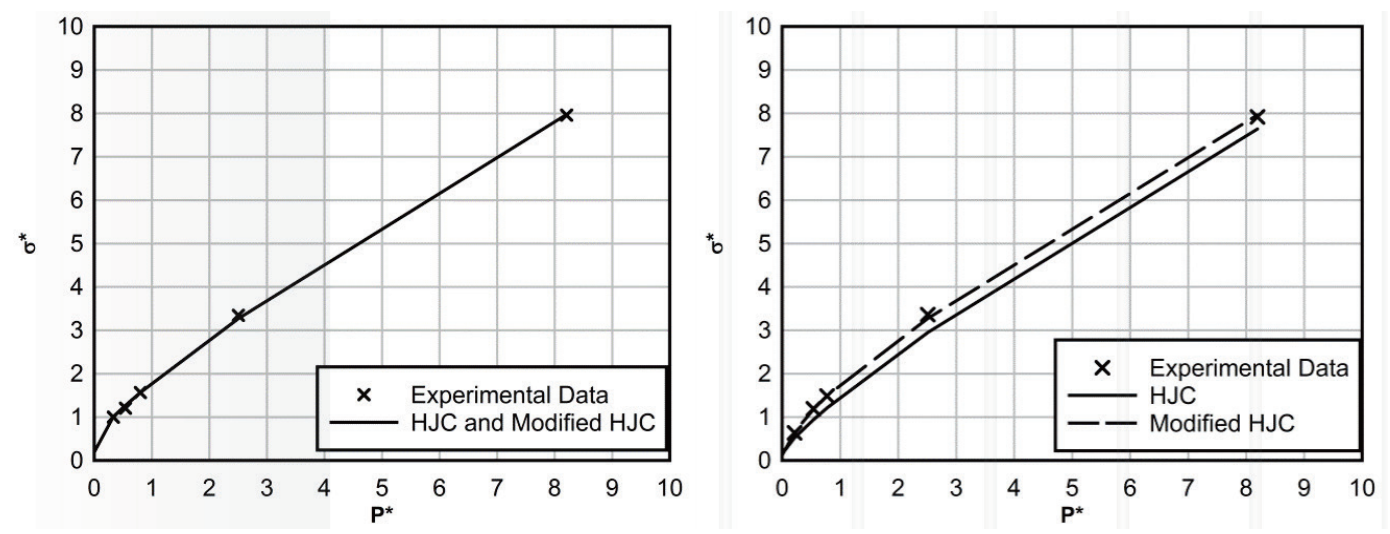

The three damage constants (D1, D2, and EFMIN in Eq. 5.4) were chosen in a manner similar to that of Holmquist et al. (1993), which used cyclic uniaxial compression tests to determine EFMIN. Instead of cyclic tests, the unconfined compression tests on undamaged and damaged samples were used to define an assumed failure surface seen in Figure 5-7. This method indicates a total loss of strength at $\varepsilon_{\mathrm{p}}^{\mathrm{f}}=0.011$, so EFMIN was set equal to 0.011. D2 was chosen to equal 1.0, which assumes the plastic fracture strain increases linearly with pressure. D1 was then calculated using Eq. 5.4 and the uniaxial compression data.

Hydrostatic compression data was used to determine the constants (Eqs. 5.5 and 5.6) that define the pressure-volume response of the material. No damage effects on the bulk modulus were incorporated into the modified version of the HJC so the pressure- volume response is the same for the original and modified HJC. The locking region in the pressure-volume response was assumed linear for the purposed of this work. 
Figure 5-7. Uniaxial compression data used to determine HJC damage constants.

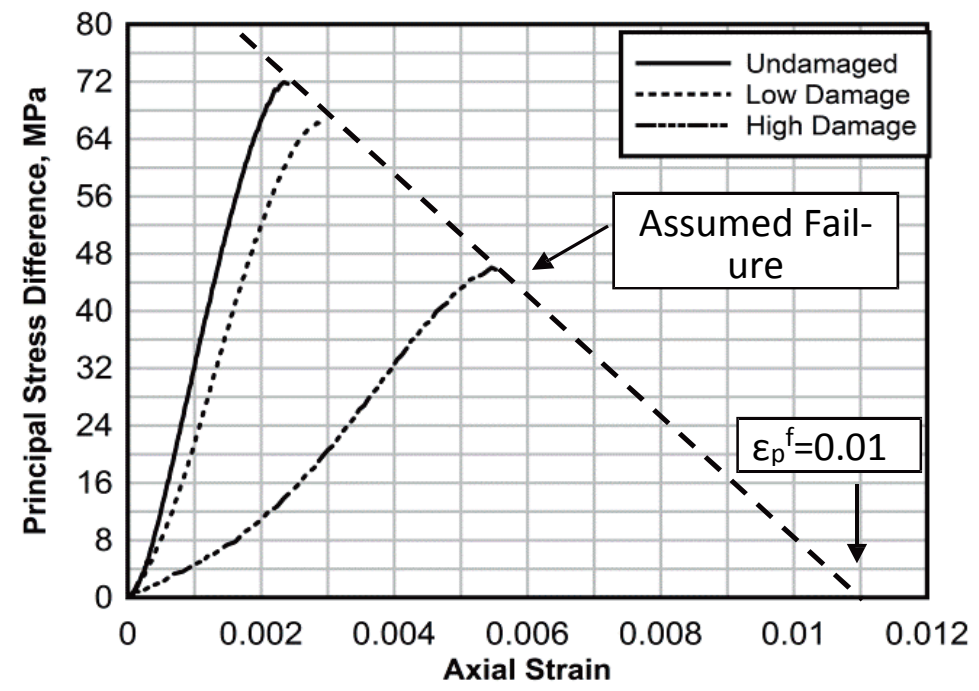

After fitting all of the constants for the original HJC model, the three additional constants for the HJC modifications were determined including the normalized threshold pressure $P^{*}$ Threshold, the damage constant DC, and a fully damaged shear modulus $\mathrm{G}_{\mathrm{D}} . P^{*}$ Threshold was set to the brittle-to-ductile transition of the material to allow softening of the material to occur up to the brittle-to-ductile transition. The damage constant DC determines how quickly the effects of damage disappear with pressure and was fit to give the desired results. Lastly, the fully damaged shear modulus, $\mathrm{G}_{D}$, was determined from the sonic velocities of the material heat treated to the highest temperature $\left(800^{\circ} \mathrm{C}\right)$.

To determine the strain rate parameter C (Eq. 5.1), a numerical analysis of the SHPB experiments discussed in the previous chapter was performed. Initial simulations were performed with no strain rate dependence, $\mathrm{C}=\mathrm{O}$. Then, the strain rate dependence was gradually increased until the simulated strain-time response matched that of the experiment (see Figure 5 -8). These simulations will be discussed in more detail later.

Table 5-1 shows the rate-independent and dependent constants for the modified HJC model for Salem limestone. 
Figure 5-8. Strain-time response for SHPB simulations with and without rate dependence.

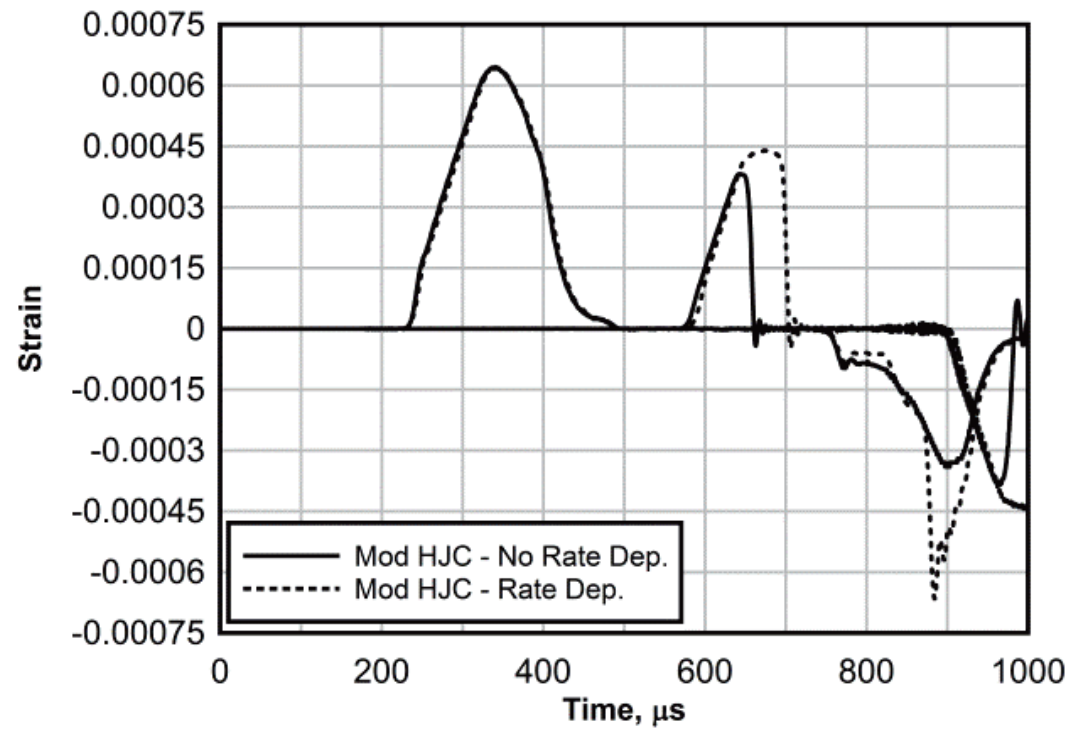

Table 5-1. Constants for the modified HJC model.

\begin{tabular}{|c|c|c|}
\hline \multicolumn{3}{|c|}{ Original HJC Constants } \\
\hline Initial Density, g/cc & No Strain Rate Dep. & Strain Rate Dep. \\
\hline Initial Shear Modulus, MPa & 2.30 & 2.30 \\
\hline Cohesive Strength A & 10000.00 & 10000.00 \\
\hline Pressure Hardening Coefficient B & 0.50 & 0.50 \\
\hline Pressure Hardening Exponent N & 1.286 & 1.373 \\
\hline Strain Rate Coefficient C & 0.8362 & 0.8273 \\
\hline Compressive Strength F'c, MPa & 0.00 & 0.0038 \\
\hline Max Stress & 72.00 & 72.00 \\
\hline Pcrush, MPa & 13.00 & 13.00 \\
\hline Ucrush & 195.00 & 195.00 \\
\hline Pressure Coefficient K1, MPa & 0.013 & 0.013 \\
\hline Pressure Coefficient K2, MPa & 44300.00 & 44300.00 \\
\hline Pressure Coefficient K3, MPa & 0.00 & 0.00 \\
\hline Plocki, MPa & 0.00 & 0.00 \\
\hline Ulock & 665.00 & 665.00 \\
\hline Max Tensile Pressure T, MPa & 0.13 & 0.13 \\
\hline Damage Coefficient D1 & 6.00 & 6.00 \\
\hline Damage Exponent D2 & 0.05 & 0.05 \\
\hline Minimum Failure Strain & 1.00 & 1.00 \\
\hline D*threshold & 0.011 & 0.011 \\
\hline DC & 3.50 & 3.50 \\
\hline Gd, MPa & 8.00 & 8.00 \\
\hline & 2000.00 & 2000.00 \\
\hline
\end{tabular}




\subsection{Results}

Numerical simulations using the material parameters in Table 5.1 were performed with the original HJC and modified HJC models to compare with the experimental stress- strain data. The solid mechanics code Sierra (SAND2011-7597) was used for both the quasi-static and dynamic simulations.

\subsubsection{Quasi-static test analysis}

The quasi-static simulations consisted of unconfined compression (UC) and triaxial compression (TXC) tests and were analyzed using a single brick element. The results labeled undamaged indicate no induced damage in the experimental samples, and $\mathrm{Do}=0$ in the material model setup. The results labeled high damage indicate experimental samples with damage induced from the $450^{\circ} \mathrm{C}$ heat treatment, and $\mathrm{Do}=0.65$ per the MacKenzie damage parameter mentioned earlier. Post-peak data is given for comparison purposes only; the experimental and numerical implications associated with post-peak response are not discussed because it is beyond the scope of this analysis.

Figure 5-9 compares the experimental results with the original and modified HJC models for the uniaxial compression tests. The principal stress difference (PSD)-axial strain response is given for the comparisons. The modified HJC provides better results for the strength and stiffness under uniaxial compression. The lower initial stiffness (due to crack closure) observed in the experimental results (circled in Figure 5-9) is not captured by the modified HJC, which lead to differences in the amount of axial strain induced by the loading. Beyond the lower initial stiffness in the experimental results, the simulation and experimental responses are approximately parallel. 
Figure 5-9. Unconfined compression data compared with original HJC (left) and modified HJC model (right).
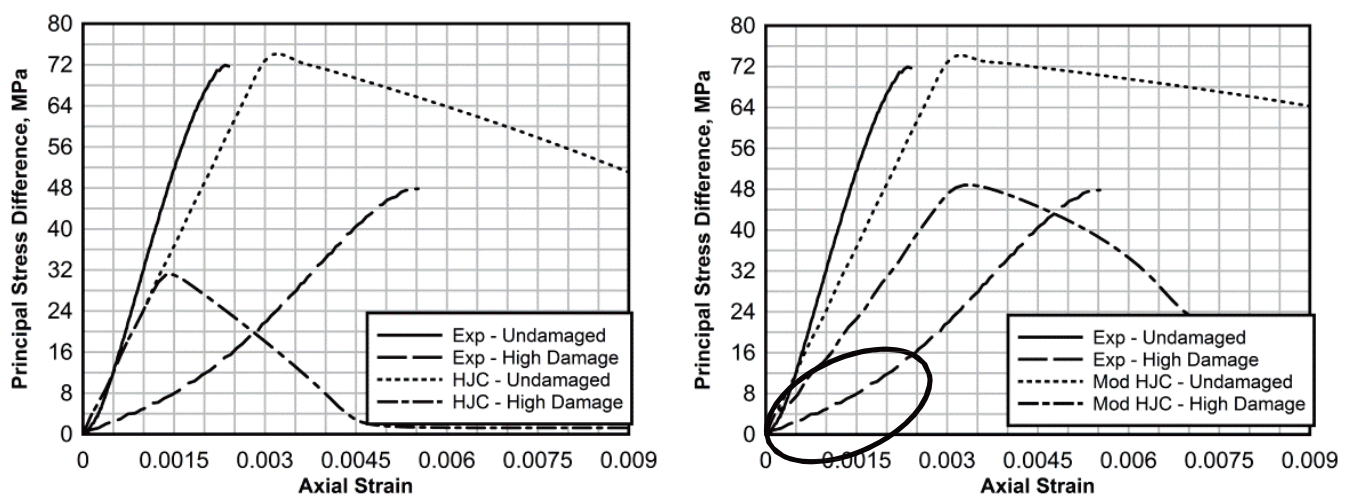

Figure 5-10 to Figure 5-12 compare the experimental results with the original and modified HJC models for the triaxial compression tests. The HJC results show that a reduction of the failure surface with increasing damage does not represent the actual effects of damage especially at higher pressures. The modifications to the HJC implemented in this work better capture the effects of damage on the yield surface, which provides a better prediction of the peak stresses obtained during triaxial loading. The modified HJC also captures some of the damage effects on the elastic moduli.

Figure 5-10. Triaxial compression data (10 MPa confining pressure) compared with original HJC (left) and modified HJC model (right).
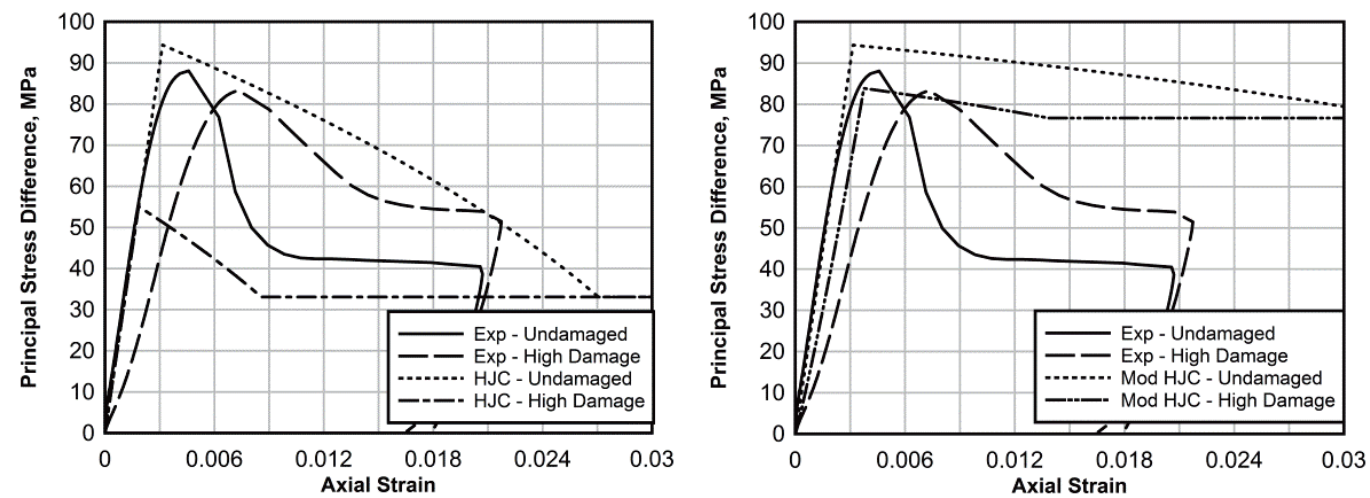
Figure 5-11 Triaxial compression data (20 MPa confining pressure) compared with original HJC (left) and modified HJC model (right).
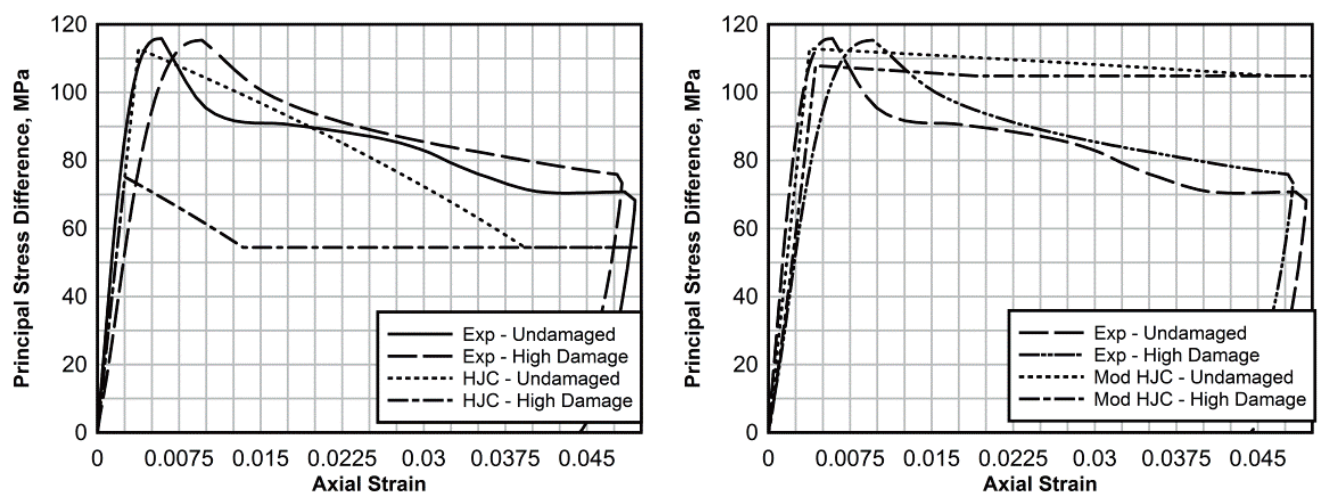

Figure 5-12. Triaxial compression data (100 MPa confining pressure) compared with original HJC (left) and modified HJC model (right).
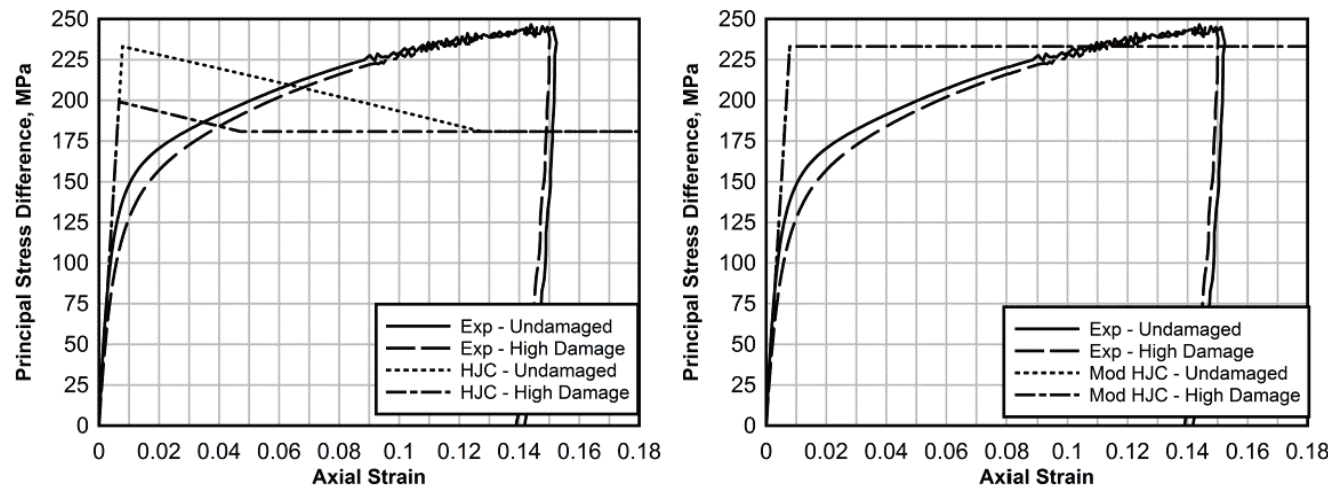

\subsubsection{Dynamic test analysis}

The numerical analysis of the dynamic tests consisted of simulating the split Hopkinson pressure bar (SHPB) tests. The SHPB geometry, given in Chapter 4, was modeled in quarter symmetry with 168,96o brick elements, as shown in Figure 5-13. Instead of explicitly modeling the striker bar and pulse shaper, the stress wave created by the striker bar in the experiments was input into the incident bar. The incident strain measurements from the analysis match the incident bar gage measurements from the experiments indicating that explicitly modeling the striker bar and pulse shaper is not necessary. 
Figure 5-13. SHPB geometry used in numerical analysis.
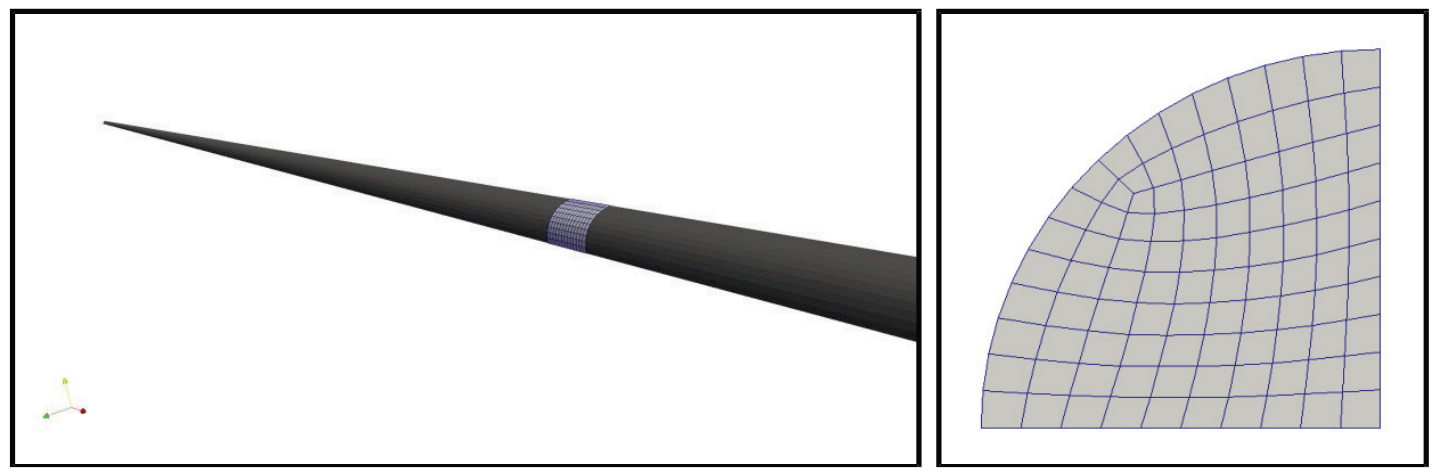

Figure 5-14. SHPB simulation of undamaged and damaged samples with (left) original HJC and (right) modified HJC model.
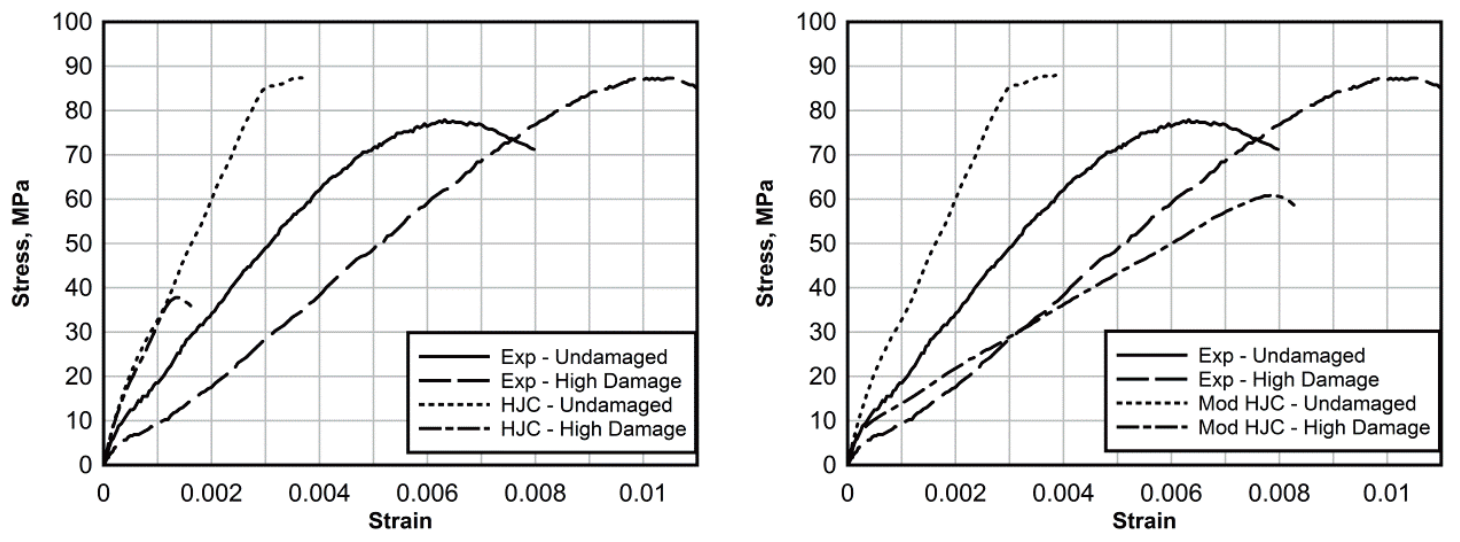

Figure 5-14 compares the experimental results of the SHPB tests with the original and modified HJC models. For the initially undamaged samples, the two models give similar responses. For the damaged samples, the original HJC (Figure 5-14 left) over predicts the elastic stiffness and shows much lower strength, approximately 57 percent lower, than the experimental results. The modified HJC (Figure 5-14 right) matches the yield strength and stiffness of the experiments better than the original HJC though the yield strength is still lower than the experimental results. The modified HJC also captures the higher initial stiffness observed in the damaged experimental results (seen at stresses lower than $10 \mathrm{MPa}$ ). This may indicate that the higher initial stiffness is a structural response instead of a material response.

Furthermore, Figure 5-14 illustrates the magnitude of the under prediction of strain energy (area under the stress-strain curve) by the HJC model for high strain rate events on initially damaged materials. Table 5-2 compares the energies from the experiments and two models. Though the models give similar results for the undamaged material, the $\mathrm{HJC}$ model yields a 
94 percent decrease from the strain energy in the experiment on the initially damaged material. The modified HJC performs significantly better with a 53 percent decrease.

Table 5-2. Energy comparison for SHPB tests with HJC and modified HJC models.

\begin{tabular}{|c|c|c|c|}
\hline & \multicolumn{3}{|c|}{ Strain Energy (MPa) } \\
\hline Damage Level & Experiment & HJC & Mod HJC \\
\hline No Damage & 0.427 & 0.205 & 0.213 \\
\hline High Damage & 0.644 & 0.040 & 0.301 \\
\hline
\end{tabular}

The numerical analysis of the SHPB tests was also used to examine whether the strength increase observed in the tests was due solely to strain rate or if radial confinement, caused by inertia or friction, caused the strength to increase. During a SHPB test, the rapid axial strain acceleration causes radial inertial effects, which can lead to radial confining pressures. Friction between the bar-sample interfaces also causes radial confinement near the ends of the sample. In pressure dependent materials, the confining pressures due to inertia and friction could cause strength increases that may be misinterpreted as a strain rate effect.

To investigate the inertia and friction effects during the SHPB tests, the strain rate independent constants (Table 5.1) were used to model the SHPB geometry used in the experiments. Strain rate independent models have been used in other studies to investigate the effects of non-strain-rate effects (Bertholf and Karnes 1975; Meng and Li 2003; Li and Meng 2003; Li et al. 2009) because any differences between the quasi-static unconfined behavior and the SHPB behavior using strain rate independent parameters can be attributed to effects unrelated to strain rate.

The effect of inertia on the sample was determined by simulating the SHPB test with no friction between the bar-sample interfaces and using the strain rate independent constants. Thus, any differences between the unconfined compressive strength and strengths determined from these simulations would be attributed to inertia causing radial confinement. Table 5-3 shows the results of the simulations on the initially undamaged and damaged material. The insignificant changes between the UC and SHPB test results provide evidence that radial confinement due to inertia did not increase the strength of the sample during the SHPB test. 
Table 5-3. Comparison of strengths from UC simulations and SHPB simulations with no friction and no rate dependency.

\begin{tabular}{|c|c|c|}
\hline \multirow{2}{*}{ Test Type } & \multicolumn{2}{|c|}{$\begin{array}{c}\text { Peak Sample } \\
\text { Strength, MPa }\end{array}$} \\
\cline { 2 - 3 } & $\mathrm{D}_{0}=0$ & $\mathrm{D}_{0}=0.65$ \\
\hline UC & 74.28 & 48.82 \\
\hline SHPB & 74.55 & 48.34 \\
\hline
\end{tabular}

To illustrate the effects of inertia, pressure was plotted at three different times during the SHPB test. Figure 5-15 shows the stress levels at which these plot were made. Figure 5.16 (top) shows Point A in Figure 5-15, Figure 5.16 (middle) shows Point B, and Figure 5.16 (bottom) shows Point C.

Figure 5-15. Stress-strain response from SHPB test showing stress levels for images in Figures 5.16 and 5.17.

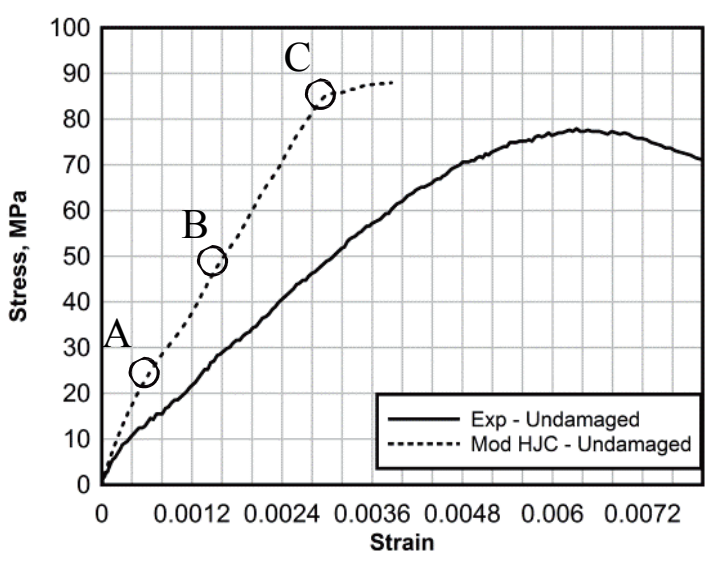


Figure 5-16. Pressure in sample during SHPB test.
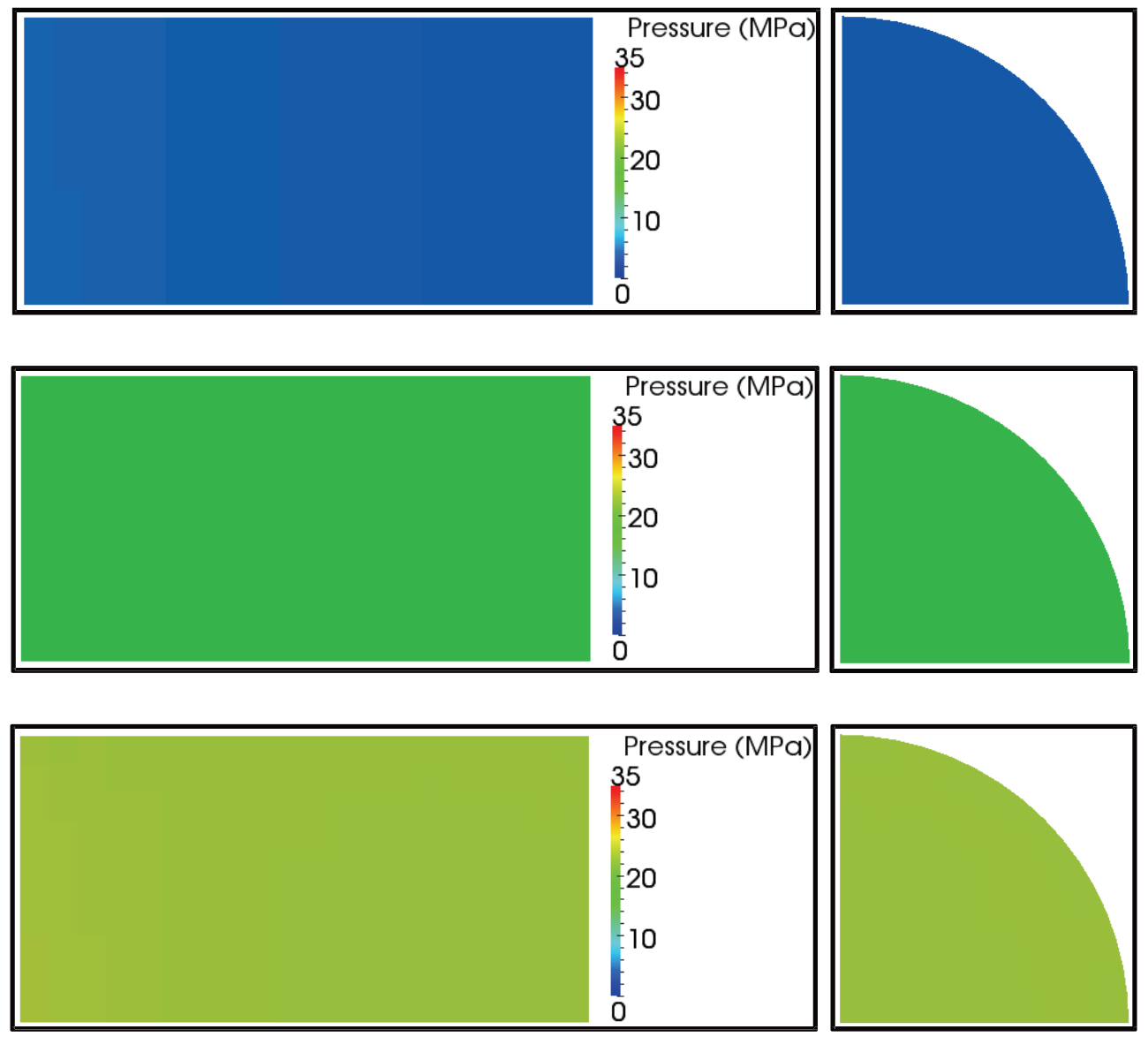

Because inertia did not have an effect on these tests, the pressures in Figure 5.16 are simply one third of the axial stress in the sample. To view the effects of inertia more clearly, one third of the axial stress was subtracted from the pressure (shown in Figure 5-17), which is the effective confining pressure throughout the SHPB test. The effective confining pressure remains zero throughout the entire test showing no additional confining pressure due to inertia. Because the strain rate found in these simulations is approximately $80 \mathrm{~s}^{-1}$, these results are supported by the findings of other studies (Malvern et al. 1985; Tang et al. 1992) where inertia did not play a significant role at strain rates below $100 \mathrm{~s}^{-1}$. 
Figure 5-17. Effective confining pressure during SHPB test showing inertial effects on sample.
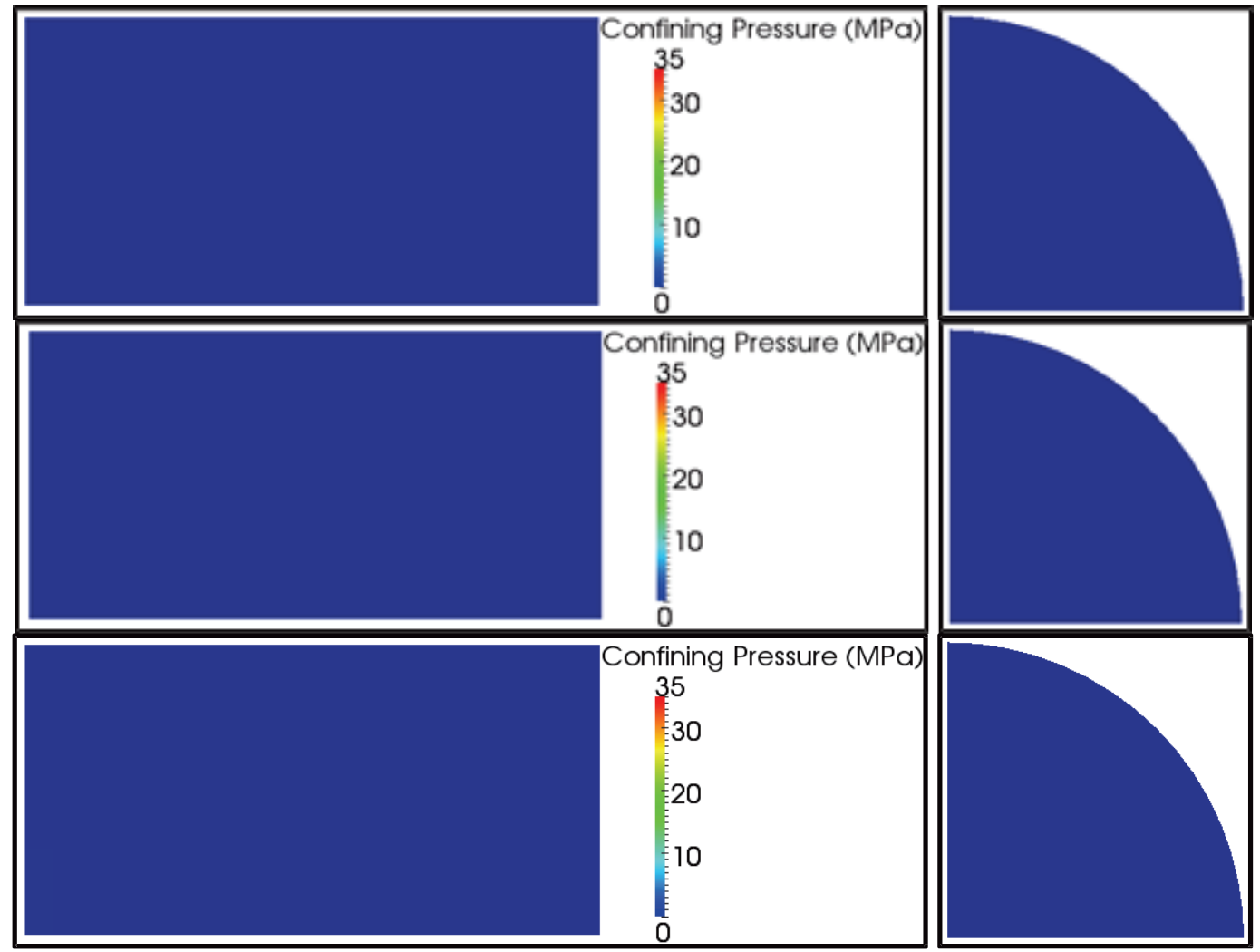

To determine the effects of friction on the dynamic strength, a parametric analysis using the SHPB simulations was performed by varying the constant friction coefficients for the bar-sample interfaces from 0.0 to 0.5. This range was chosen because it is the range of friction values most likely found in a SHPB test (Bertholf and Karnes 1975). In this analysis, the strain rate independent constants were also used. Table 5-4 shows the results of the analysis. An increase of two percent in peak sample strength is observed from no friction to a friction coefficient of 0.1 for the initially undamaged material. Peak sample strengths increase a negligible amount thereafter. For the initially damaged sample, the strength increases slightly and then decreases as the friction coefficient increases. This was due to localized element failure that happened early in the test and governed the solution despite mesh refinement. Regardless, negligible changes in the strength were seen with varying levels of friction; however, further discussion will be limited to the initially undamaged material because of this numerical issue. 
Table 5-4. Variation in peak strength with various constant friction coefficients between bar-sample interfaces in SHPB simulation.

\begin{tabular}{|c|c|c|}
\hline \multirow{2}{*}{$\begin{array}{c}\text { Constant Friction } \\
\text { Coefficient }\end{array}$} & \multicolumn{2}{|c|}{$\begin{array}{c}\text { Peak Sample } \\
\text { Strength, MPa }\end{array}$} \\
\cline { 2 - 3 } & $\mathrm{D}_{0}=0$ & $\mathrm{D}_{0}=0.65$ \\
\hline 0.0 & 74.55 & 48.34 \\
\hline 0.1 & 76.21 & 49.55 \\
\hline 0.2 & 76.37 & 48.68 \\
\hline 0.3 & 76.37 & 47.47 \\
\hline 0.4 & 76.37 & 46.59 \\
\hline 0.5 & 76.37 & 46.96 \\
\hline
\end{tabular}

Similar to the plots made for the inertia analysis, Figure 5.18 shows pressure at different times during the SHPB test for a constant pressure coefficient of 0.1. Figure 5-18 (top) shows Point A in Figure 5-15, Figure 5-18 (middle) shows Point B, and Figure 5-18 (bottom) shows Point C. In contrast to Figure 5.16 (where friction is zero), Figure 5-18 shows a pressure gradient that increases as the SHPB test progresses.

Figure 5-18. Pressure in the sample during the SHPB with a constant friction coefficient of 0.1 .

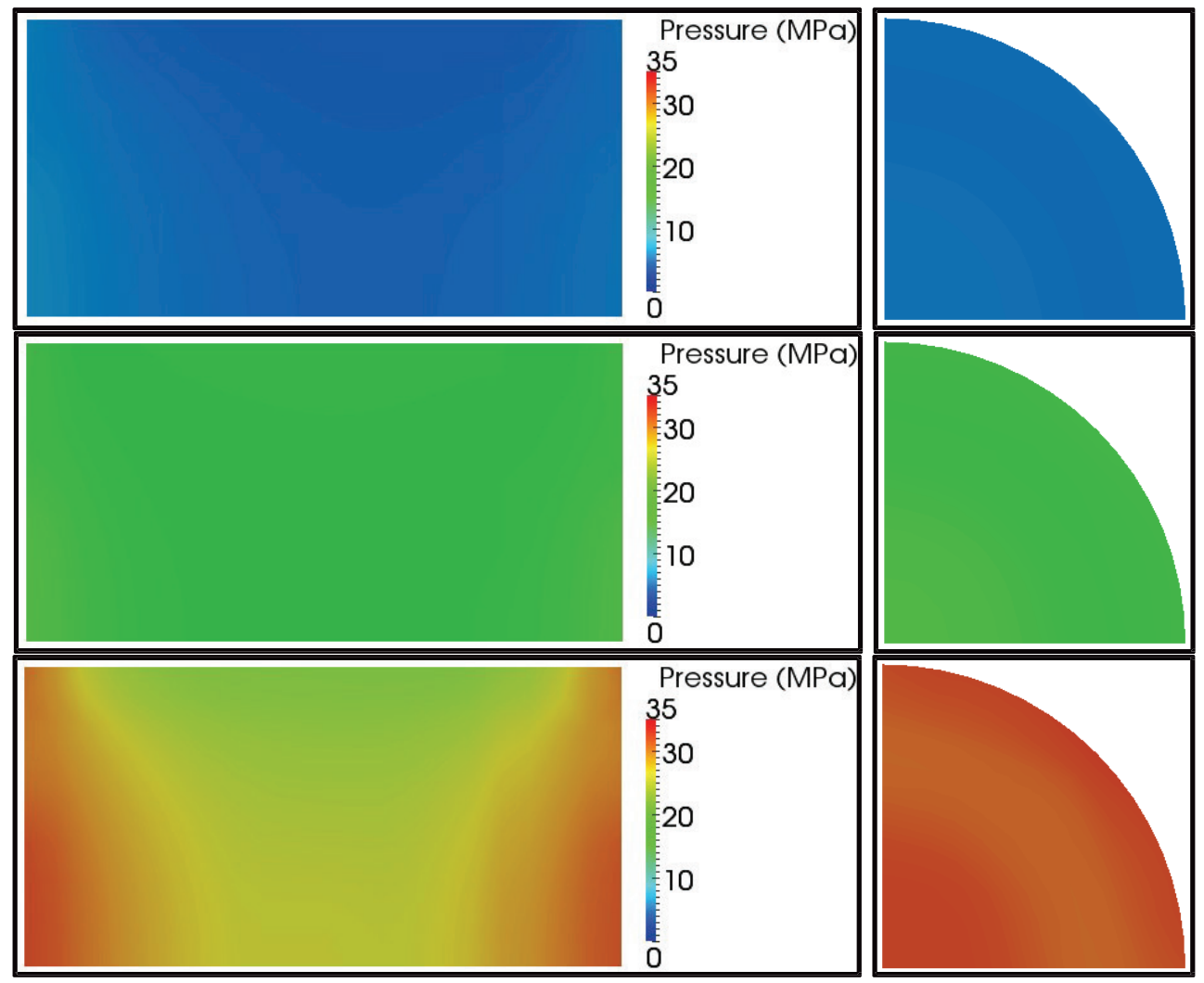


Figure 5 - 19 shows corresponding plots of pressure minus the pressure due to axial load to illustrate the effective confining pressures during the test. Figure 5-19 (bottom), taken at peak axial load, indicates that these confining pressures can reach approximately $10 \mathrm{MPa}$ towards the center of the sample and $5 \mathrm{MPa}$ along the outer radius. From the quasi-static TXC test with $10 \mathrm{MPa}$ confining pressure, an increase in strength of approximately $40 \mathrm{MPa}$ can be expected in the areas with $10 \mathrm{MPa}$ confinement. These confining pressures between 5 and $10 \mathrm{MPa}$ on the end of the samples resulted in the two percent increase in the sample strength.

Figure 5-19. Effective confining pressure during SHPB test with a constant friction coefficient of 0.1 showing the effects of friction.
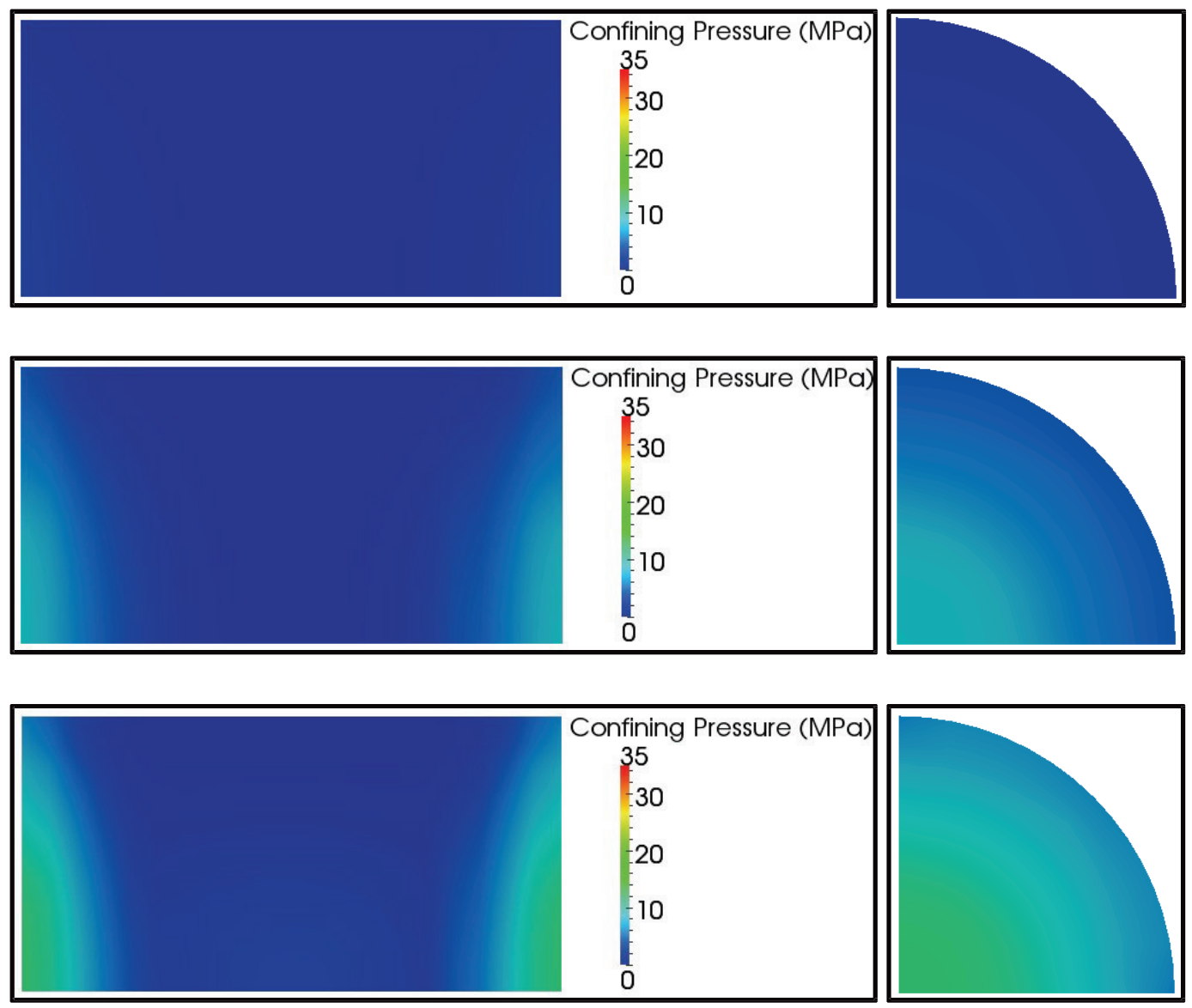

Though the confining pressures due to friction in these tests did not result in a significant increase in strength, it is an indication that care should be taken when using shorter specimens, which would place a larger percentage of the sample volume under the increased confining pressures. The presence of these pressures should also be taken intoconsideration when interpreting the results of the SHPB tests for samples with microcracks. The quasi-static mechanical tests indicated that confining pressures as low 
as $10 \mathrm{MPa}$ were enough to eliminate the effects of microcracking on the sample strength. Figure 5-19 shows that a friction coefficient as low as 0.1 is enough to induce pressures that would alter the effects of microcracks on a portion of the sample during SHPB tests. Thus, this provides further justification that friction should be eliminated during high rate testing. Friction and inertial confinement should be investigated further to determine its effects on microstructural mechanisms during high rate loading.

\subsection{Summary}

The HJC model has been examined and modified based on the damaged material response observed in the previous chapter. Modifications were made to account for shear modulus degradation and failure surface changes, which were the main effects of damage on the material behavior observed in the experimental data. The original and modified HJC models were used in a numerical analysis of the quasi-static and dynamic tests performed in this work. For the quasi-static and dynamic simulations, the modified HJC provided better results for damaged material when compared to the experimental tests.

An analysis of the effects of inertia and friction on the dynamic strength of the material during the SHPB test was also performed. The analysis indicated that inertia did not increase the dynamic strength of the material likely due to the relatively low strain rates used. Confinement due to friction between the bar-sample interfaces did not cause a significant increase in the sample strength. However, the analysis showed that effective confining pressures of $10 \mathrm{MPa}$ was possible during the SHPB tests for a constant friction coefficient of 0.1. Because 10 MPa confining pressures eliminated the effects of microcracking from the quasi-static strength of the material, the presence of pressures of this magnitude prompts further study of the effects of friction on microstructural mechanisms during high rate tests. 


\section{Conclusions}

This report investigated the effects of thermally induced microcracking on the mechanical properties of Salem limestone. The investigation included three parts: introduction of quantifiable levels of microcracks by means of thermal treating, mechanical testing of limestone samples with varying levels of microcracks, and modification of a commonly used numerical model to incorporate the measured effects. This work demonstrated that the three part approach is useful for examination of the mechanical effects of microcracking on quasi-brittle materials. It also demonstrates that the information can be used to improve the predictive capabilities of material models incorporating the effects of microcrack damage.

Salem limestone was chosen because of its homogeneity and its behavior is similar to that of other quasi-brittle materials such as concrete and concrete mortars. Its homogeneity simplified the microscale quantification by isolating microcracking as the only microscale mechanism involved in the material characterization. The limestone's homogeneous nature also enhanced the determination of microcrack effects by allowing for consistently reproducible results in the mechanical tests.

Thermal treating was found to induce quantifiable levels of microcracks in a consistent, reproducible way in Salem limestone. Sample preparation using thermal treating and non-destructive evaluation were economical and straightforward. Using this method, multiple test samples can be produced simultaneously in a period of about 1 day. Induced damage was controlled primarily by one experimental parameter, maximum temperature. The range of maximum temperatures required to induce various levels of damage was largely making correlation with specific damage levels straight forward, and reproducibility of specific damage levels consistent.

Non-destructive evaluation of treated samples using sonic wave velocities was a quick and effective means for assessing desired damage levels. The sonic wave testing takes only a few minutes for each sample before and after the heat treatments. The changes in sonic wave velocities, which decrease with increasing maximum heat treatment temperatures, indicated that the induced microstructural changes were a function of the maximum temperature. The wave velocities showed little variability for a particular choice of maximum heat treatment temperature that demonstrated the effectiveness of the approach for inducing consistent levels of microcracking. 
$\mathrm{XRD}$, DSC, and TGA confirmed that no composition changes occurred at $500^{\circ} \mathrm{C}$ or below; therefore, room temperature to $500^{\circ} \mathrm{C}$ became the temperature range of interest for the microcrack characterization and mechanical testing.

CT scanning, SEM, and OM were used to directly observe microstructural changes caused by the heat treatments. The OM analysis was found to be the most useful method for microcrack characterization yielding both qualitative and quantitative data.

OM images showed an increase in grain boundary and intragranular cracking with increasing maximum temperatures in the heat treatments. Stereological evaluation provided microcrack densities for the corresponding heat treatments and indicated that microcrack density increased as function of the maximum temperature in the heat treatments.

Quasi-static testing was performed to characterize the mechanical response of the intact and damaged limestone. The quasi-static tests included uniaxial compression, triaxial compression, hydrostatic compression, and uniaxial strain/constant volume tests. These tests demonstrated that microcracking lowers peak strengths (by 40 percent for the high damage level) at confining pressures lower than $10 \mathrm{MPa}$. Microcracking did not affect the limestone's strength at pressures greater than $10 \mathrm{MPa}$. The initial shear modulus was reduced from approximately 14,000 MPa to 4,000 MPa (for UC tests). This change was observed for all levels of confining pressure, but the effects decreased with increasing confining pressure.

Unconfined dynamic compression tests were also performed on undamaged and intact limestone using a modified SHPB. These tests showed that microcracks lower the stiffness of the material even at higher strain rates. In contrast to the quasi-static testing, initial microcrack density did not have an effect on the dynamic strength of the limestone. Peak strengths of the limestone in the quasi-static tests were approximately $72 \mathrm{MPa}$; peak strengths in the dynamic tests were approximately $90 \mathrm{MPa}$ regardless of the damage level. Though similar incident stress pulses were imparted to the samples, higher strain rates were observed for increasing levels of damage. This is most likely due to an initial lower stiffness in the samples (due to cracks closing), which offers little resistance initially that allows 
the strain rate to increase at a higher rate. This behavior may be responsible for undamaged and damage samples having the same dynamic strengths. A limited number of samples were available for SHPB tests, and more dynamic tests are needed to confirm if these trends remain for a larger sample size.

The mechanical responses of the intact and damaged limestone were used to modify the HJC model. Modifications were made to account for shear modulus degradation and failure surface changes, which were the main effects of damage on the material behavior observed in the experimental data. The original and modified HJC models were used in a numerical analysis of the quasi-static and dynamic experiments performed in this work. For the quasi-static and dynamic loading, the modified HJC provided better results for damaged material when compared with the experimental tests.

An analysis of the effects of inertia and friction on the dynamic strength of the material during the SHPB test was also performed. The analysis provided evidence that inertia and friction did not increase the dynamic strength of the material likely due to the relatively low strain rates used. However, the analysis showed that effective confining pressures of $10 \mathrm{MPa}$ was possible during the SHPB tests for a constant friction coefficient of o.1. Because $10 \mathrm{MPa}$ confining pressures eliminated the effects of microcracking from the quasi-static strength of the material, the presence of pressures of this magnitude prompts further study of the effects of friction on microstructural mechanisms during high rate tests especially if strain rates greater than $100 \mathrm{~s}^{-1}$ are used.

In summary, this report demonstrates a systematic approach, that is both simple and economical, to evaluate microcracking and its effects on the mechanical response of a homogeneous, quasi-brittle material. This approach provides a starting point for examining microcracking in other quasi-brittle materials (e.g., concrete mortars, simple concrete composites) in which microcracking is one of the fundamental components of the failure process. Microcracks are caused by many processes including mechanical loading, thermal loading, freezing/thawing, and chemical processes (especially alkali-silica reactions) and understanding its effects on these materials is vital because quasi-brittle materials are universally used in military structures and civil infrastructure. This work also provides the 
basis for more rapid testing of damaged materials, which is vital in evaluating the mechanical response of a structure subjected to microcracking.

The mechanical test data provided by the procedures developed in this work is also valuable in the development of predictive models. The experimental data obtained with these procedures was used to establish basic principles of damaged limestone behavior that were implemented in a simple material model to provide a more realistic response to damage. Applying this systematic approach to other quasi-brittle materials, such as concrete, would provide much needed experimental data that could be implemented into both simple and complex material models. Improved damage effects implementation is valuable in the design and analysis capabilities of structures composed of quasi-brittle materials. 


\section{References}

ACI 318. 2011. Building code requirements for reinforced concrete. Detroit, MI: American Concrete Institute.

ASTM. 2005b. Standard test method for obtaining and testing drilled cores and sawed beams of concrete. Standard C42-04. West Conshohocken, PA: ASTM International.

ASTM. 2005c. Standard test method for pulse velocity through concrete. Standard C59797. West Conshohocken, PA: ASTM International.

ASTM. 2005d. Standard test method for laboratory determination of water (moisture) content of soil and rock by mass. Standard D2216-05. West Conshohocken, PA: ASTM International.

ASTM. 2005e. Standard test method for preparing rock core specimens and determining dimensional and shape tolerances. Standard D4543-04. West Conshohocken, PA: ASTM International.

Bauer, S. J., and B. Johnson. 1979. Effects of slow uniform heating on the physical properties of the westerly and charcoal granites. In Proceedings of the 2oth U.S. Symposium on Rock Mechanics, 4-6 June, Austin, TX, 7-18.

Bazant, Z. P., and G. Zi. 2003. Microplane constitutive model for porous isotropic rocks. International Journal for Numerical and Analytical Methods in Geomechanics 27:25-47.

Bažant, Zdeněk P., and Pere C. Prat. 1988. Microplane model for brittle-plastic material: II. Verification. Journal of Engineering Mechanics 114:1689-702.

Bertholf, L. D., and C. H. Karnes. 1975. Two-dimensional analysis of the split-hopkinson pressure bar system. Journal of the Mechanics and Physics of Solids 23:1-19.

Brace, W. F., B. W. Paulding, Jr., and C. Scholz. 1966. Dilatancy in the fracture of crystalline rocks. Journal of Geophysical Research 71:3939-953.

Churcher, P. L., P. R. French, J. C. Shaw, and L. L. Schramm. 1991. Rock properties of Berea sandstone, Baker dolomite, and Indiana limestone. In Proceedings of SPE International Symposium on Oilfield Chemistry, 20-22 February, Anaheim, CA, $431-46$.

Cummins, Toney K. 1991. Effective stress behavior of intact Salem limestone. SL-91-22. Vicksburg, MS: U.S. Army Engineer Waterways Experiment Station.

David, C., B. Menendez, and M. Darot. 1999. Influence of stress-induced and thermal cracking on physical properties and microstructure of La Peyratte granite. International Journal of Rock Mechanics and Mining Sciences 36:433-448.

Ferrero, A. M., and P. Marini. 2001. Experimental studies on the mechanical behaviour of two thermal cracked marbles. Rock Mechanics and Rock Engineering 34.1:57-66. 
Fossum, A. F., P. E. Senseny, T. W. Pfeifle, and K. D. Mellegard. 1995. Experimental determination of probability distributions for parameters of a Salem limestone cap plasticity model. Mechanics of Materials 21:119-37.

Fredrich, Joanne T., and Teng-fong Wong. 1986. Micromechanics of thermally induced cracking in three crustal rocks. Journal of Geophysical Research 91.B12:1274312764 .

Fredrich, Joanne T., Brian Evans, and Teng-Fong Wong. 1989. Micromechanics of the brittle to plastic transition in carrara marble. Journal of Geophysical Research 94:4129-145.

Frew, D. J., M. J. Forrestal, and W. Chen. 2001. A split Hopkinson pressure bar technique to determine compressive stress-strain data for rock materials. Experimental Mechanics 41:40-46.

Frew, D. J., S. A. Akers, W. Chen, and M. L. Green. 2010. Development of a dynamic triaxial kolsky bar. Measurement Science and Technology 21:1-10.

Frew, Danny J. 2001. Dynamic response of brittle materials from penetration and split Hopkinson pressure bar experiments. ERDC/GSL TR-01-6. Vicksburg, MS: U.S. Army Engineer Research and Development Center.

Friedman, M., and B. Johnson. 1978. Thermal cracks in unconfined sioux quartzite. In Proceedings of the 19th U.S. Symposium on Rock Mechanics, 1-3 May, Reno, NV, 757-766.

Gebbeken, N., and M. Ruppert. 2000. A new material model for concrete in high-dynamic hydrocode simulations. Archive of Applied Mechanics 70:463-78.

Golshani, A., Y. Okui, M. Oda, and T. Takemura. 2006. A micromechanical model for brittle failure of rock and its relation to crack growth observed in triaxial compression tests of granite. Mechanics of Materials 38:287-303.

Hadley, Kate. 1976. Comparison of calculated and observed crack densities and seismic velocities in westerly granite. Journal of Geophysical Research 81:3484-494.

Holmquist, T. J., G. R. Johnson, and W. H. Cook. 1993. A computational constitutive model for concrete subjected to large strains, high strain rates and high pressures. In Proceedings of 14th International Symposium on Ballistics, 26-29 September, Quebec, Canada, 591-600.

Homand, Francoise, Dashnor Hoxha, Tikou Belem, Marie-Noelle Pons, and Nasser Hoteit. 2000. Geometric analysis of damaged microcracking in granites. Mechanics of Materials 32:361-76.

Homand-Etienne, F., and R. Houpert. 1989. Thermally induced microcracking in granites: characterization and analysis. International Journal of Rock Mechanics and Mining Sciences \& Geomechanics Abstracts 26.2:125-134.

Homand-Etienne, Francoise, and Jean-Pierre Troalen. 1984. Behavior of granites and limestones subjected to slow and homogeneous temperature changes.

Engineering Geology 20:219-233. 
Hoxha, D., and F. Homand. 2000. Microstructural approach in damage modeling. Mechanics of Materials 32:377-87.

Indiana Limestone Handbook. 2007. 22nd edition. Bedford, IN: Indiana Limestone Institute of America.

Johnson, Brann, A. F. Gangi, and J. Handin. 1978. Thermal cracking of rock subjected to slow, uniform temperature changes. In Proceedings of the 19th U.S. Symposium on Rock Mechanics, 1-3 May, Reno, NV: 259-267.

Johnson, Brann, and Anthony F. Gangi. 1980. Thermal cracking of nonuniformly heated, thick-walled hollow cylinders of westerly granite. 21st U.S. Symposium on Rock Mechanics. Rolla, MO: 197-226.

Karihaloo, B. L. 1995. Fracture mechanics and structural concrete. Harlow, Essex, England: Longman Scientific \& Technical.

Keshavarz, M., F. L. Pellet, and B. Loret. 2010. Damage and changes in mechanical properties of a gabbro thermally loaded up to $1000^{\circ} \mathrm{C}$. Pure and Applied Geophysics 167:1511-1523.

Kranz, Robert L. 1983. Microcracks in rocks: a review. Tectonophysics 100:449-80.

Lewis, C. F. 1979 . Properties and selection: nonferrous alloys and pure metals. In Metals handbook. 9th ed. Metals Park, OH: American Society for Metals.

Li, Q. M., and H. Meng. 2003. About the dynamic strength enhancement of concrete-like materials in a split Hopkinson pressure bar test. International Journal of Solids and Structures 40:343-60.

Li, Q. M., Y. B. Lu, and H. Meng. 2009. Further investigation on the dynamic compressive strength enhancement of concrete-like materials based on split Hopkinson pressure bar tests part II: numerical simulations. International Journal of Impact Engineering 36:1335-345.

Lin, Weiren. 2002. Permanent strain of thermal expansion and thermally induced microcracking in Inada granite. Journal of Geophysical Research 107.B10:ECV31-ECV3-16.

Malvern, L. E., D. A. Jenkins, T. Tianxi, and C. A. Ross. 1985. Dynamic compressive testing of concrete. In Proceedings of Second Symposium on the Interaction of Nonnuclear Munitions with Structures, 15-18 April, Panama City Beach, FL, 397-402.

Meng, H., and Q. M. Li. 2003. Correlation between the accuracy of a SHPB test and the stress uniformity based on numerical experiments. International Journal of Impact Engineering 28:537-55.

Mertens, Stijn. 2009. Hysteresis, damage and moisture effects in quasi-brittle porous materials. Diss., University of Leuven.

Nolen-Hoeksema, R. C., and R. B. Gordon. 1987. Optical detection of crack patterns in the opening-mode fracture of marble. International Journal of Rock Mechanics and Mining Sciences \& Geomechanics Abstracts 24:135-44. 
Ockert, J. 1997. Ein stoffgesetz fur die schockwellenausbreitung in beton. Diss., Karlsruhe Institute of Technology.

Polanco-Loria, M., O. S. Hopperstad, T. Borvik, and T. Berstad. 2008. Numerical predictions of ballistic limits for concrete slabs using a modified version of the HJC concrete model. International Journal of Impact Engineering 35:290-303.

Riedel, W., K. Thoma, S. Hiermaier, and E. Schmolinske. 1999. Penetration of reinforced concrete by BETA-B-500 numerical analysis using a new macroscopic concrete model for hydrocodes." In Proceedings of 9th International Symposium on the Interaction of the Effects Munitions with Structures, Berlin, 315-22.

Shao, J. F., and J. W. Rudnicki. 2000. A microcrack-based continuous damage model for brittle geomaterials. Mechanics of Materials 32:607-19.

Shao, J. F., D. Hoxha, M. Bart, F. Homand, G. Duveau, M. Souley, and N. Hoteit. 1999. Modelling of induced anisotropic damage in granites. International Journal of Rock Mechanics and Mining Sciences 36:1001-012.

Sierra/SolidMechanics 4.22 User's Guide. 2011. Rep. no. SAND2011-7597. Albuquerque, NM: Sandia National Laboratories.

Simmons, G., and D. Richter. 1976. Microcracks in rock. In The physics and chemistry of minerals and rocks, ed. R. G. J. Strens, 105-37. London: Wiley.

Sprunt, E., and W. F. Brace. 1974. Some permanent structural changes in rock due to pressure and temperature. In Proceedings of Third Congress of the International Society for Rock Mechanics, 1-7 September, Denver, CO. 524-29.

Tang, T., L. E. Malvern, and D. A. Jenkins. 1992. Rate effects in uni-axial dynamic compression of concrete. ASCE Journal of Engineering Mechanics 118:108-24.

Tapponnier, Paul, and W. F. Brace. 1976. Development of stress-induced microcracks in Westerly granite. International Journal of Rock Mechanics and Mining Sciences \& Geomechanics Abstracts 13:103-112.

Wawersik, W. R., and W. F. Brace. 1971. Post-failure behavior of a granite and diabase. Rock Mechanics 3:61-85.

Wong, Teng-fong. 1985. Geometric probability approach to the characterization and analysis of microcracking in rocks. Mechanics of Materials 4:261-76.

Yavuz, H., S. Demirdag, and S. Caran. 2010. Thermal effect on the physical properties of carbonate rocks. International Journal of Rock Mechanics and Mining Sciences 47:94-103.

Yong, C., and C. Y. Wang. 1980. Thermally induced acoustic emission in westerly granite. Geophysical Research Letters 7:1089-092.

Zhao, Yonghong. 1998. Crack pattern evolution and a fractal damage constitutive model for rock. International Journal of Rock Mechanics and Mining Sciences 35:349-66.

Zhou, J. W., W. Y. Xu, and X. G. Yang. 2010. A microcrack damage model for brittle rocks under uniaxial compression. Mechanics Research Communications 37:399-405. 


\section{Appendix A: Quasi-Static Testing Results}

Figure A.1. Principal stress difference vs. axial strain for all unconfined compression tests.

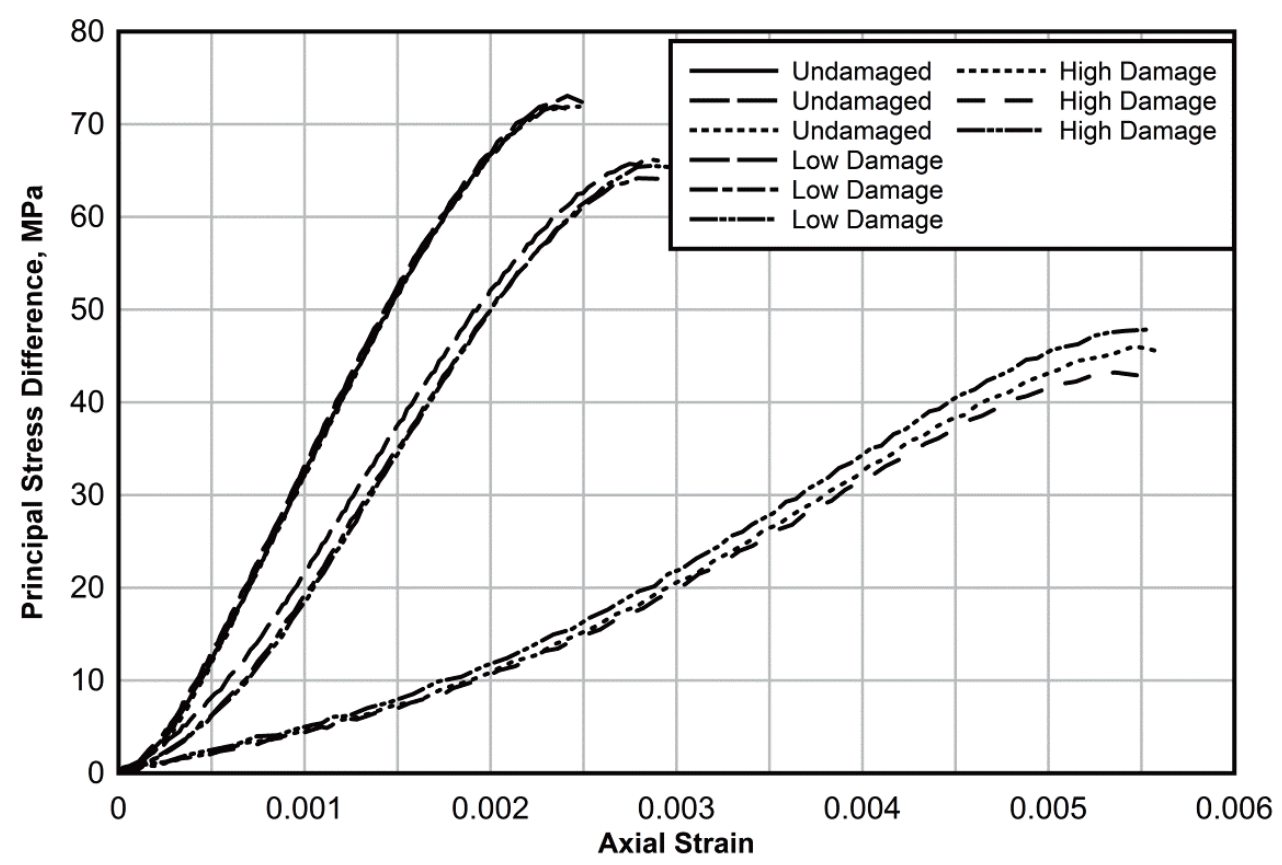

Figure A.2. Principal stress difference vs. volumetric strain for all unconfined compression tests.

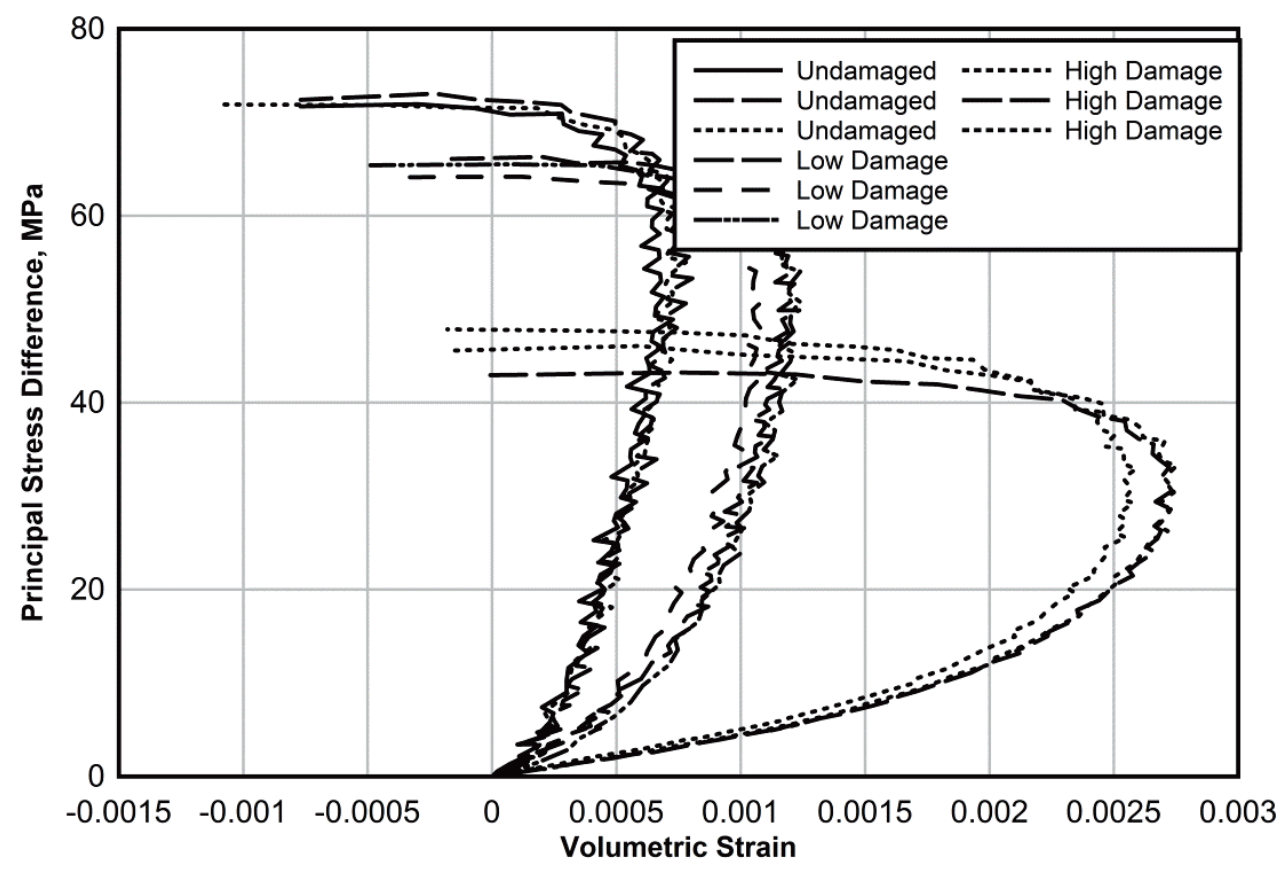


Figure A.3. Principal stress difference vs. axial strain for all triaxial compression tests with $10 \mathrm{MPa}$ confining pressure.

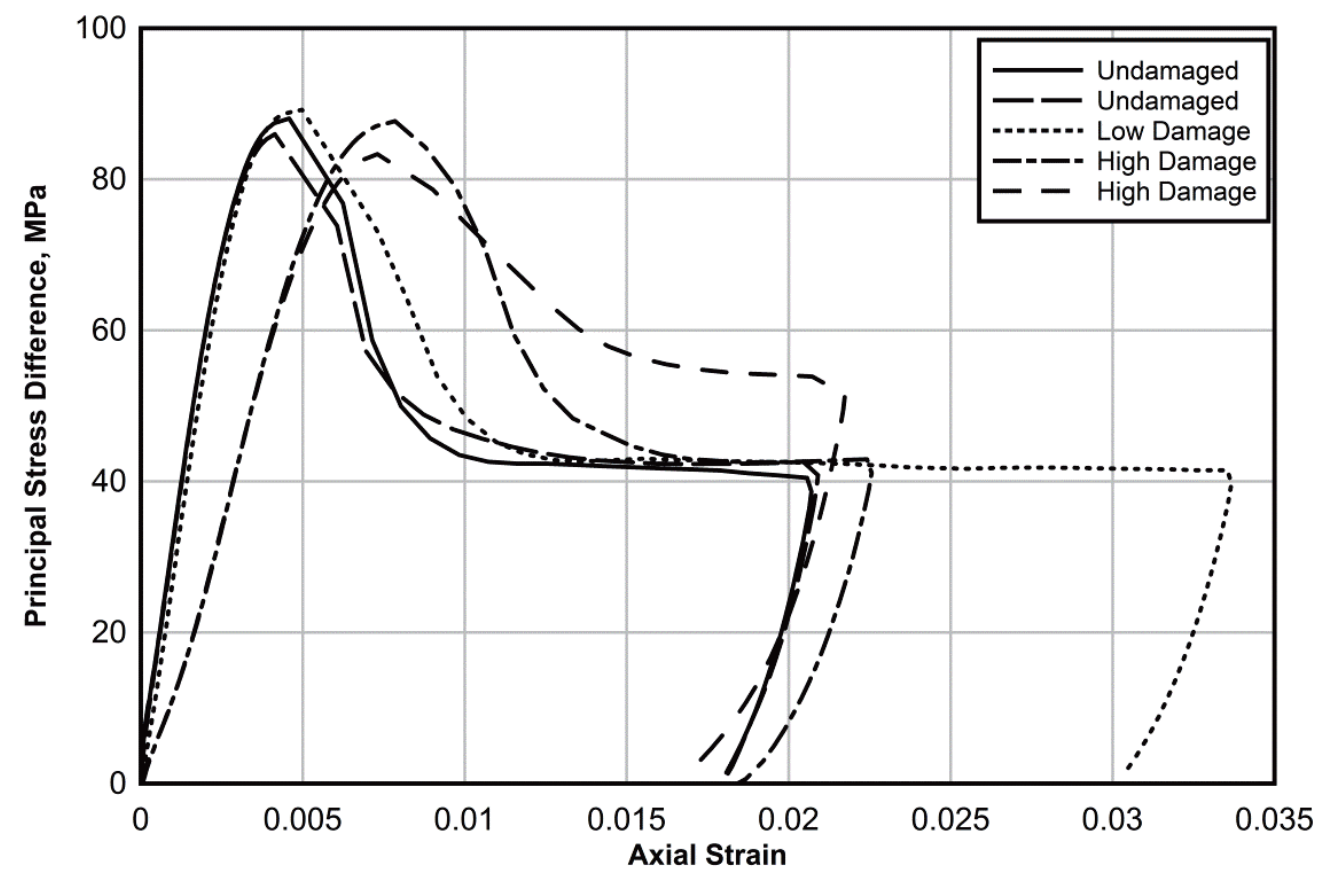

Figure A.4. Principal stress difference vs. volumetric strain for all triaxial compression tests with $10 \mathrm{MPa}$ confining pressure.

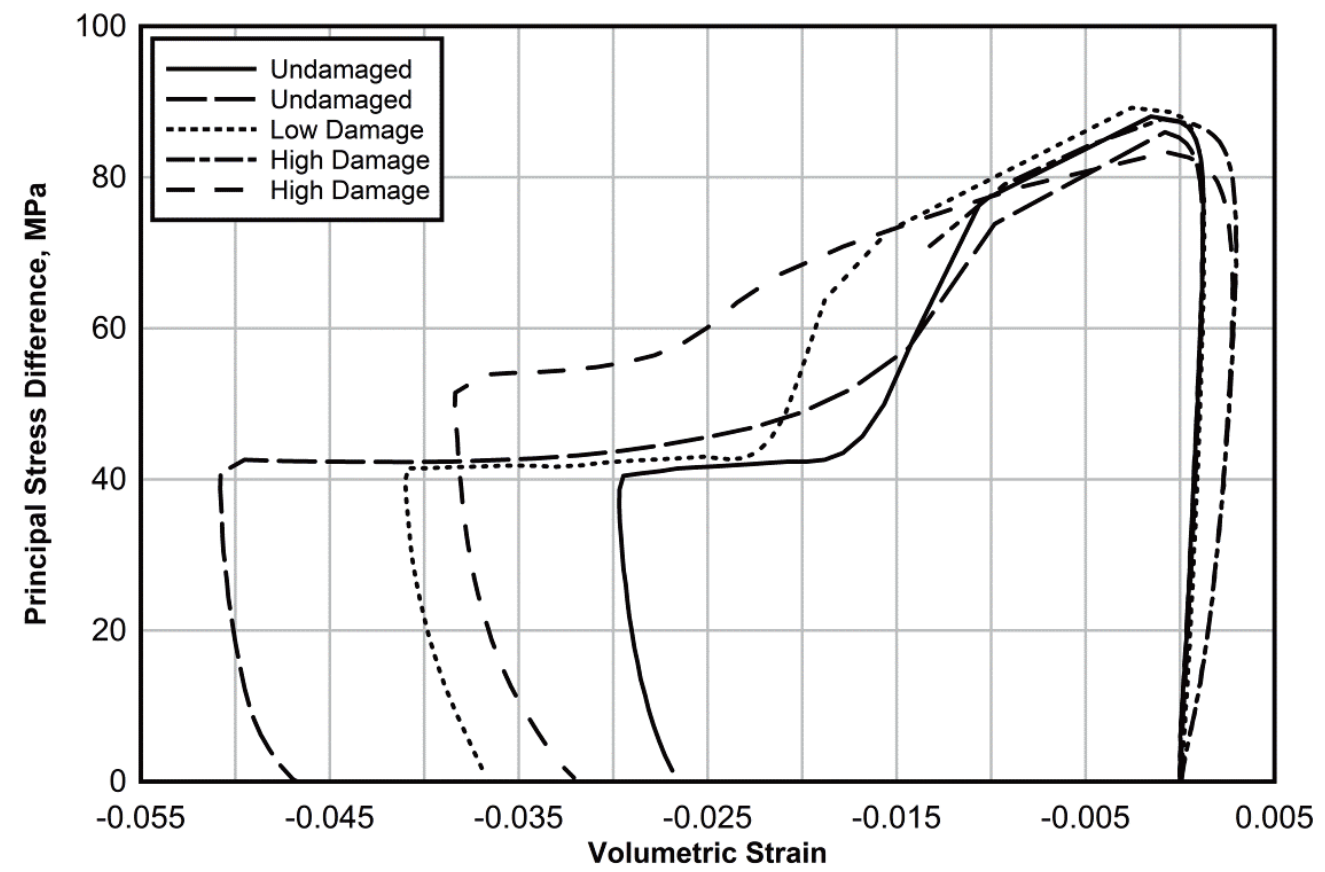


Figure A.5. Principal stress difference vs. axial strain for all triaxial compression tests with $20 \mathrm{MPa}$ confining pressure.

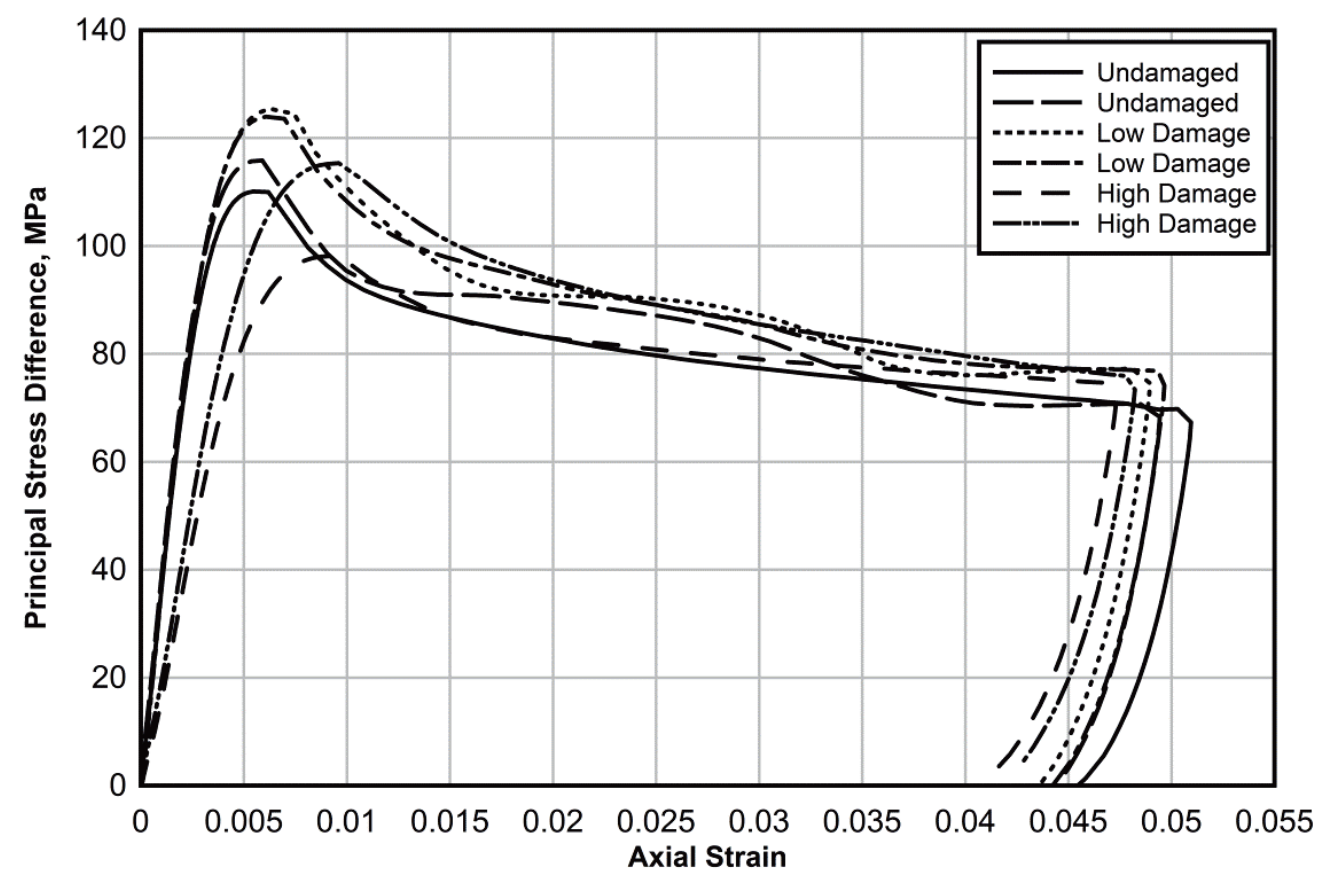

Figure A.6. Principal stress difference vs. volumetric strain for all triaxial compression tests with $20 \mathrm{MPa}$ confining pressure.

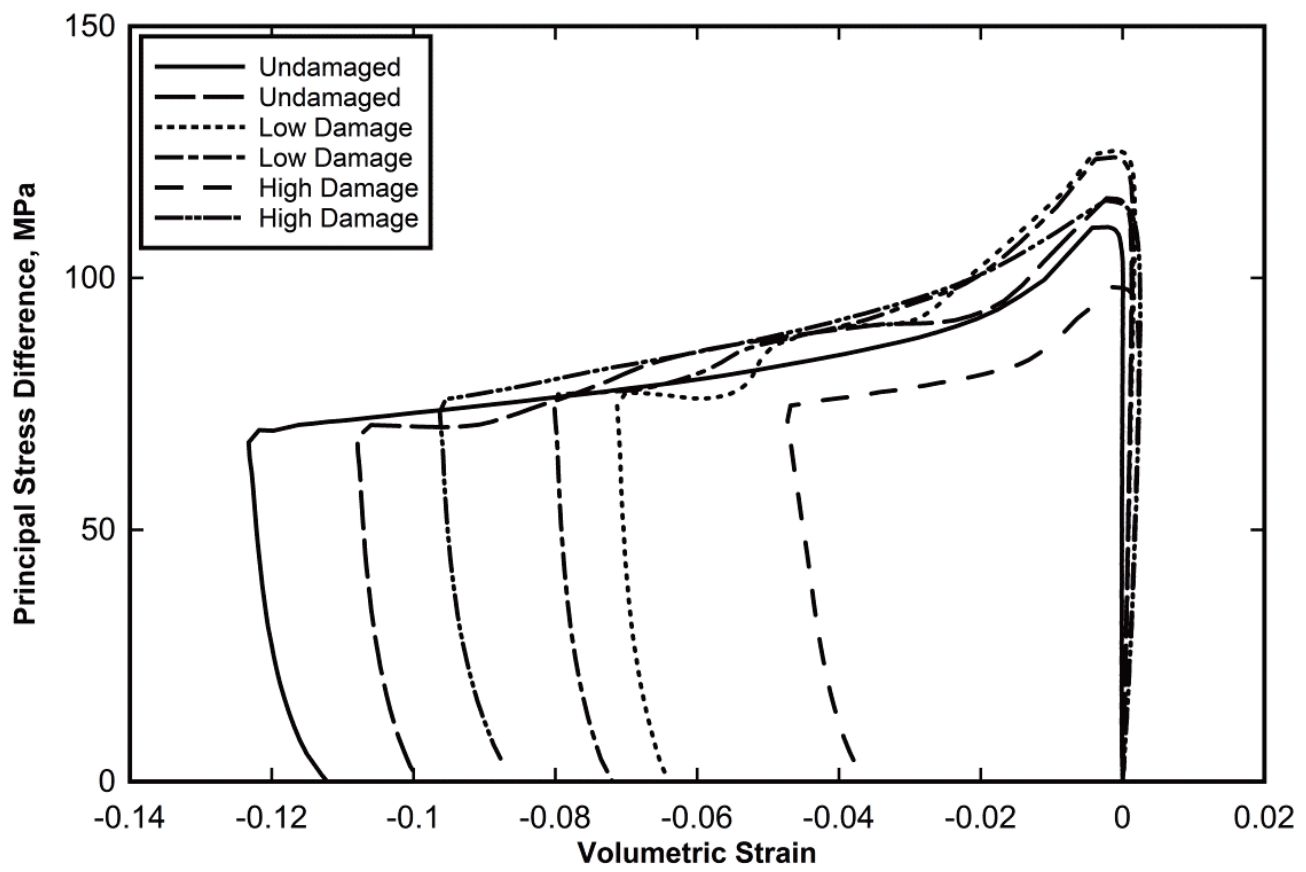


Figure A.7. Principal stress difference vs. axial strain for all triaxial compression tests with $100 \mathrm{MPa}$ confining pressure.

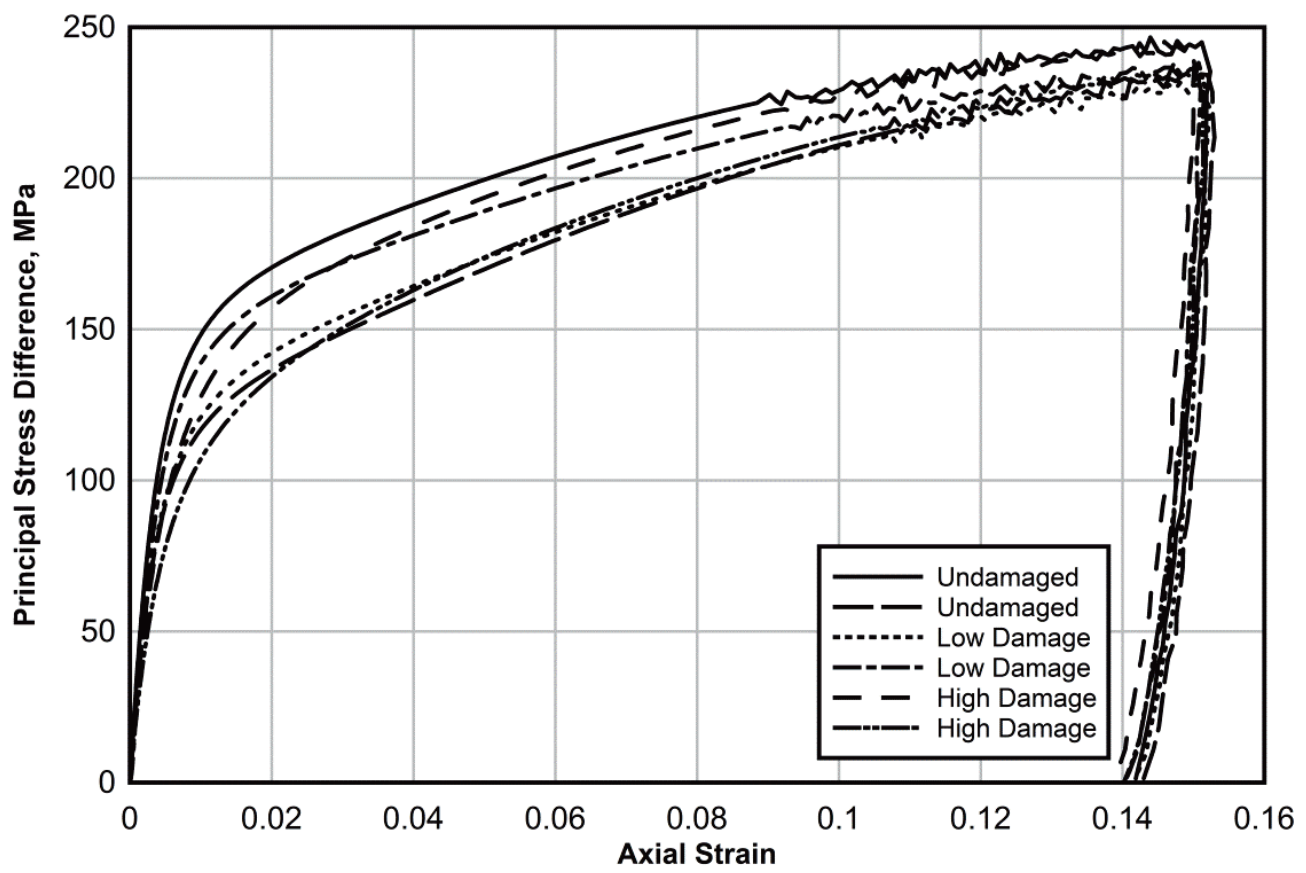

Figure A.8. Principal stress difference vs. volumetric strain for all triaxial compression tests with $100 \mathrm{MPa}$ confining pressure.

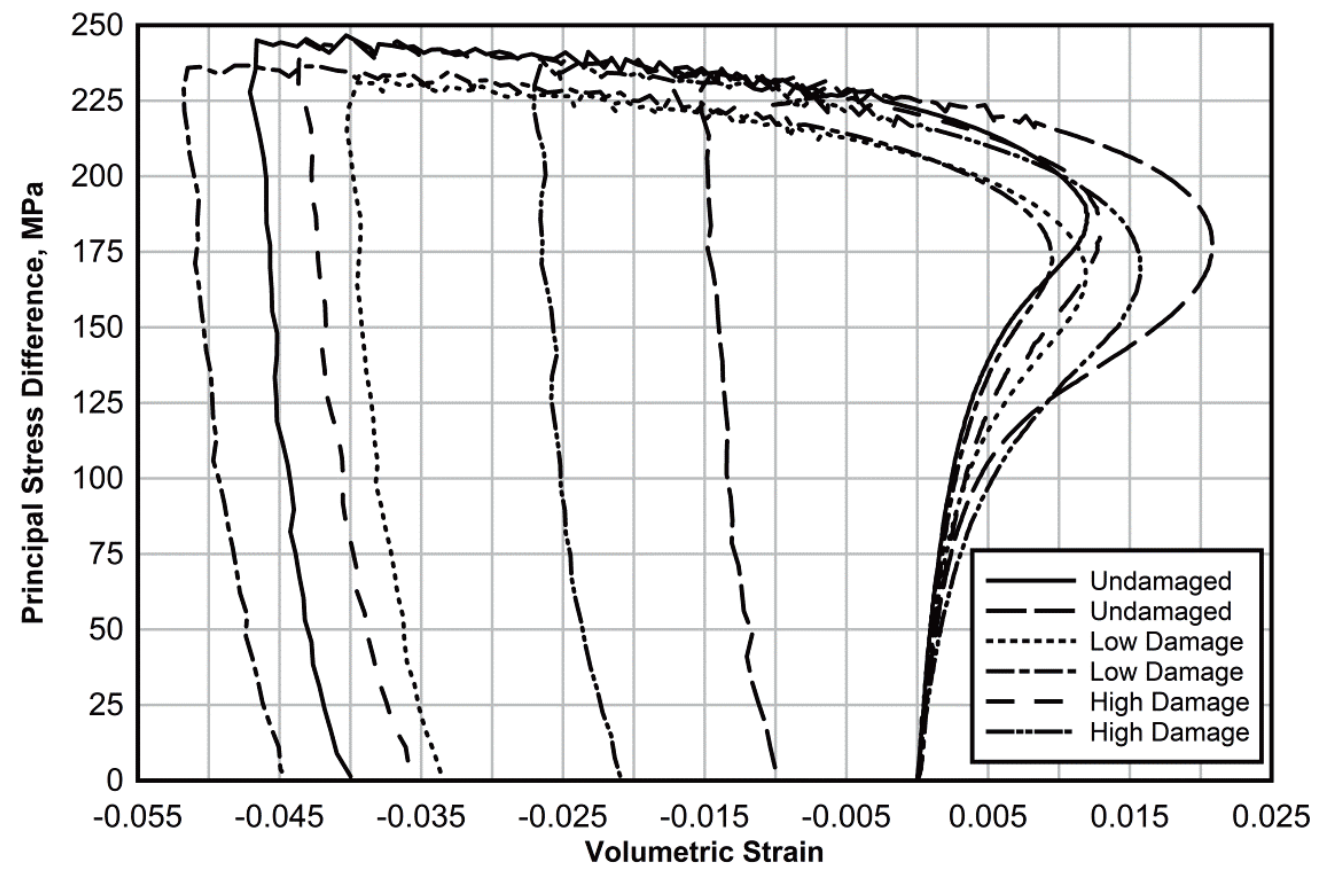


Figure A.9. Principal stress difference vs. axial strain for all triaxial compression tests with $400 \mathrm{MPa}$ confining pressure.

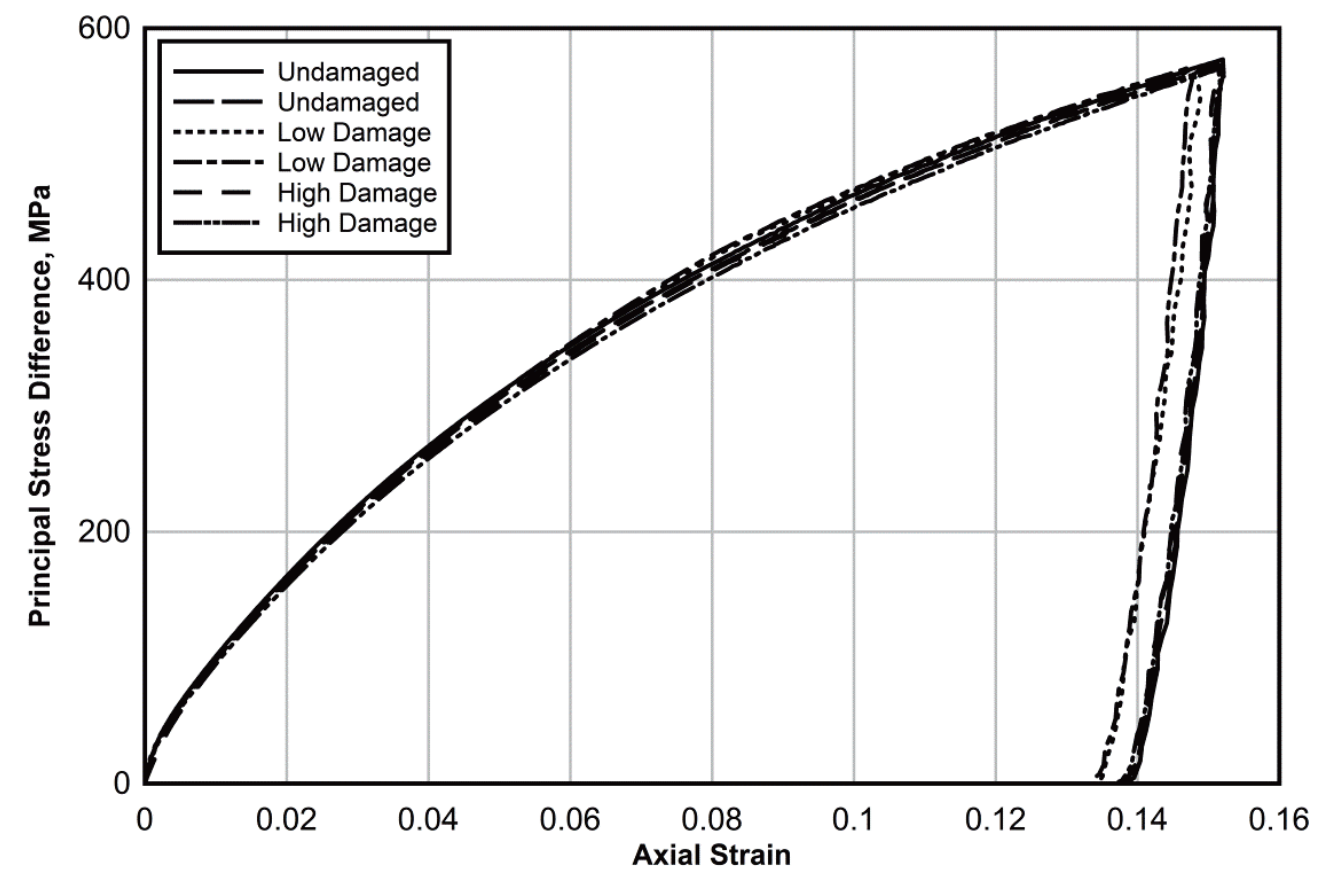

Figure A.10. Principal stress difference vs. volumetric strain for all triaxial compression tests with $400 \mathrm{MPa}$ confining pressure.

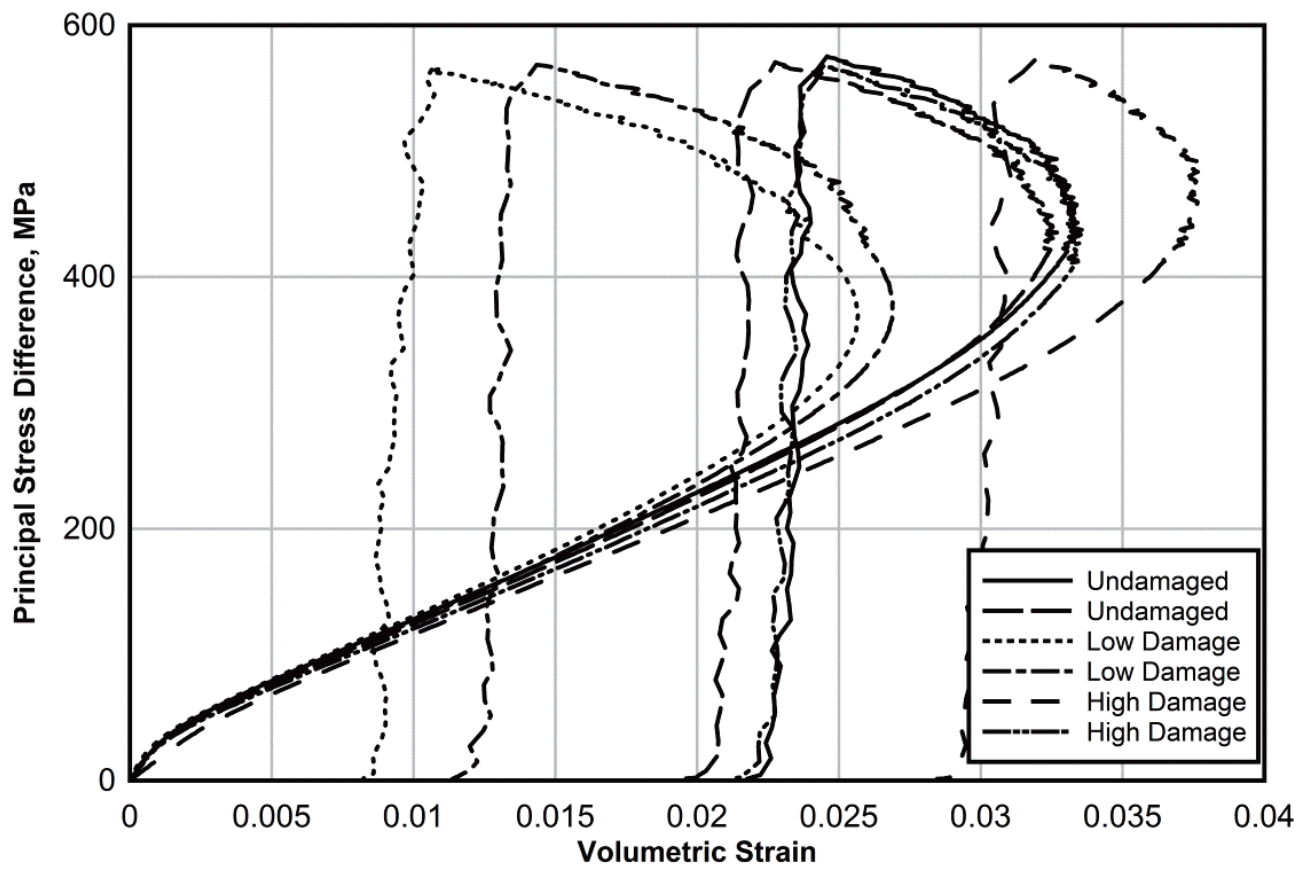


Figure A.11. Axial stress vs. axial strain for UX/CV tests with UX phase up to $100 \mathrm{MPa}$ pressure.

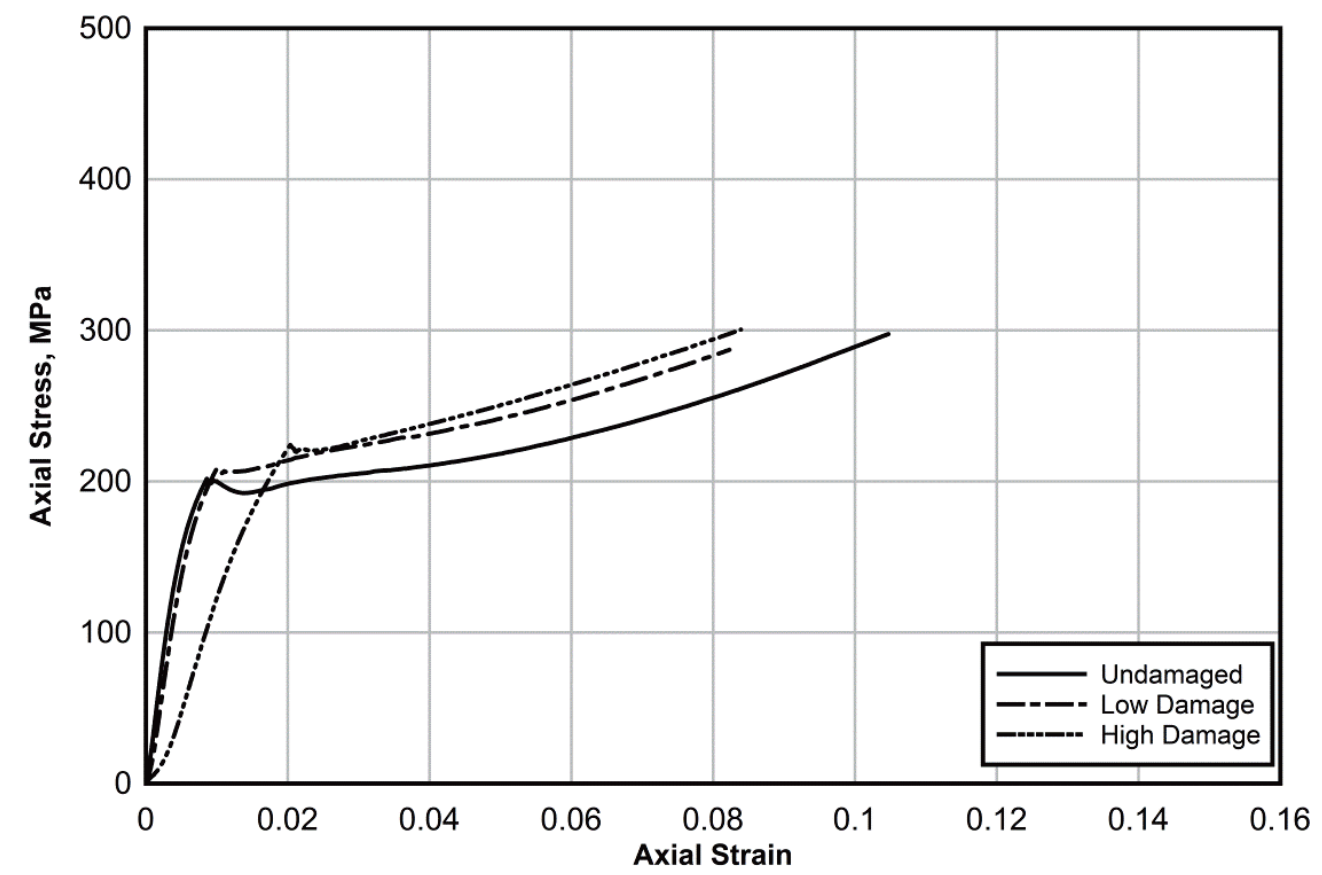

Figure A.12. Mean normal stress vs. volumetric strain for UX/CV tests with UX phase up to $100 \mathrm{MPa}$ pressure.

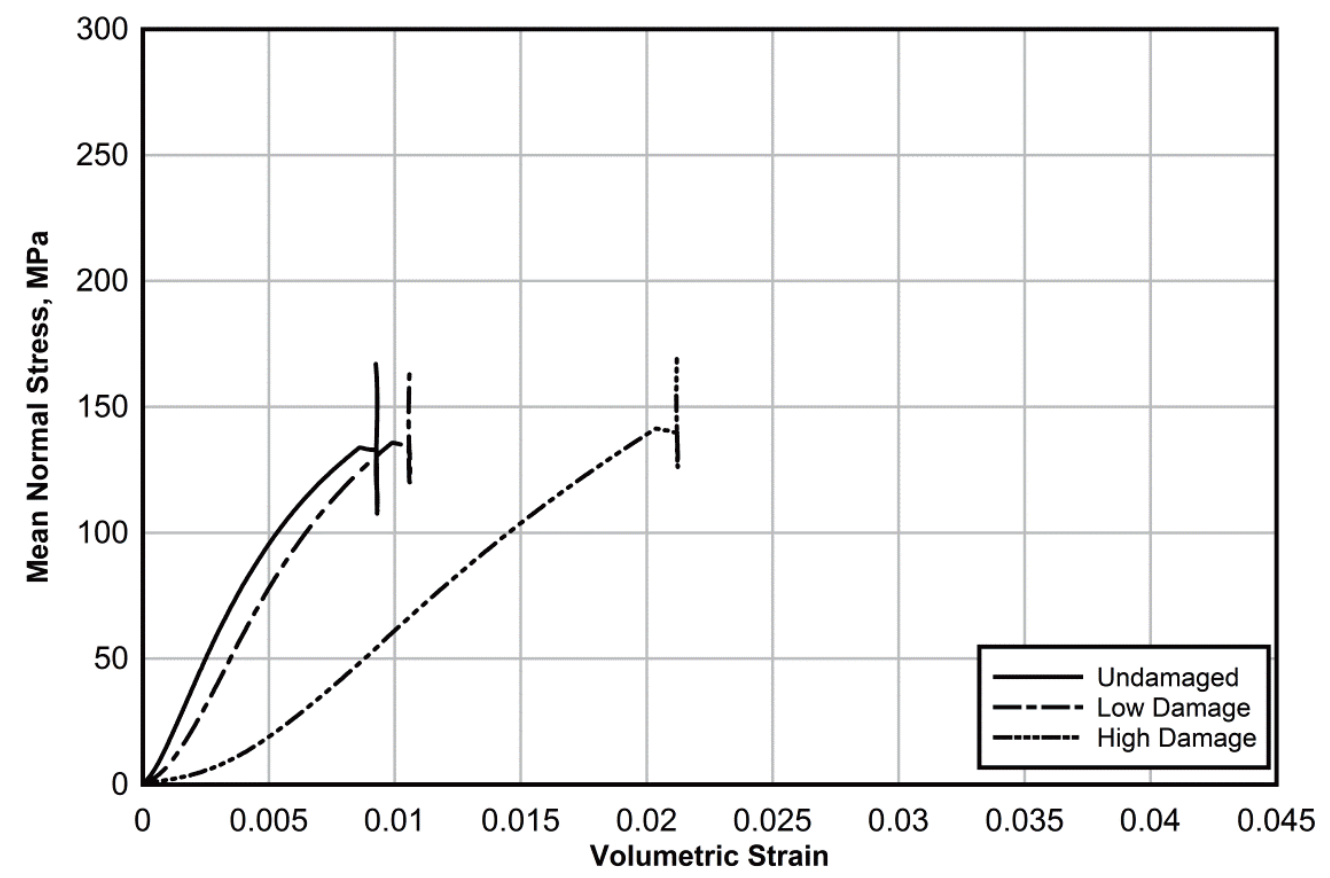


Figure A.13. Principal stress difference vs. mean normal stress for UX/CV tests with UX phase up to $100 \mathrm{MPa}$ pressure.

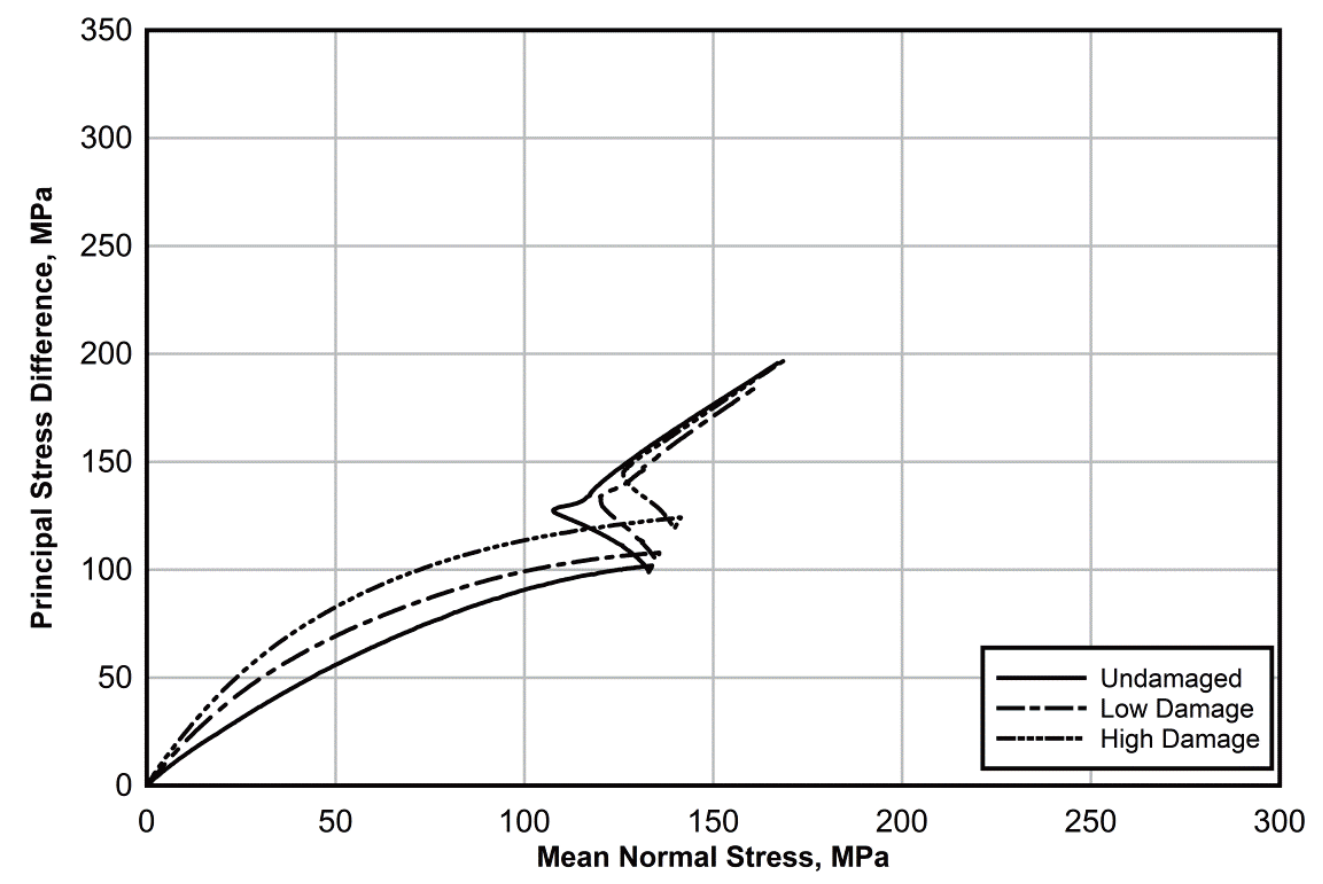

Figure A.14. Principal stress difference vs. axial strain for UX/CV tests with UX phase up to $100 \mathrm{MPa}$ pressure.

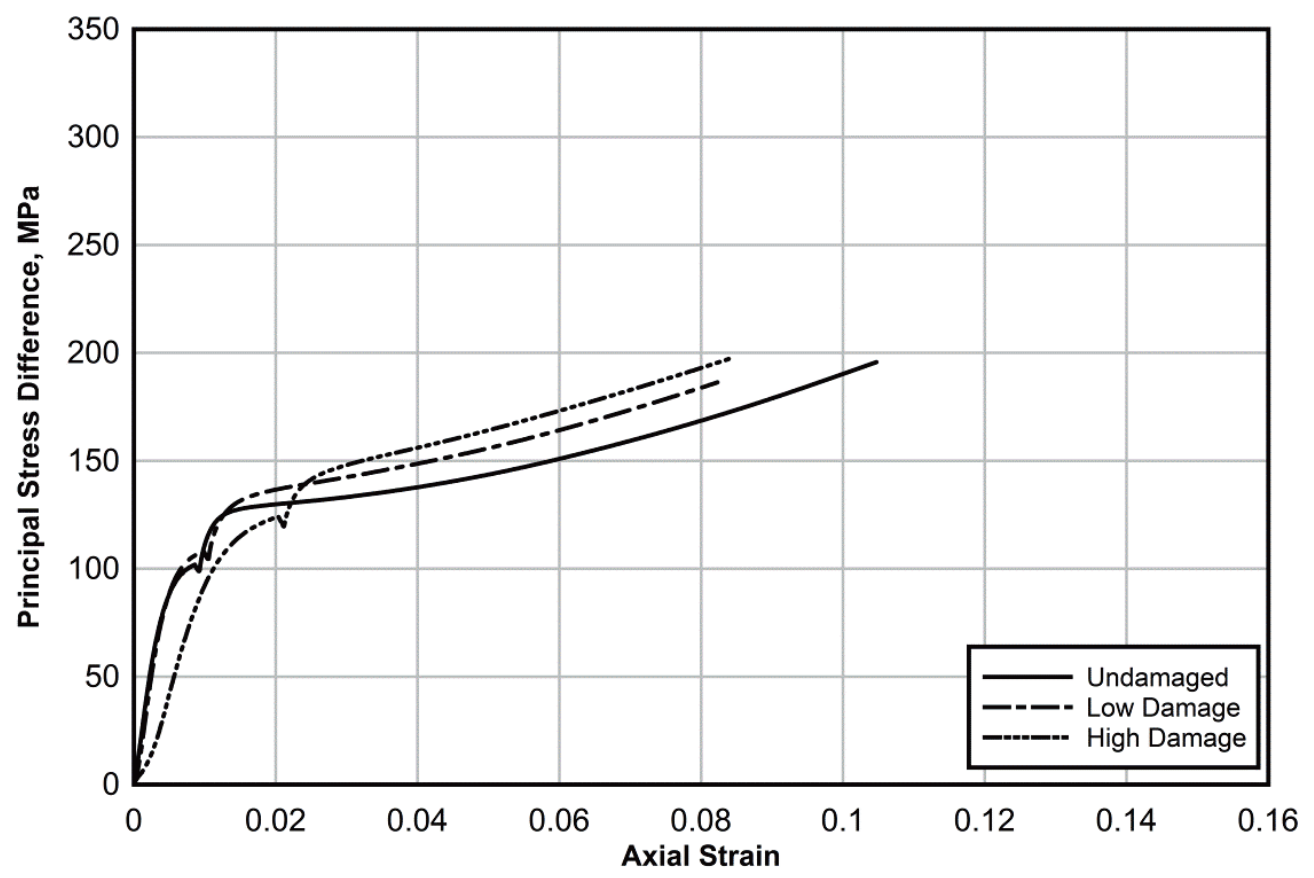


Figure A.15. Axial stress vs. axial strain for UX/CV tests with UX phase up to $150 \mathrm{MPa}$ pressure.

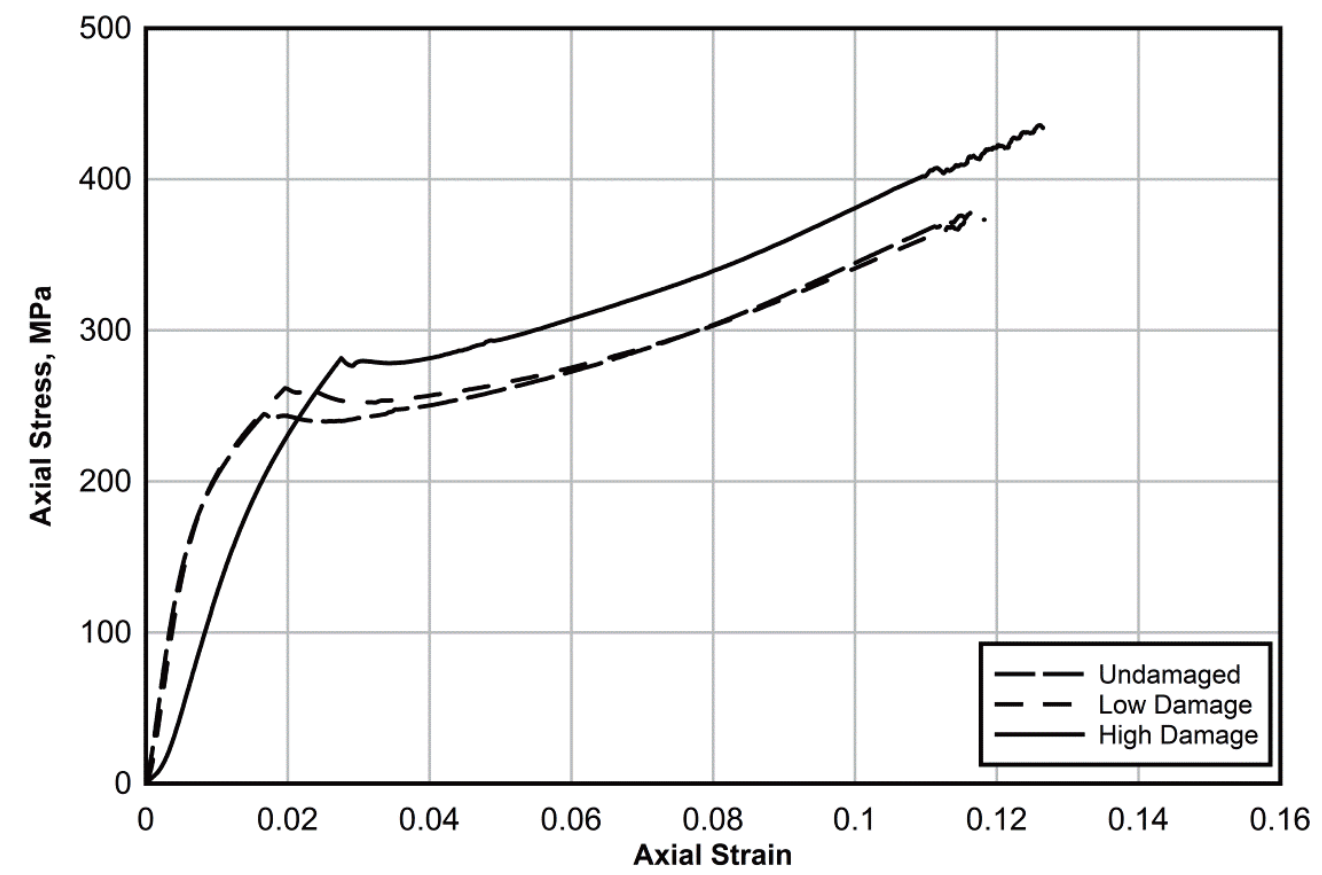

Figure A.16. Mean normal stress vs. volumetric strain for UX/CV tests with UX phase up to $150 \mathrm{MPa}$ pressure.

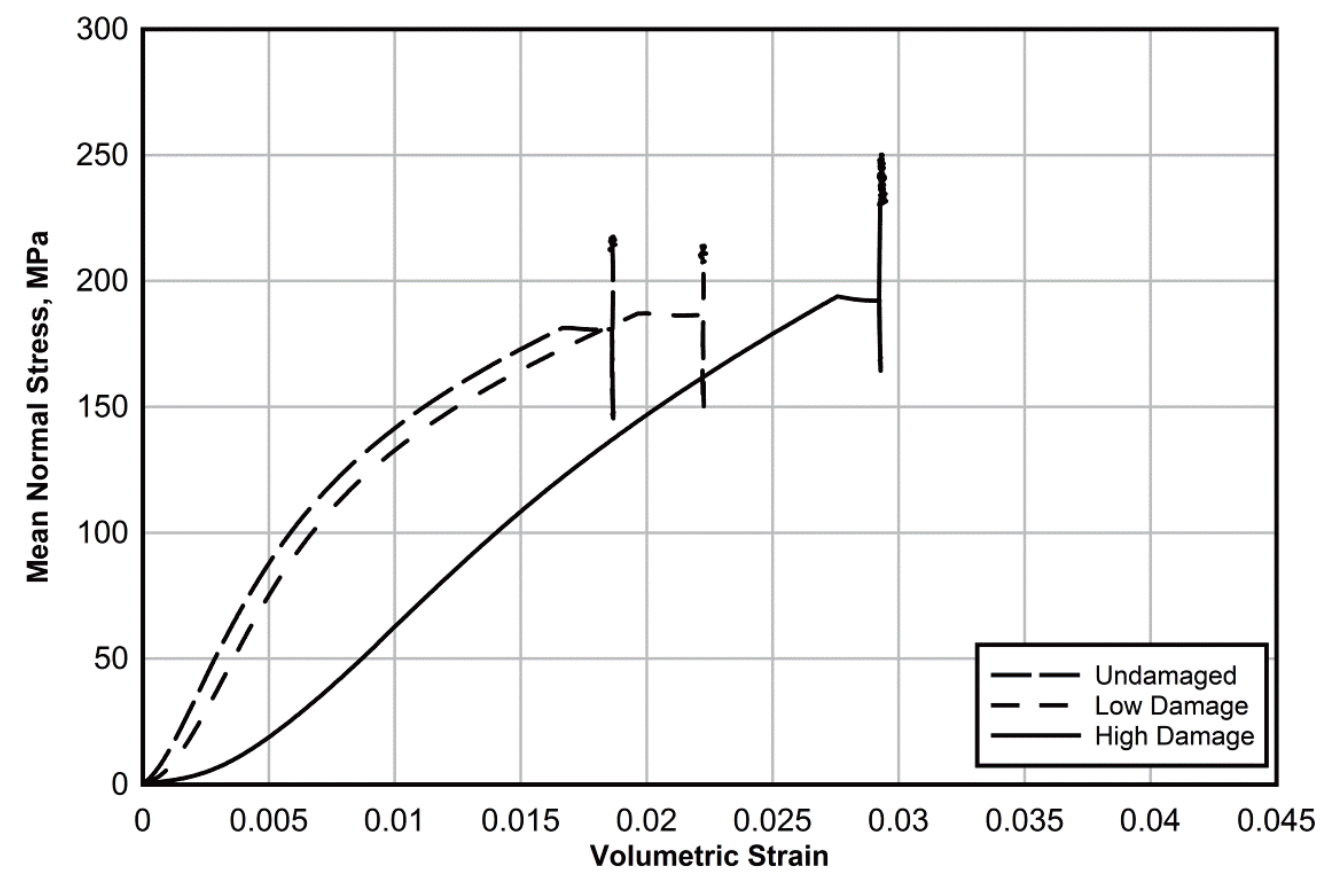


Figure A.17. Principal stress difference vs. mean normal stress for UX/CV tests with UX phase up to $150 \mathrm{MPa}$ pressure.

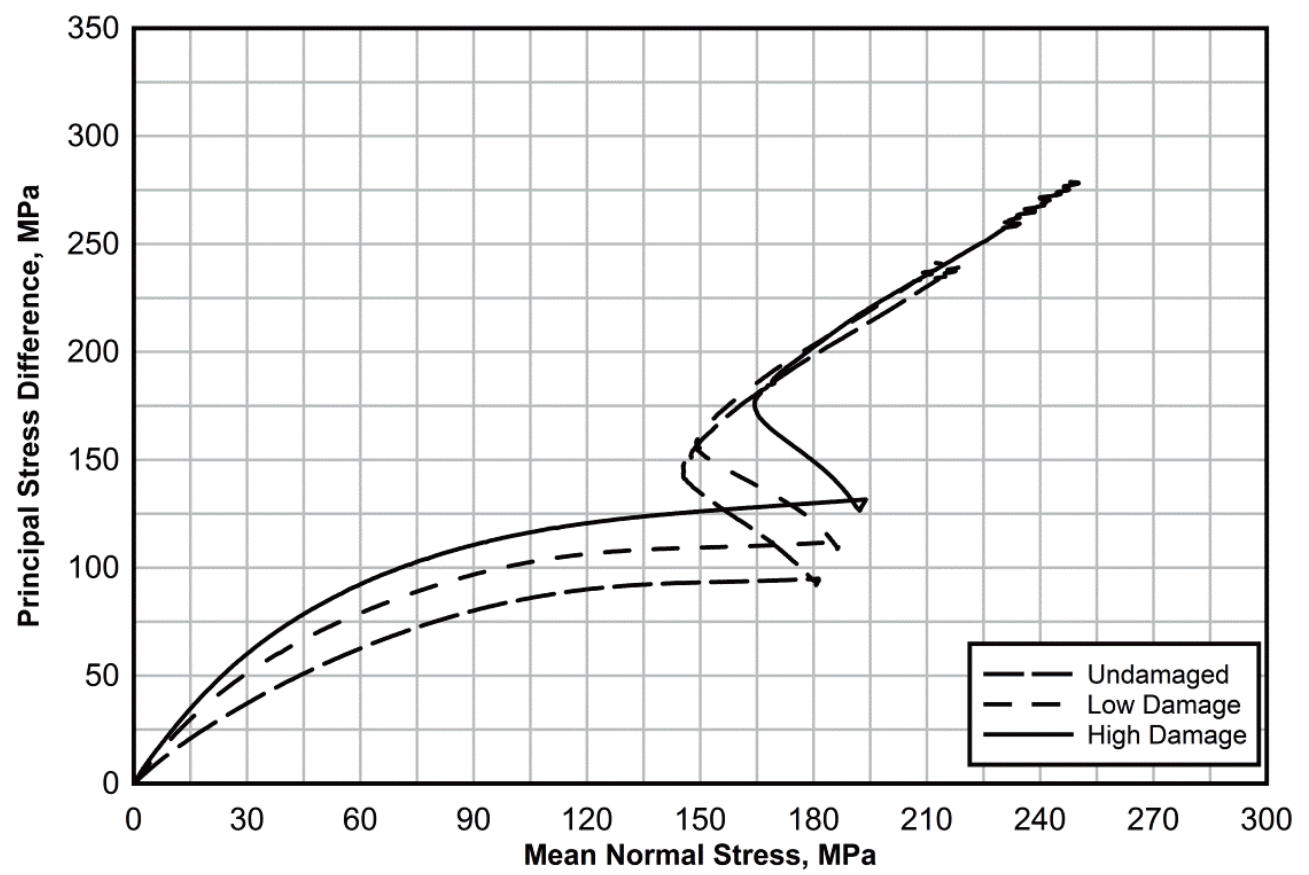

Figure A.18. Principal stress difference vs. axial strain for UX/CV tests with UX phase up to $150 \mathrm{MPa}$ pressure.

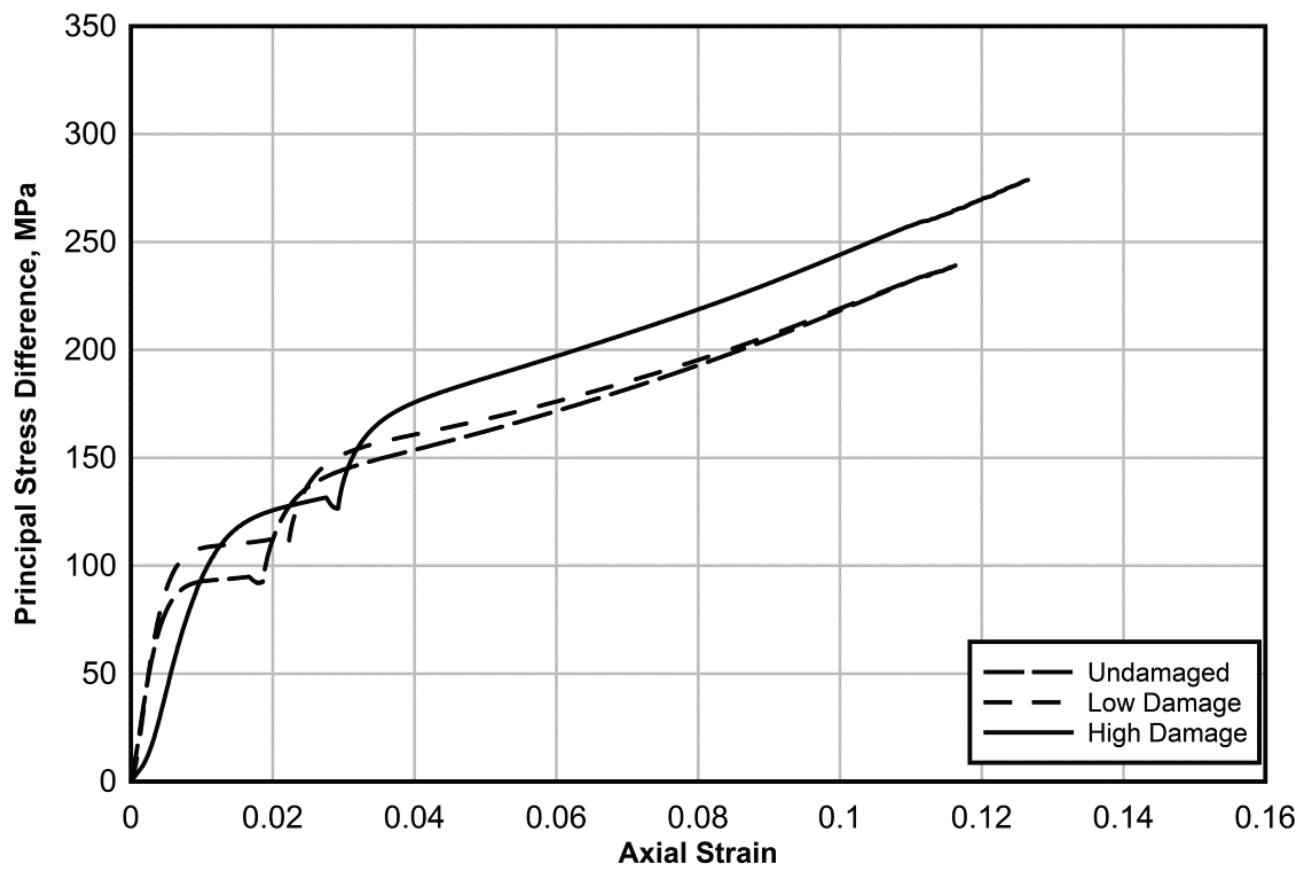


Figure A.19. Axial stress vs. axial strain for UX/CV tests with UX phase up to $200 \mathrm{MPa}$ pressure.

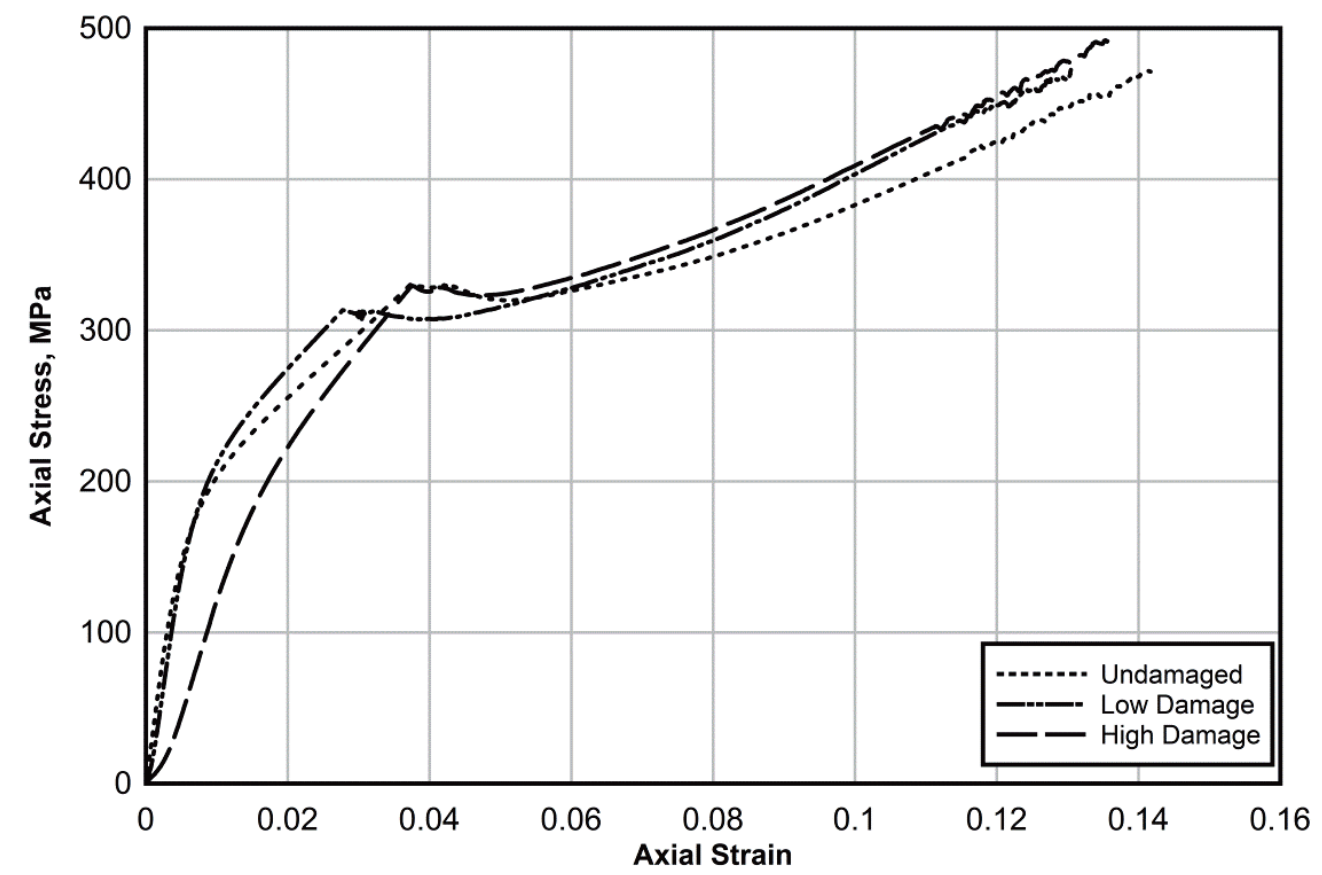

Figure A.20. Mean normal stress vs. volumetric strain for UX/CV tests with UX phase up to $200 \mathrm{MPa}$ pressure.

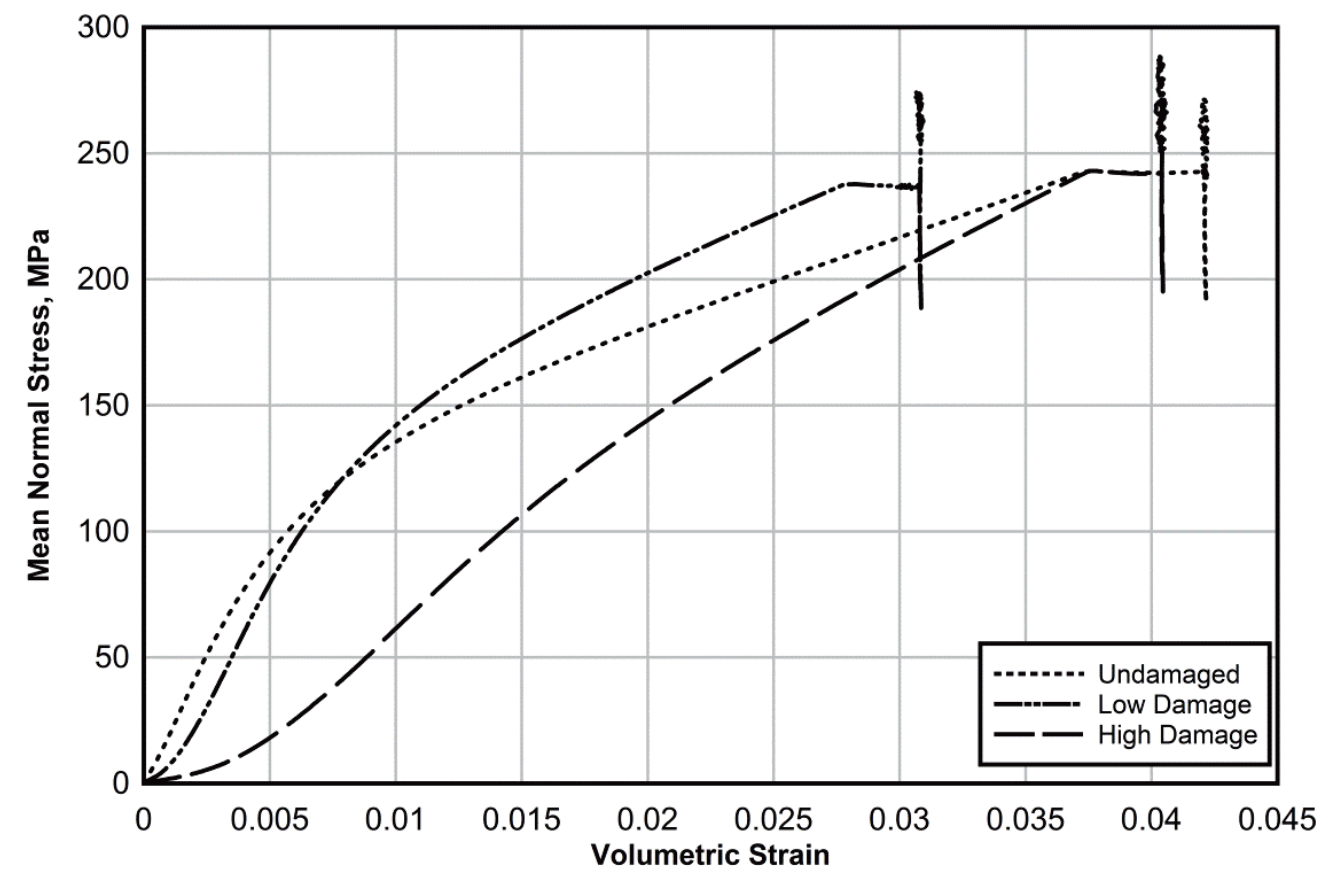


Figure A.21. Principal stress difference vs. mean normal stress for UX/CV tests with UX phase up to $200 \mathrm{MPa}$ pressure.

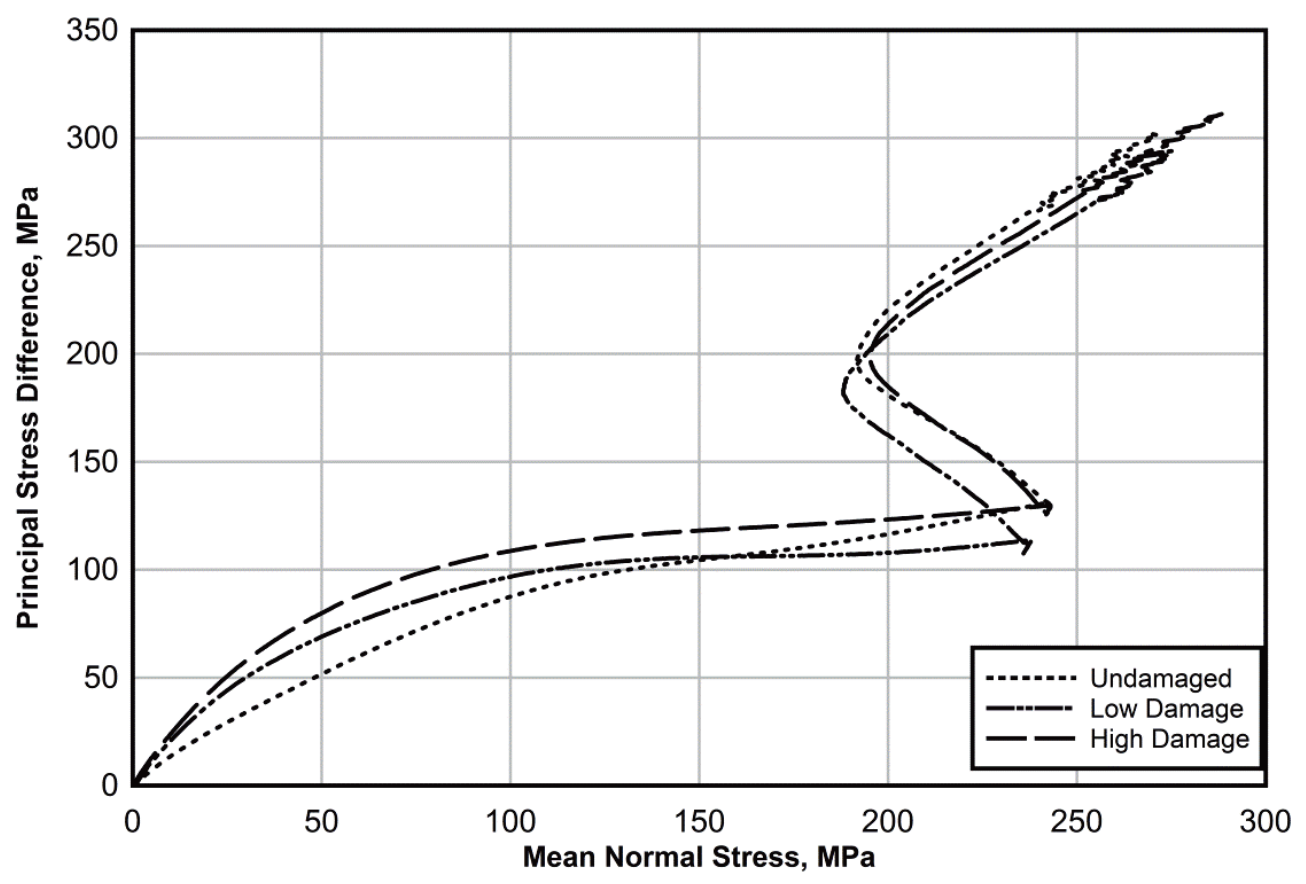

Figure A.22. Principal stress difference vs. axial strain for UX/CV tests with UX phase up to $200 \mathrm{MPa}$ pressure.

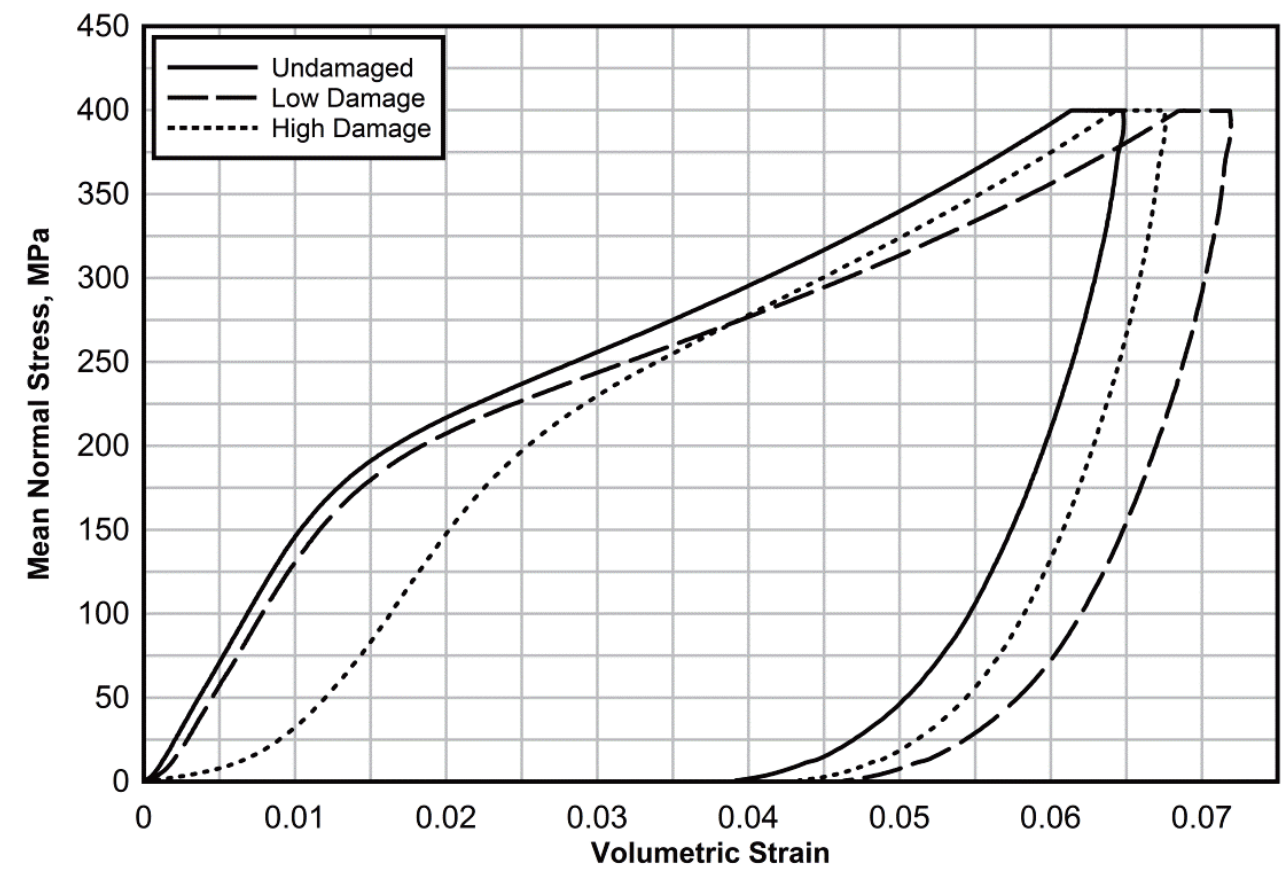


Figure A.23. Mean normal stress vs. volumetric strain for $\mathrm{HC}$ tests.

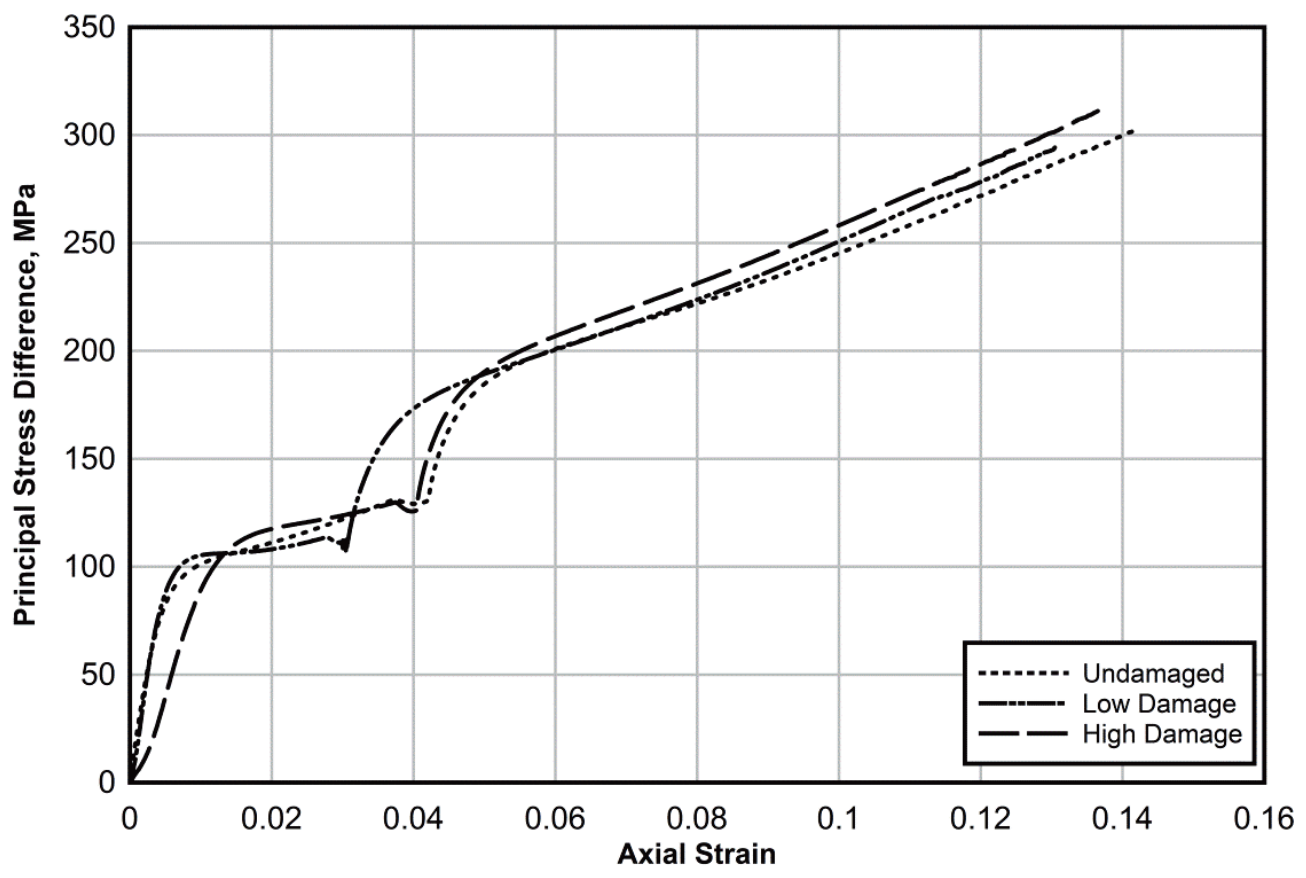




\section{Appendix B: Dynamic Testing Results}

Figure B.1. Interface stresses and strain rate from modified SHPB test on undamaged sample (sample 12F).

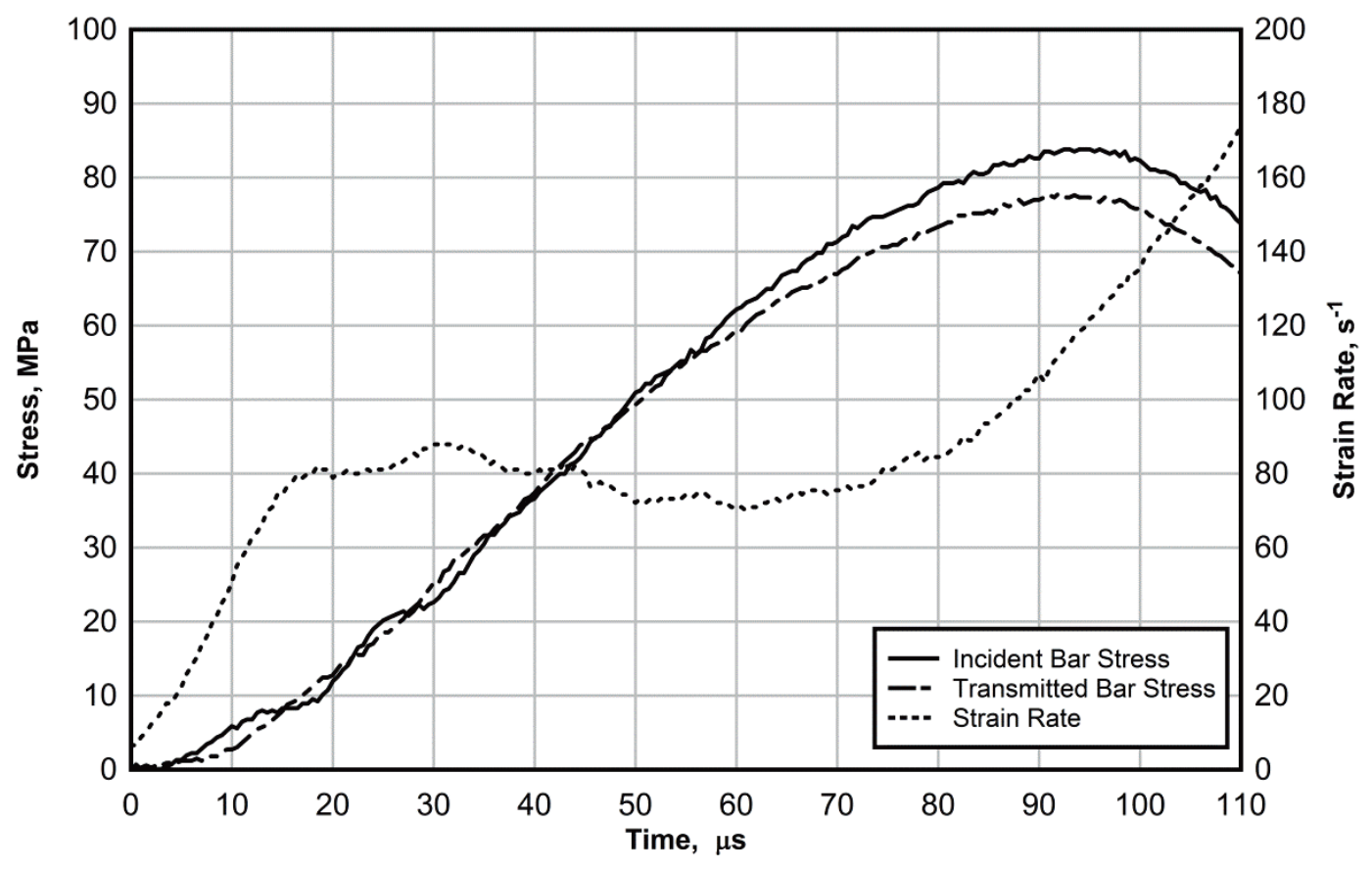


Figure B.2. Interface stresses and strain rate from modified SHPB test on undamaged sample (sample 15D).

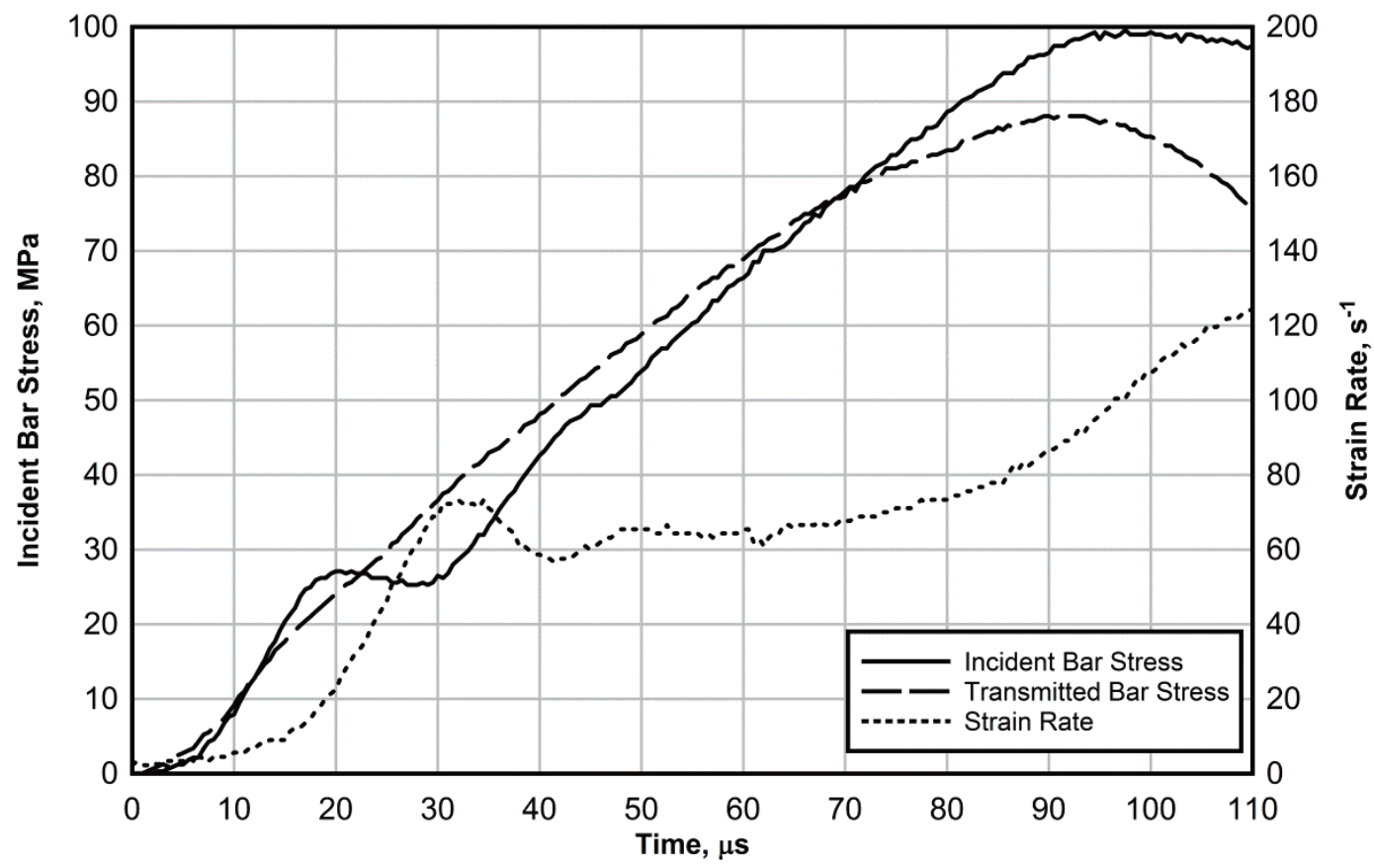

Figure B.3. Interface stresses and strain rate from modified SHPB test on low damage sample (sample 17D).

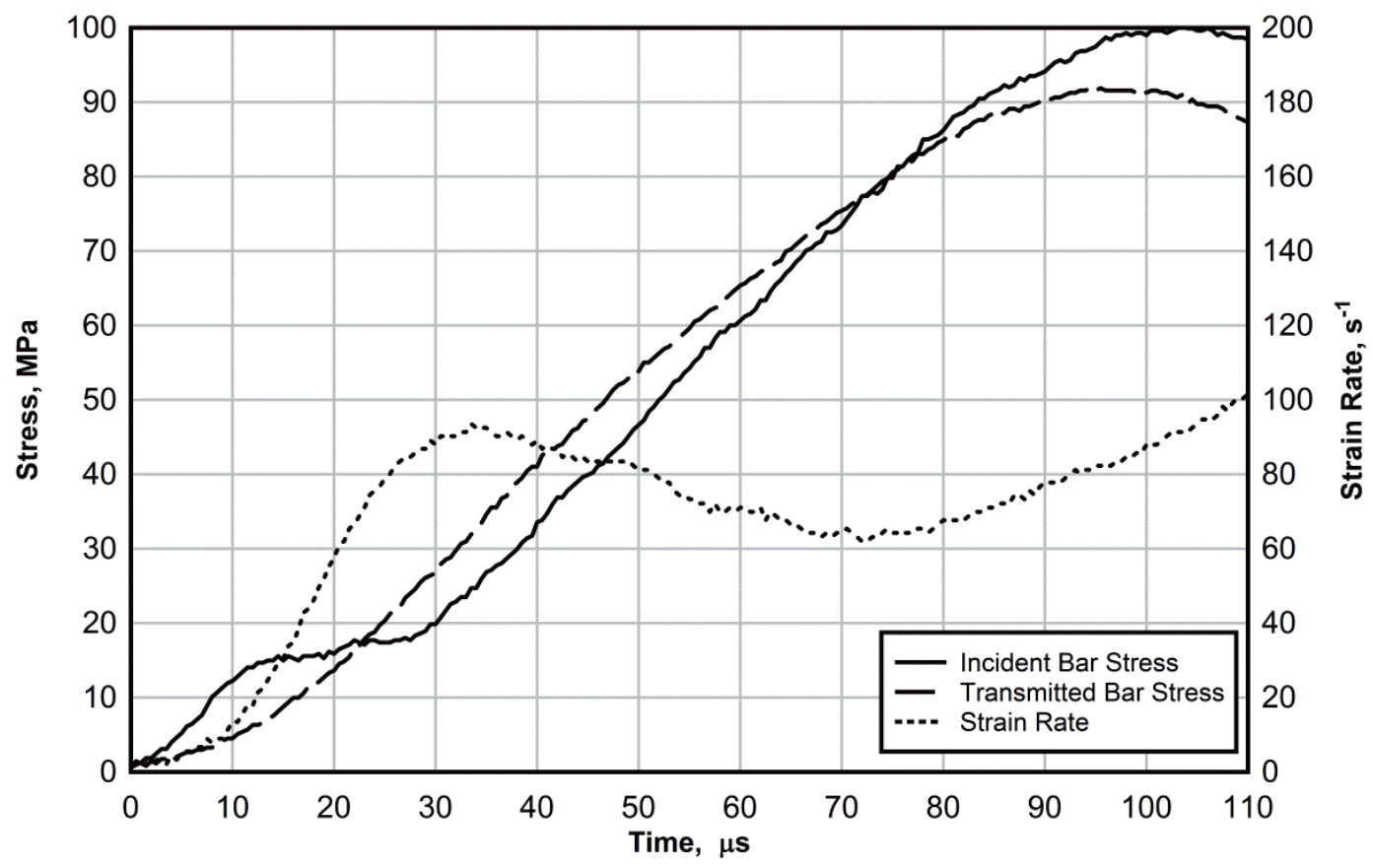


Figure B.4. Interface stresses and strain rate from modified SHPB test on low damage sample (sample 17B).

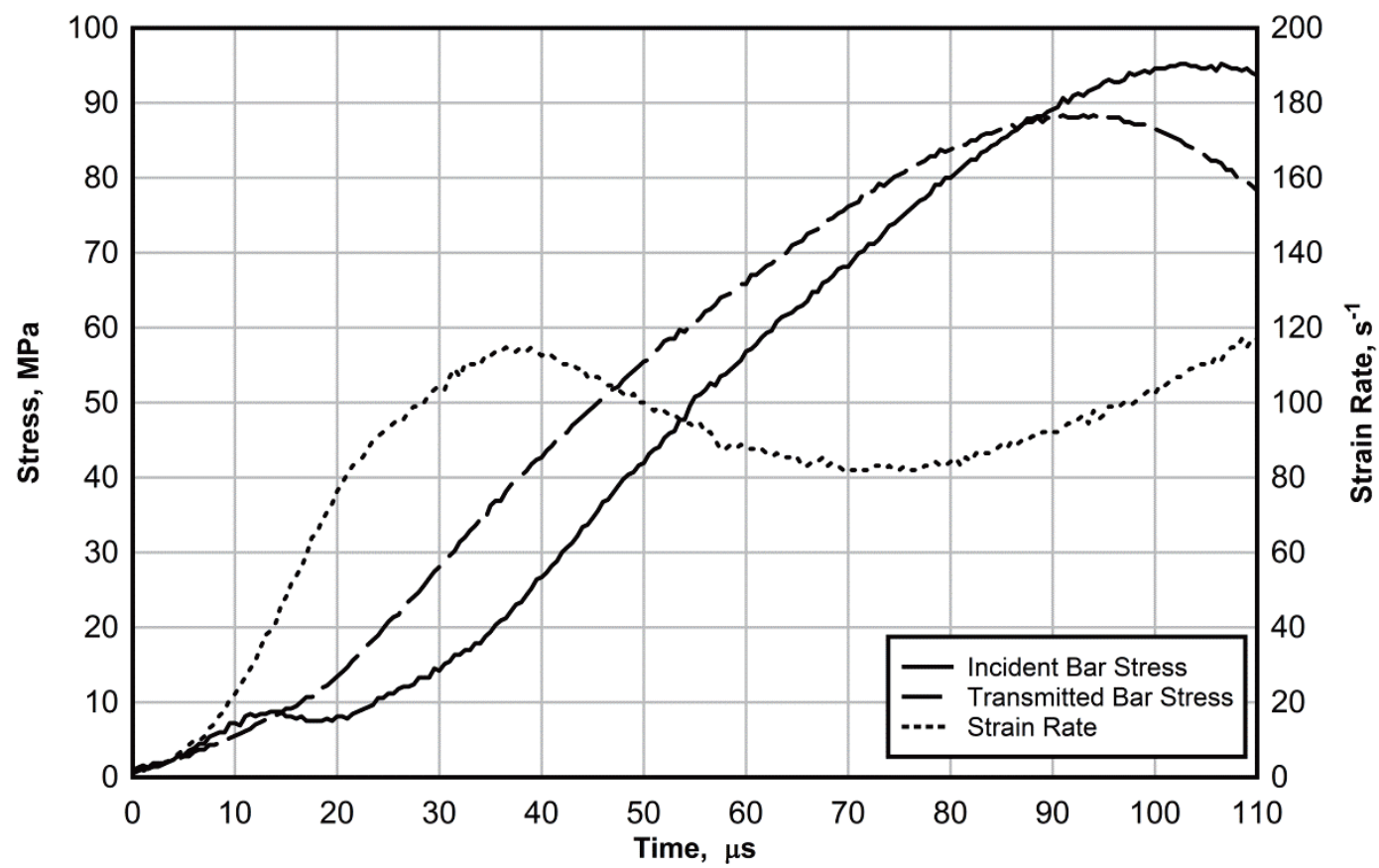

Figure B.5. Interface stresses and strain rate from modified SHPB test on low damage sample (sample 22A).

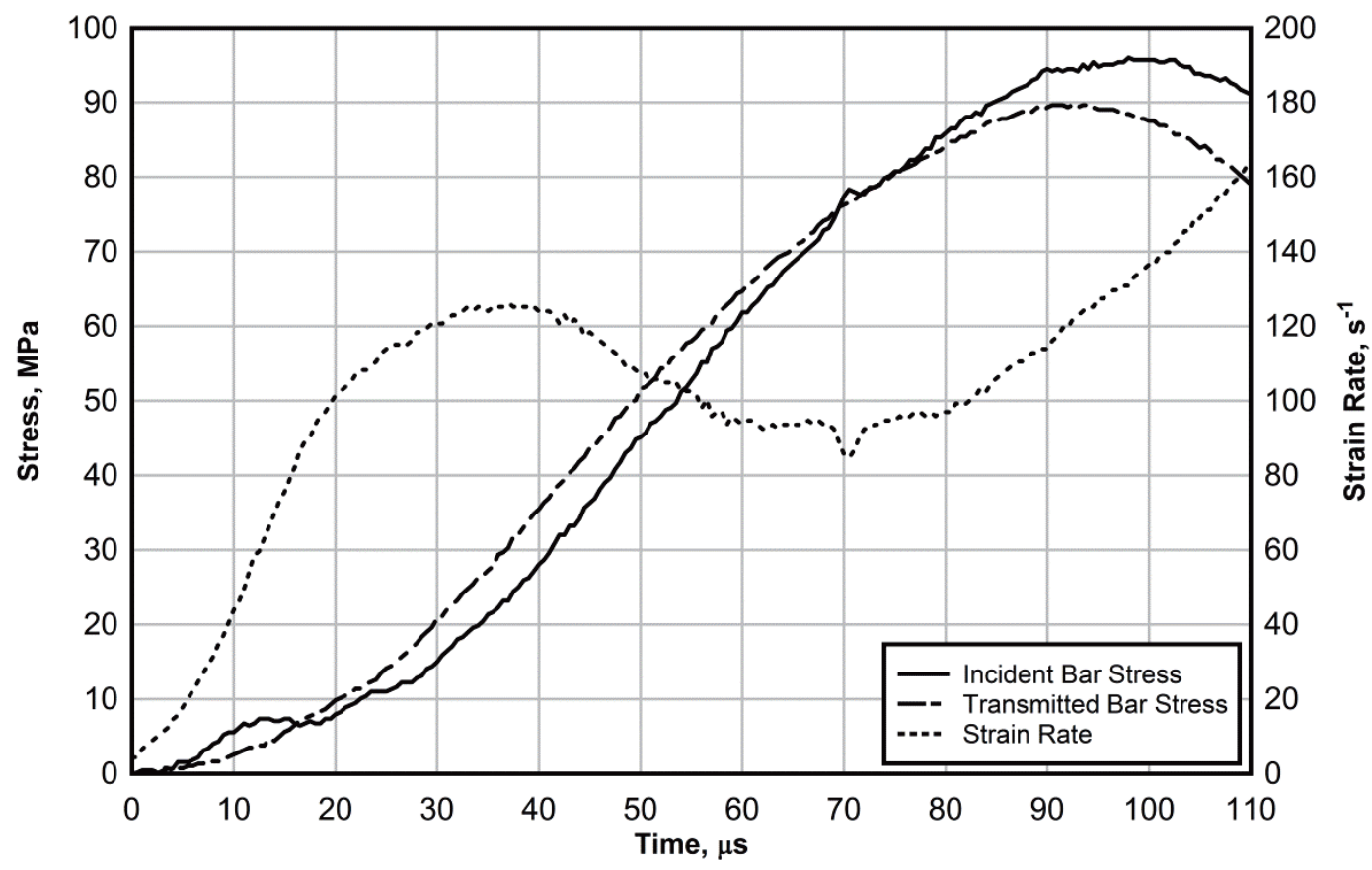


Figure B.6. Interface stresses and strain rate from modified SHPB test on high damage sample (sample 17C).

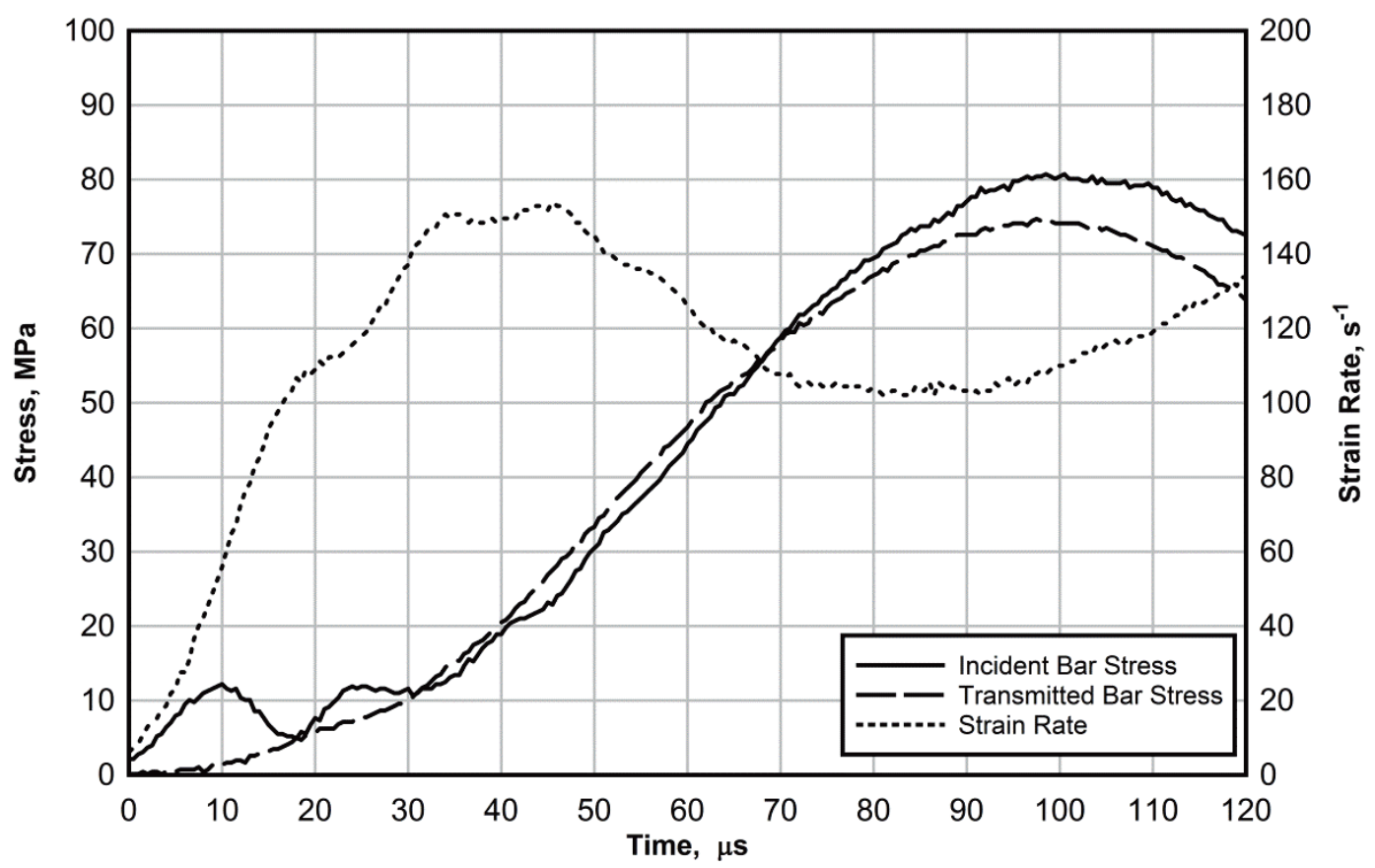

Figure B.7. Interface stresses and strain rate from modified SHPB test on high damage sample (sample 19E).

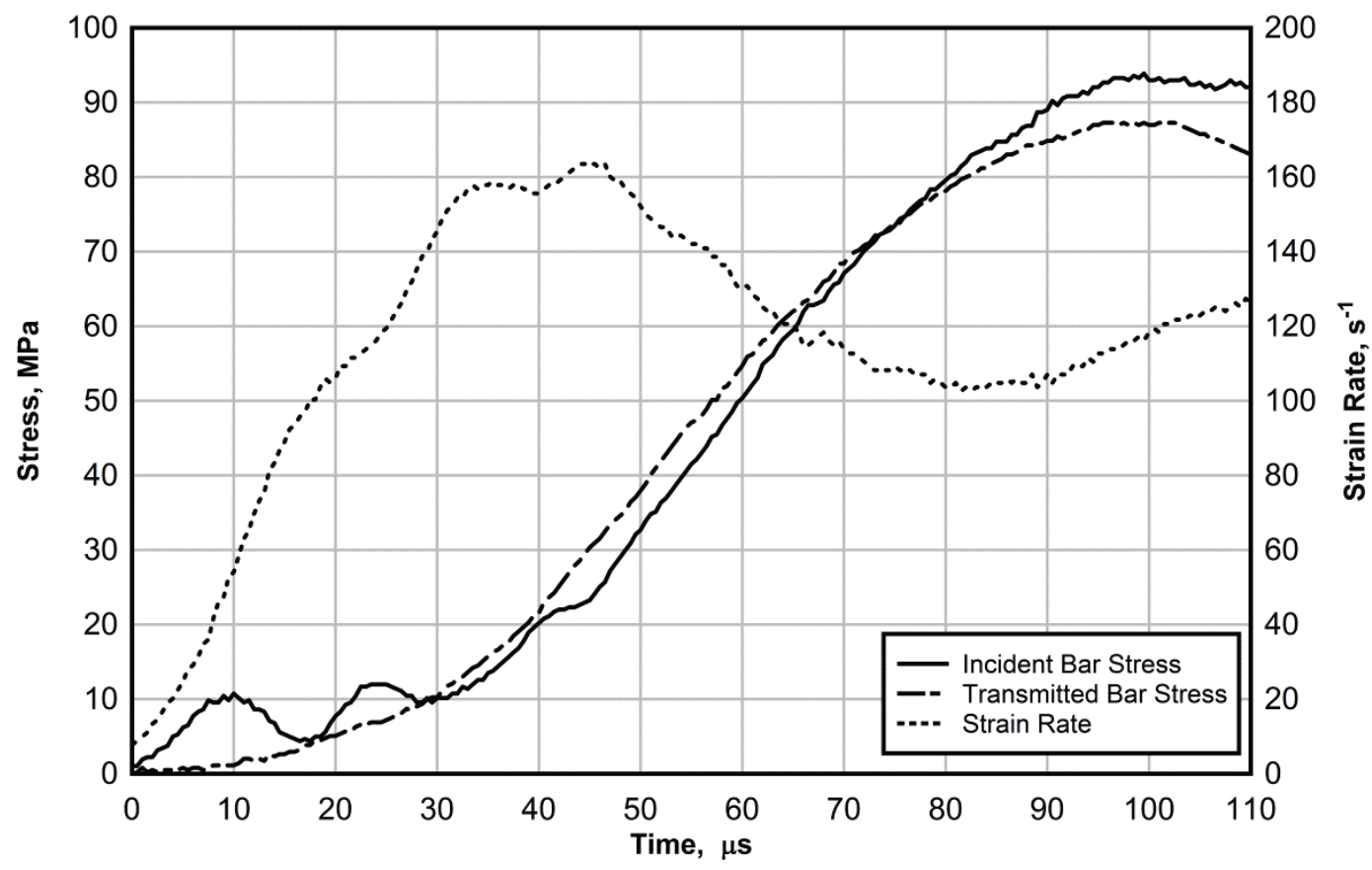


Figure B.8. Axial stress vs. axial strain for all SHPB tests.

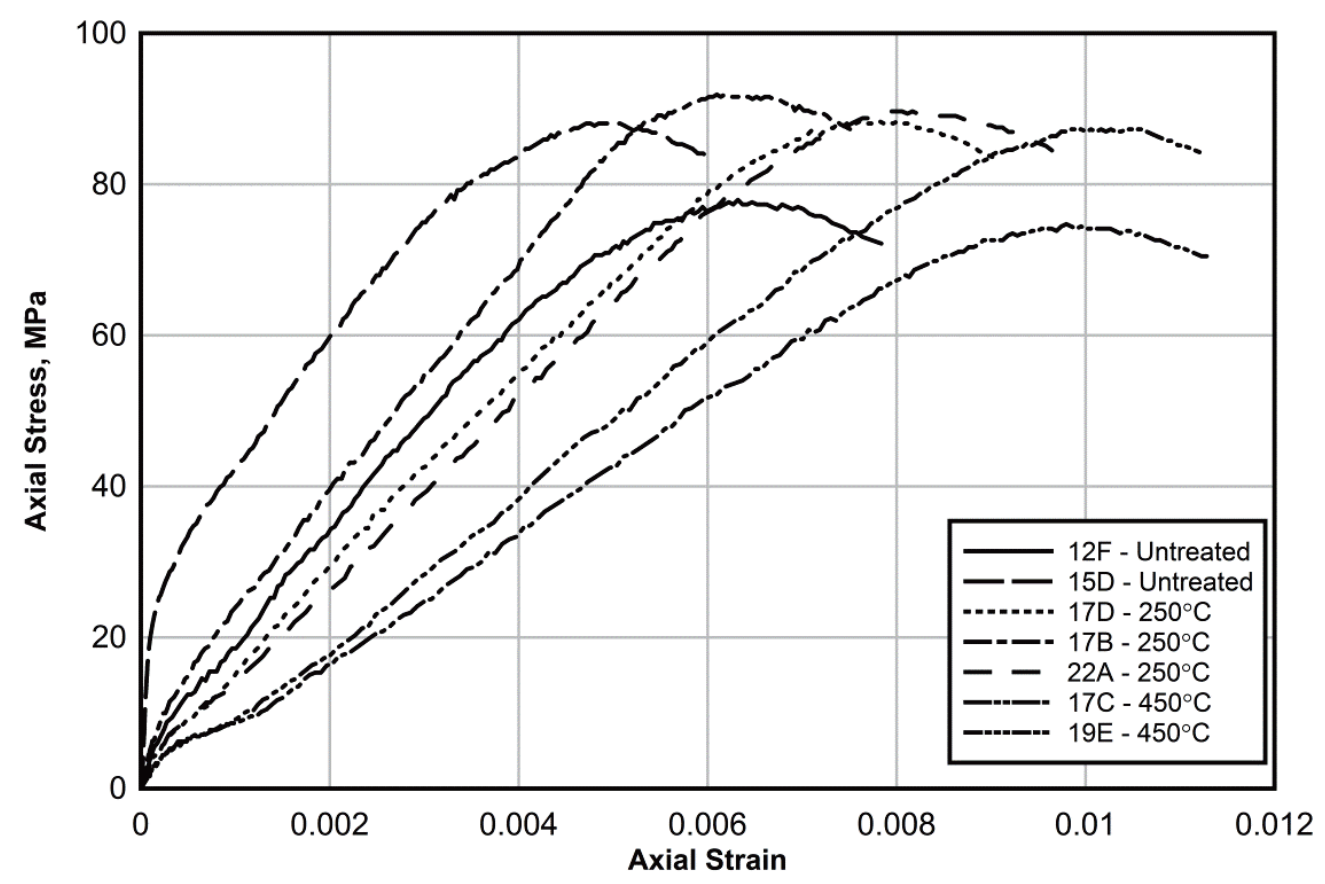




\section{Appendix C: Mechanical Test Sample Properties}

Table C.1. Mechanical test sample properties.

\begin{tabular}{|c|c|c|c|c|c|c|c|}
\hline $\begin{array}{c}\text { Test } \\
\text { Number }\end{array}$ & Type of Test & ID & Height, in & Dia, in & $\mathrm{Wt}, \mathrm{g}$ & Rad Stress, MPa & $\begin{array}{l}\text { Wet Density, } \\
\text { Mg/m3 }\end{array}$ \\
\hline 11sla01 & UC & SL-01-J-01 & 4.382 & 2.000 & 534.73 & & 2.370 \\
\hline 11sla02 & UC & SL-01-J-02 & 4.444 & 2.000 & 542.30 & & 2.370 \\
\hline 11sla03 & UC & SL-01-K-01 & 4.360 & 2.001 & 532.83 & & 2.371 \\
\hline 11sla04 & UC & SL-01-G-01 & 4.429 & 2.013 & 540.77 & & 2.341 \\
\hline 11sla05 & UC & SL-01-G-02 & 4.463 & 2.012 & 543.77 & & 2.339 \\
\hline 11sla06 & UC & SL-01-I-02 & 4.439 & 2.013 & 541.66 & & 2.340 \\
\hline 11sla07 & $\mathrm{UC}$ & SL-01-H-01 & 4.424 & 2.017 & 532.39 & & 2.298 \\
\hline 11sla08 & $\mathrm{UC}$ & SL-01-H-02 & 4.443 & 2.018 & 534.09 & & 2.294 \\
\hline 11sla09 & UC & SL-01-I-01 & 4.391 & 2.021 & 535.55 & & 2.320 \\
\hline $11 \mathrm{slb} 01$ & $\mathrm{TXC} / 20$ & SL-01-T-01 & 4.344 & 2.008 & 519.60 & 20 & 2.305 \\
\hline $11 \mathrm{slb} 02$ & $\mathrm{TXC} / 20$ & SL-01-O-01 & 4.416 & 1.999 & 535.46 & 20 & 2.358 \\
\hline $11 \mathrm{slb} 03$ & $\mathrm{TXC} / 20$ & SL-01-Q-01 & 4.439 & 2.000 & 542.51 & 20 & 2.374 \\
\hline $11 \mathrm{slb} 04$ & $\mathrm{TXC} / 20$ & SL-01-U-01 & 4.413 & 2.008 & 536.91 & 20 & 2.344 \\
\hline $11 \mathrm{slb} 05$ & $\mathrm{TXC} / 100$ & SL-01-P-01 & 4.402 & 1.999 & 543.22 & 100 & 2.399 \\
\hline $11 \mathrm{slb} 06$ & TXC/100 & SL-01-R-02 & 4.370 & 2.000 & 527.09 & 100 & 2.343 \\
\hline $11 \mathrm{slb} 07$ & TXC/100 & SL-01-U-02 & 4.412 & 2.008 & 534.62 & 100 & 2.335 \\
\hline $11 \mathrm{slb} 08$ & $\mathrm{TXC} / 100$ & SL-01-T-02 & 4.438 & 2.008 & 530.45 & 100 & 2.303 \\
\hline 11 slb09 & $\mathrm{TXC} / 20$ & SL-01-Y-01 & 4.418 & 2.002 & 523.22 & 20 & 2.296 \\
\hline 11 slb10 & $\mathrm{TXC} / 20$ & SL-01-Y-02 & 4.384 & 2.002 & 528.93 & 20 & 2.339 \\
\hline 11 slb11 & $\mathrm{TXC} / 100$ & SL-01-X-02 & 4.344 & 2.003 & 539.48 & 100 & 2.405 \\
\hline 11 slb12 & $\mathrm{TXC} / 100$ & SL-01-Z-01 & 4.338 & 2.001 & 543.27 & 100 & 2.430 \\
\hline 11 slb13 & $\mathrm{HC}$ & SL003 & 4.374 & 2.004 & 526.80 & 400 & 2.330 \\
\hline 11 slb14 & $\mathrm{HC}$ & SL014 & 4.410 & 2.012 & 533.19 & 400 & 2.321 \\
\hline 11 slb15 & $\mathrm{HC}$ & SL026 & 4.354 & 2.008 & 528.19 & 400 & 2.338 \\
\hline 11 slb16 & $\mathrm{TXC} / 10$ & SL006 & 4.396 & 2.004 & 531.65 & 10 & 2.340 \\
\hline $11 \mathrm{slb} 18$ & $\mathrm{TXC} / 10$ & SL015 & 4.374 & 2.017 & 535.84 & 10 & 2.340 \\
\hline 11 slb19 & $\mathrm{TXC} / 10$ & SL016 & 4.409 & 2.019 & 536.52 & 10 & 2.319 \\
\hline $11 \mathrm{slb} 20$ & $\mathrm{TXC} / 10$ & SL029 & 4.455 & 2.009 & 540.93 & 10 & 2.337 \\
\hline $11 \mathrm{slb} 21$ & $\mathrm{TXC} / 400$ & SL001 & 4.404 & 2.003 & 529.43 & 10 & 2.328 \\
\hline $11 \mathrm{slb} 22$ & $\mathrm{TXC} / 10$ & SL030 & 4.419 & 2.008 & 537.46 & 10 & 2.344 \\
\hline $11 \mathrm{slb} 23$ & $\mathrm{TXC} / 400$ & SL004 & 4.420 & 2.003 & 532.23 & 400 & 2.332 \\
\hline 11 slb24 & $\mathrm{TXC} / 400$ & SL022 & 4.467 & 2.017 & 538.63 & 400 & 2.303 \\
\hline 11 slb25 & $\mathrm{TXC} / 400$ & SL023 & 4.438 & 2.016 & 532.60 & 400 & 2.294 \\
\hline $11 \mathrm{slb} 26$ & $\mathrm{TXC} / 400$ & SL024 & 4.460 & 2.009 & 538.25 & 400 & 2.323 \\
\hline $11 \mathrm{slb} 27$ & $\mathrm{TXC} / 400$ & SL025 & 4.455 & 2.009 & 539.22 & 400 & 2.330 \\
\hline $11 \mathrm{slb} 28$ & $\mathrm{UX} / \mathrm{CV} / 100$ & SL008 & 4.269 & 2.003 & 516.30 & 100 & 2.342 \\
\hline 11 slb29 & $\mathrm{UX} / \mathrm{CV} / 100$ & SL017 & 4.411 & 2.018 & 537.05 & 100 & 2.323 \\
\hline $11 \mathrm{slb30}$ & $\mathrm{UX} / \mathrm{CV} / 100$ & SL027 & 4.464 & 2.009 & 543.41 & 100 & 2.343 \\
\hline $11 \mathrm{slb} 31$ & $\mathrm{UX} / \mathrm{CV} / 150$ & SL009 & 4.442 & 2.004 & 536.79 & 150 & 2.338 \\
\hline $11 \mathrm{slb32}$ & $\mathrm{UX} / \mathrm{CV} / 150$ & SL018 & 4.469 & 2.018 & 544.79 & 150 & 2.326 \\
\hline $11 \mathrm{slb33}$ & $\mathrm{UX} / \mathrm{CV} / 150$ & SL028 & 4.404 & 2.011 & 533.39 & 150 & 2.327 \\
\hline $11 \mathrm{slb34}$ & $\mathrm{UX} / \mathrm{CV} / 200$ & SL011 & 4.355 & 2.003 & 526.08 & 200 & 2.339 \\
\hline 11 slb35 & $\mathrm{UX} / \mathrm{CV} / 200$ & SL020 & 4.443 & 2.018 & 540.61 & 200 & 2.322 \\
\hline 11slb36 & $\mathrm{UX} / \mathrm{CV} / 200$ & SL032 & 4.276 & 2.019 & 517.91 & 200 & 2.309 \\
\hline 11 slb37 & $\mathrm{TXC} / 400$ & SL-01-X-01 & 4.358 & 2.004 & 525.23 & 400 & 2.332 \\
\hline
\end{tabular}


Table C.2. Additional mechanical test sample properties.

\begin{tabular}{|c|c|c|c|c|c|c|c|c|}
\hline Test Number & Specimen ID & $\begin{array}{c}\text { Posttest } \\
\text { Water } \\
\text { Content, \% }\end{array}$ & $\begin{array}{c}\text { Dry } \\
\text { Density, } \\
\text { Mg/m3 }\end{array}$ & Porosity, \% & $\mid \begin{array}{c}\text { Degree of } \\
\text { Saturation, \% }\end{array}$ & $\begin{array}{c}\text { Volume of } \\
\text { Air, } \%\end{array}$ & $\begin{array}{l}\text { Volume of } \\
\text { Water, \% }\end{array}$ & $\begin{array}{l}\text { Volume of } \\
\text { Solids, \% }\end{array}$ \\
\hline 11 sla01 & SL-01-J-01 & 0.0 & 2.369 & 13.75 & 0.86 & 13.64 & 0.12 & 86.25 \\
\hline 11 sla02 & SL-01-J-02 & 0.0 & 2.369 & 13.76 & 1.03 & 13.62 & 0.14 & 86.24 \\
\hline 11 sla03 & SL-01-K-01 & 0.06 & 2.370 & 13.72 & 1.04 & 13.58 & 0.14 & 86.28 \\
\hline 11 sla04 & SL-01-G-01 & 0.04 & 2.340 & 14.81 & 0.63 & 14.71 & 0.09 & 85.19 \\
\hline 11 sla05 & SL-01-G-02 & 0.04 & 2.338 & 14.90 & 0.63 & 14.81 & 0.09 & 85.10 \\
\hline 11 sla06 & SL-01-I-02 & 0.04 & 2.339 & 14.86 & 0.63 & 14.77 & 0.09 & 85.14 \\
\hline 11 sla07 & SL-01-H-01 & 0.03 & 2.298 & 16.36 & 0.42 & 16.29 & 0.07 & 83.64 \\
\hline 11 sla08 & SL-01-H-02 & 0.03 & 2.293 & 16.53 & 0.42 & 16.46 & 0.07 & 83.47 \\
\hline 11sla09 & SL-01-I-01 & 0.04 & 2.319 & 15.57 & 0.60 & 15.48 & 0.09 & 84.43 \\
\hline $11 \mathrm{slb} 01$ & SL-01-T-01 & 0.05 & 2.304 & 16.13 & 0.71 & 16.02 & 0.12 & 83.87 \\
\hline $11 \mathrm{slb} 02$ & SL-01-O-01 & \begin{tabular}{l|l}
0.1 \\
\end{tabular} & 2.355 & 14.26 & 1.65 & 14.02 & 0.24 & 85.74 \\
\hline $11 \mathrm{slb} 03$ & SL-01-Q-01 & 0.1 & 2.372 & 13.67 & 1.74 & 13.43 & 0.24 & 86.33 \\
\hline $11 \mathrm{slb} 04$ & SL-01-U-01 & 0.0 & 2.344 & 14.69 & 0.64 & 14.59 & 0.09 & 85.31 \\
\hline $11 \mathrm{slb} 05$ & SL-01-P-01 & 0.18 & 2.395 & 12.81 & 3.37 & 12.38 & 0.43 & 87.19 \\
\hline $11 \mathrm{slb} 06$ & SL-01-R-02 & 0.18 & 2.339 & 14.86 & 2.83 & 14.44 & 0.42 & 85.14 \\
\hline $11 \mathrm{slb} 07$ & SL-01-U-02 & \begin{tabular}{l|l}
0.0 \\
\end{tabular} & 2.333 & 15.06 & 1.08 & 14.89 & 0.16 & 84.94 \\
\hline $11 \mathrm{slb} 08$ & SL-01-T-02 & 0.07 & 2.302 & 16.21 & 0.99 & 16.05 & 0.16 & 83.79 \\
\hline $11 \mathrm{slb} 09$ & SL-01-Y-01 & 0.1 & 2.293 & 16.52 & 1.67 & 16.25 & 0.28 & 83.48 \\
\hline $11 \mathrm{slb} 10$ & SL-01-Y-02 & 0.1 & 2.336 & 14.97 & 2.03 & 14.66 & 0.30 & 85.03 \\
\hline $11 \mathrm{slb} 11$ & SL-01-X-02 & 0.0 & 2.403 & 12.51 & 1.35 & 12.34 & 0.17 & 87.49 \\
\hline $11 \mathrm{slb} 12$ & SL-01-Z-01 & 0.06 & 2.429 & 11.59 & 1.26 & 11.44 & 0.15 & 88.41 \\
\hline $11 \mathrm{slb} 13$ & SL003 & 0.12 & 2.327 & 15.28 & 1.83 & 15.00 & 0.28 & 84.72 \\
\hline $11 \mathrm{slb} 14$ & SL014 & 0.07 & 2.319 & 15.58 & 1.04 & 15.42 & 0.16 & 84.42 \\
\hline $11 \mathrm{slb} 15$ & SL026 & 0.18 & 2.333 & 15.05 & 2.79 & 14.63 & 0.42 & 84.95 \\
\hline $11 \mathrm{slb} 16$ & SL006 & 0.05 & 2.339 & 14.87 & 0.79 & 14.75 & 0.12 & 85.13 \\
\hline $11 \mathrm{slb} 18$ & SL015 & 0.03 & 2.339 & 14.85 & 0.47 & 14.78 & 0.07 & 85.15 \\
\hline $11 \mathrm{slb} 19$ & SL016 & 0.04 & 2.319 & 15.60 & 0.59 & 15.51 & 0.09 & 84.40 \\
\hline $11 \mathrm{slb} 20$ & SL029 & 0.07 & 2.336 & 14.97 & 1.09 & 14.80 & 0.16 & 85.03 \\
\hline $11 \mathrm{slb} 21$ & SL001 & 0.05 & 2.327 & 15.29 & 0.76 & 15.17 & 0.12 & 84.71 \\
\hline $11 \mathrm{slb} 22$ & SL030 & 0.07 & 2.342 & 14.74 & 1.11 & 14.58 & 0.16 & 85.26 \\
\hline $11 \mathrm{slb} 23$ & SL004 & 0.17 & 2.328 & 15.25 & 2.59 & 14.86 & 0.40 & 84.75 \\
\hline $11 \mathrm{slb} 24$ & SL022 & 0.08 & 2.301 & 16.23 & 1.13 & 16.05 & 0.18 & 83.77 \\
\hline $11 \mathrm{slb} 25$ & SL023 & 0.09 & 2.292 & 16.56 & 1.25 & 16.35 & 0.21 & 83.44 \\
\hline $11 \mathrm{slb} 26$ & SL024 & 0.20 & 2.319 & 15.59 & 2.97 & 15.13 & 0.46 & 84.41 \\
\hline $11 \mathrm{slb} 27$ & SL025 & 0.20 & 2.325 & 15.35 & 3.03 & 14.88 & 0.47 & 84.65 \\
\hline $11 \mathrm{slb} 28$ & SL008 & 0.12 & 2.339 & 14.84 & 1.89 & 14.56 & 0.28 & 85.16 \\
\hline 11slb29 & SL017 & 0.06 & 2.322 & 15.49 & 0.90 & 15.35 & 0.14 & 84.51 \\
\hline $11 \mathrm{slb} 30$ & SL027 & 0.15 & 2.340 & 14.82 & 2.37 & 14.47 & 0.35 & 85.18 \\
\hline $11 \mathrm{slb} 31$ & SL009 & 0.12 & 2.335 & 14.99 & 1.87 & 14.71 & 0.28 & 85.01 \\
\hline $11 \mathrm{slb} 32$ & SL018 & 0.06 & 2.324 & 15.38 & 0.91 & 15.24 & 0.14 & 84.62 \\
\hline $11 \mathrm{slb} 33$ & SL028 & 0.18 & 2.323 & 15.44 & 2.71 & 15.03 & 0.42 & 84.56 \\
\hline $11 \mathrm{slb} 34$ & SL011 & 0.12 & 2.337 & 14.94 & 1.88 & 14.66 & 0.28 & 85.06 \\
\hline $11 \mathrm{slb} 35$ & SL020 & 0.07 & 2.320 & 15.55 & 1.04 & 15.39 & 0.16 & 84.45 \\
\hline $11 \mathrm{slb} 36$ & SL032 & 0.19 & 2.304 & 16.12 & 2.72 & 15.68 & 0.44 & 83.88 \\
\hline $11 \mathrm{slb} 37$ & SL-01-X-01 & 0.1 & 2.328 & 15.24 & 2.29 & 14.90 & 0.35 & 84.76 \\
\hline
\end{tabular}




\section{Appendix D: SHPB Simulation Input File}

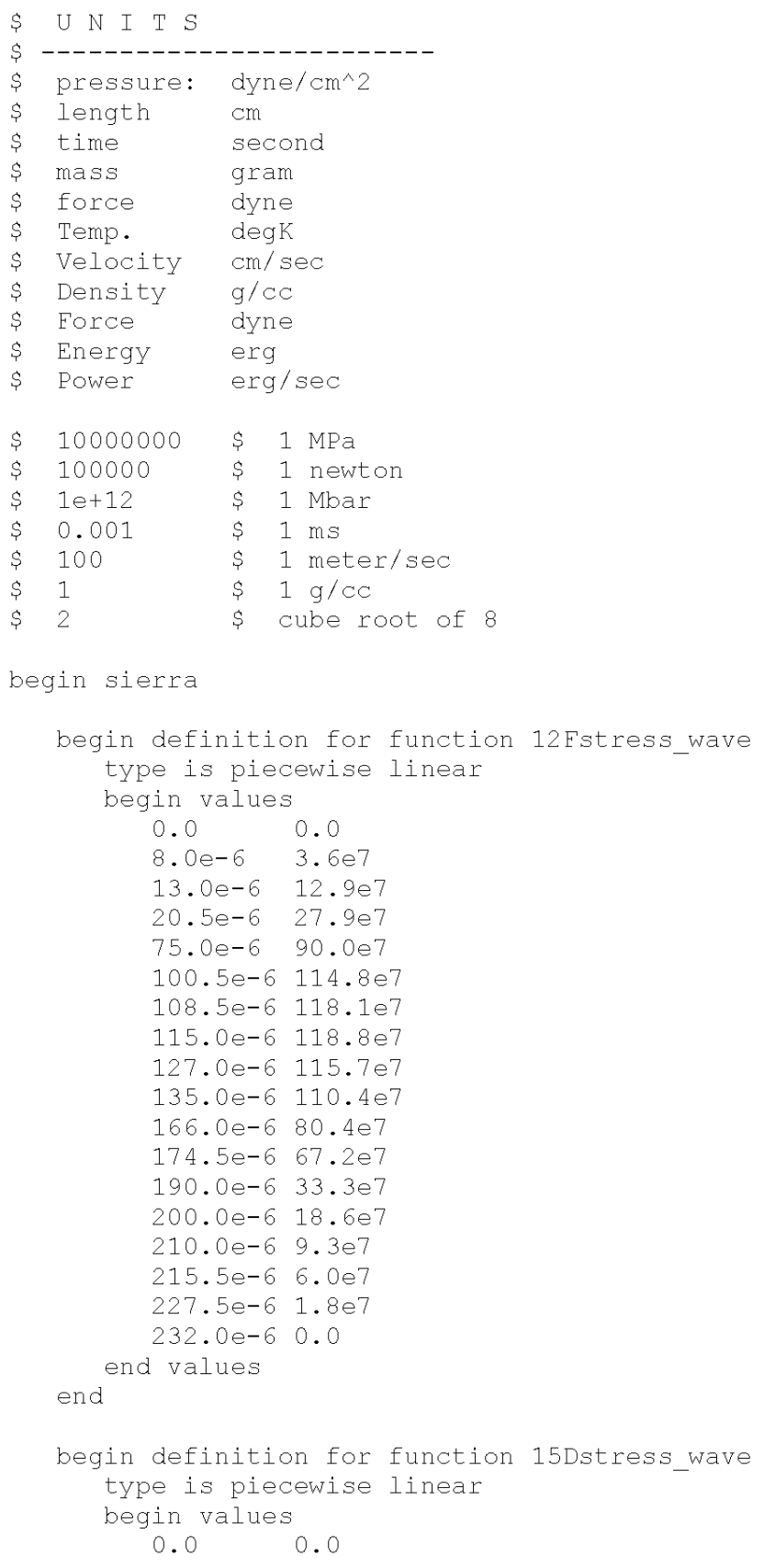




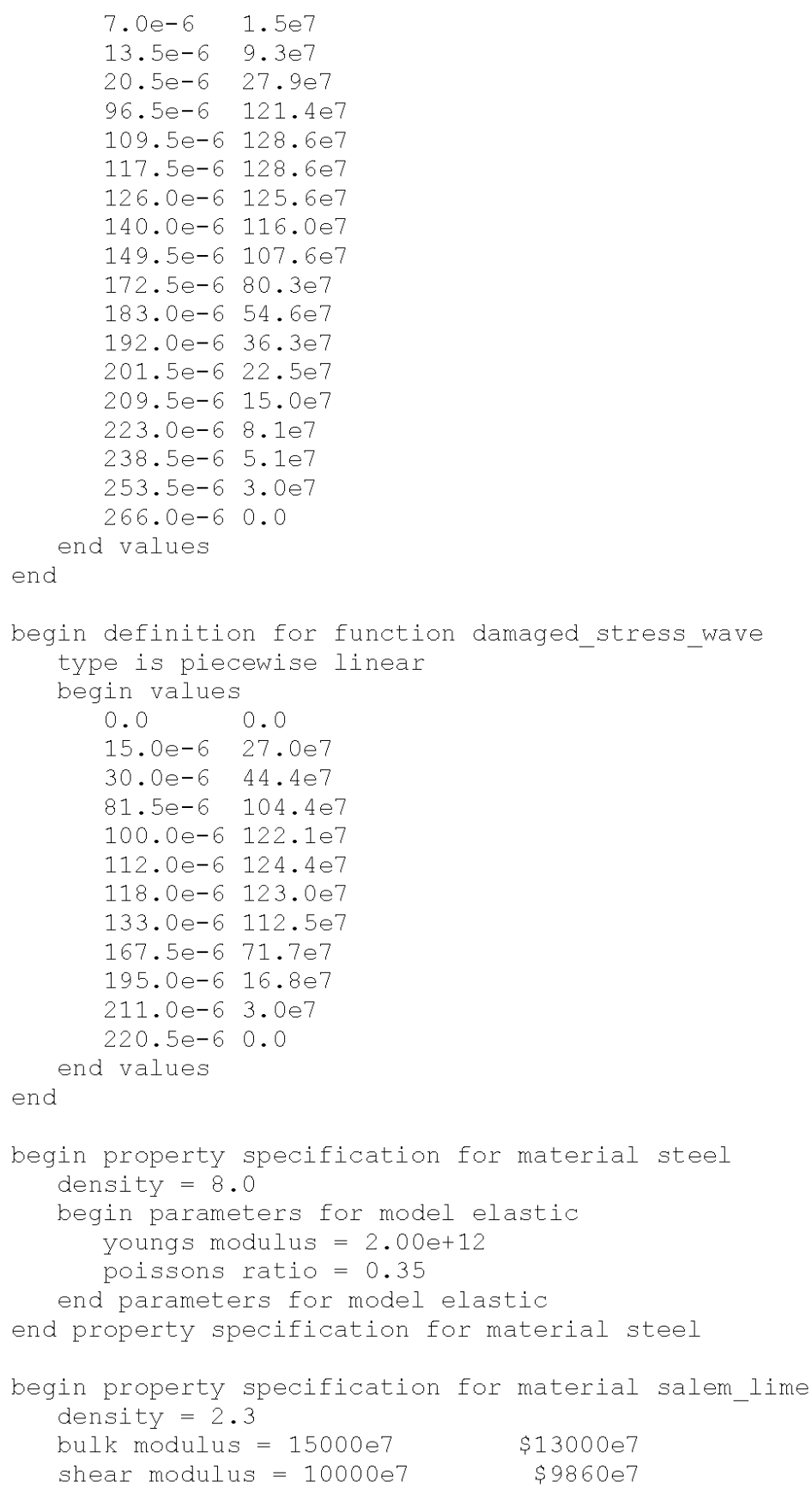




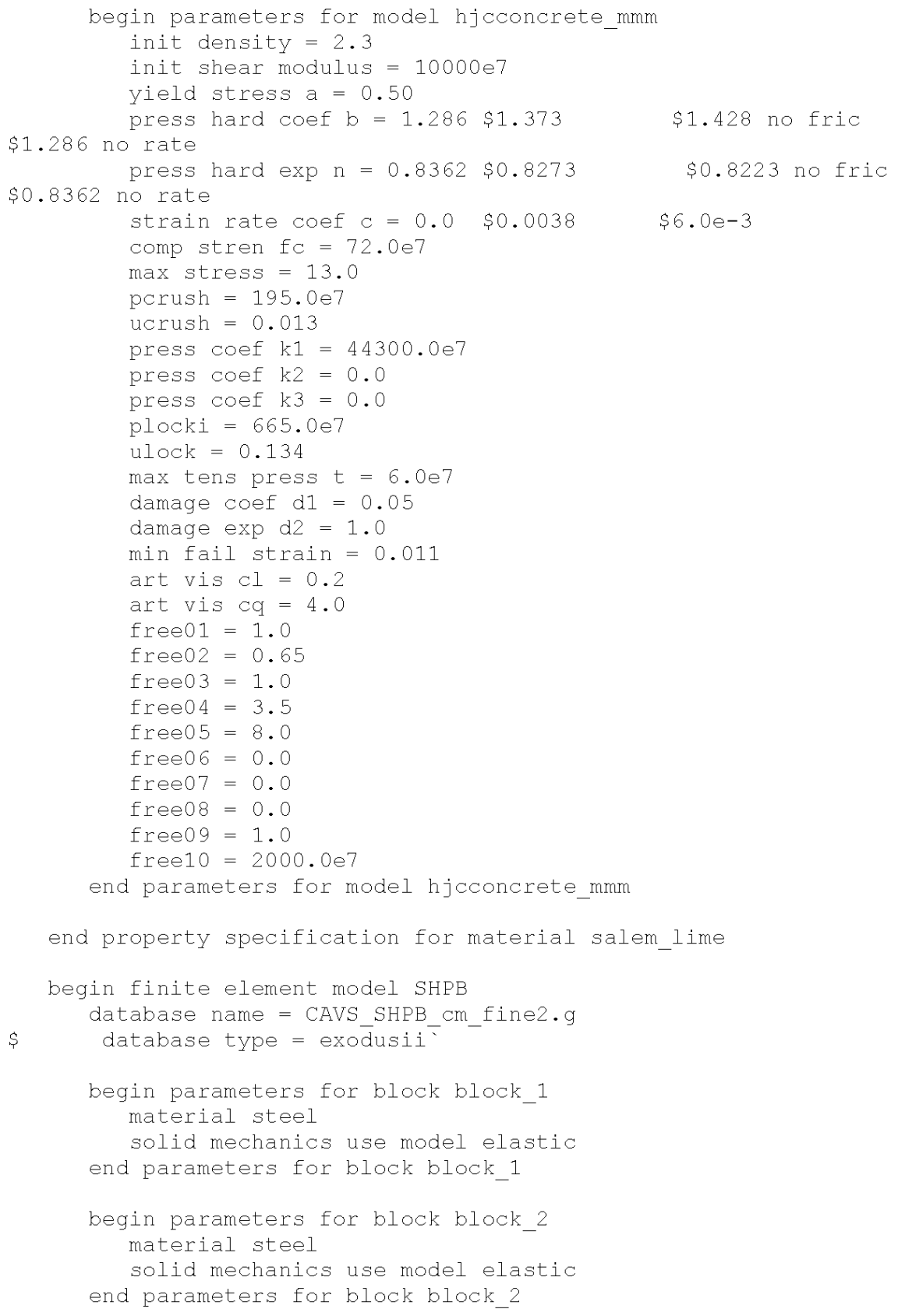




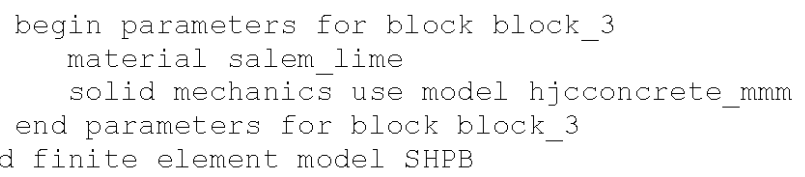

begin presto procedure presto_procedure

begin time control

begin time stepping block stress_input

start time $=0.0$

begin parameters for presto region presto_region

step interval $=25$

$\$$

S

time step scale factor $=0.10$

end parameters for presto region presto_region

end time stepping block stress_input

termination time $=1000 e-6$

end time control

begin presto region presto region

use finite element modē SHPB

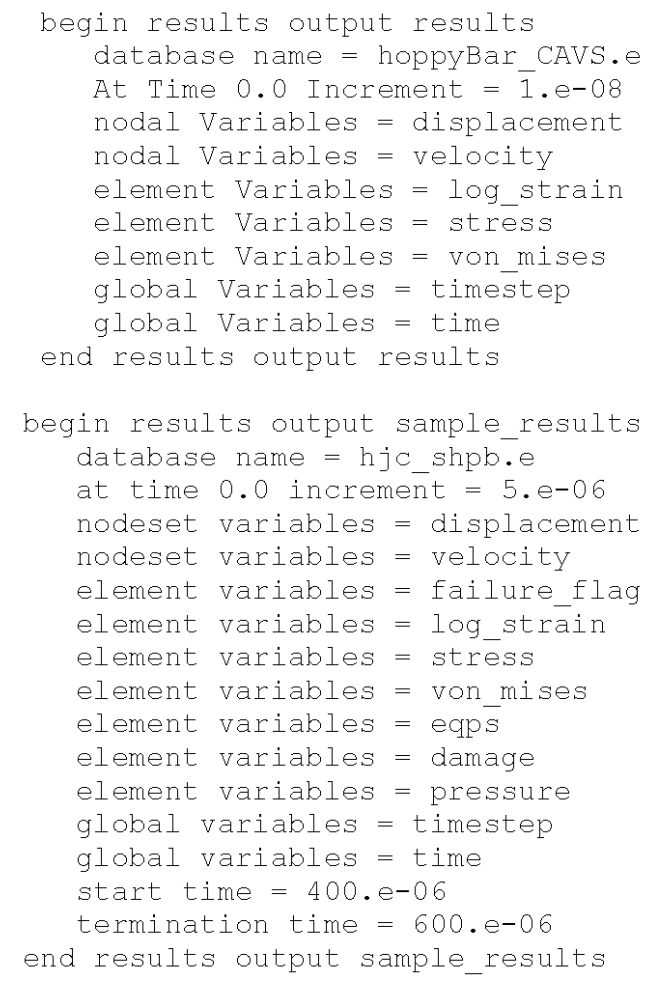




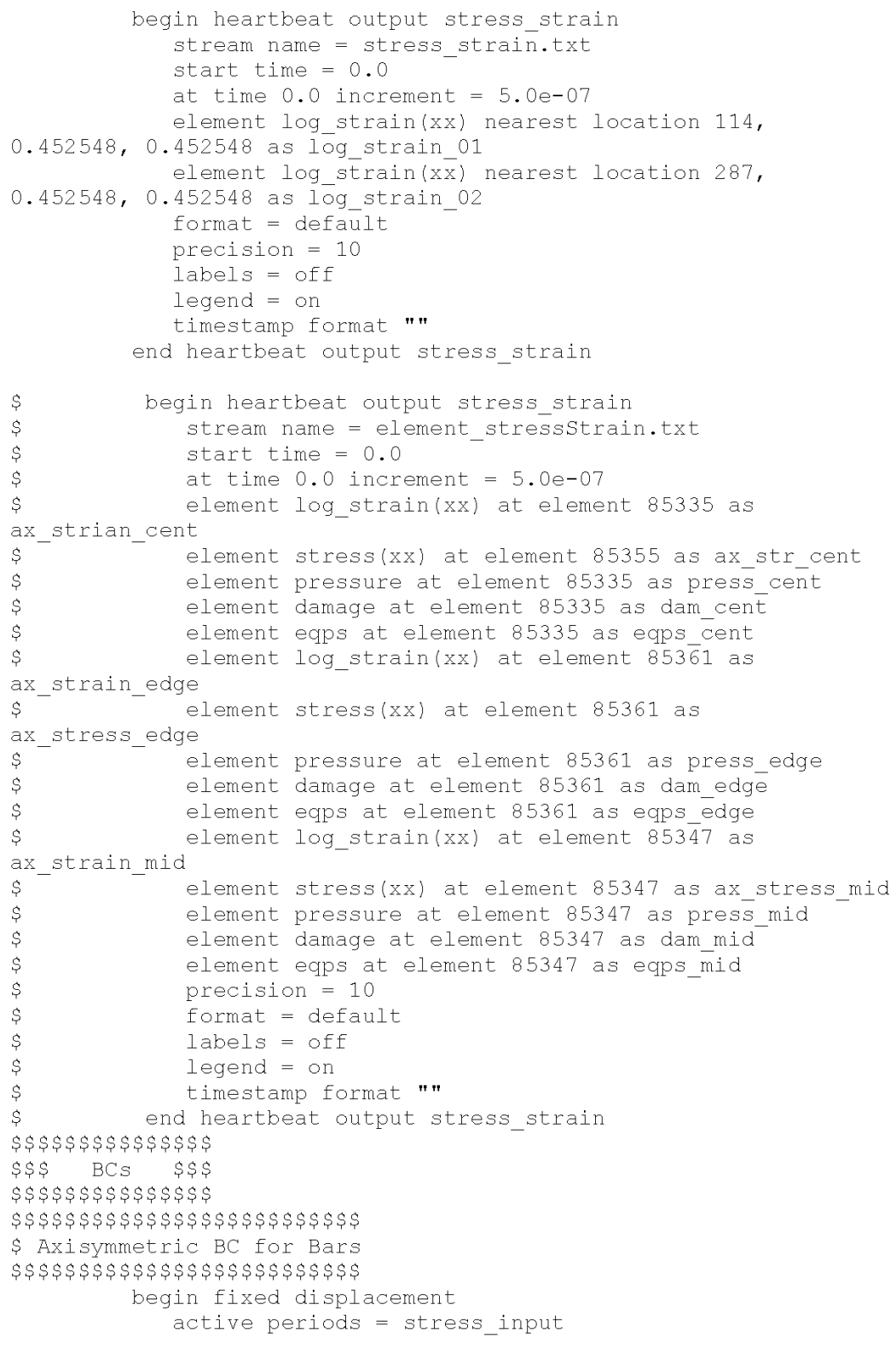




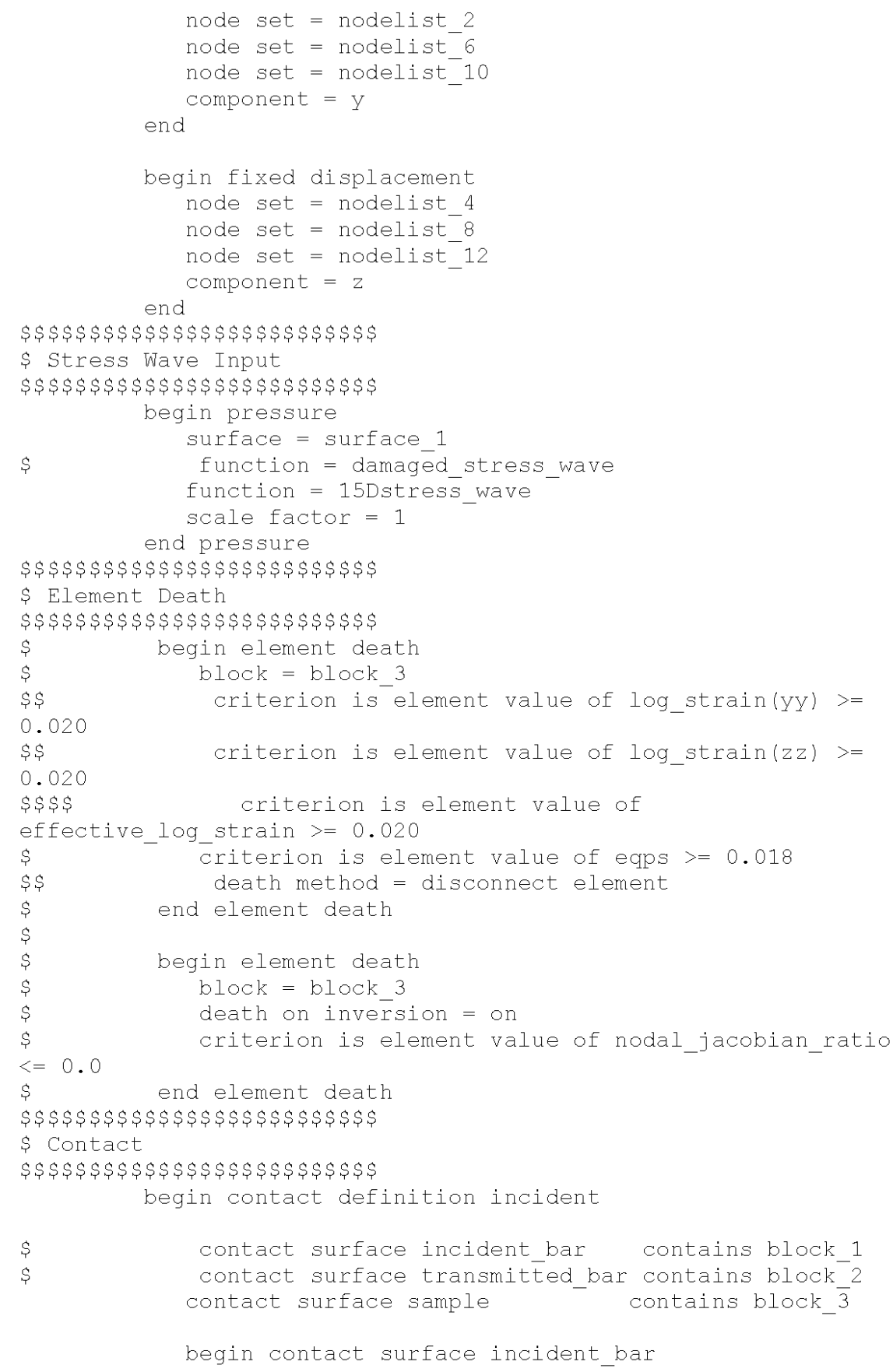




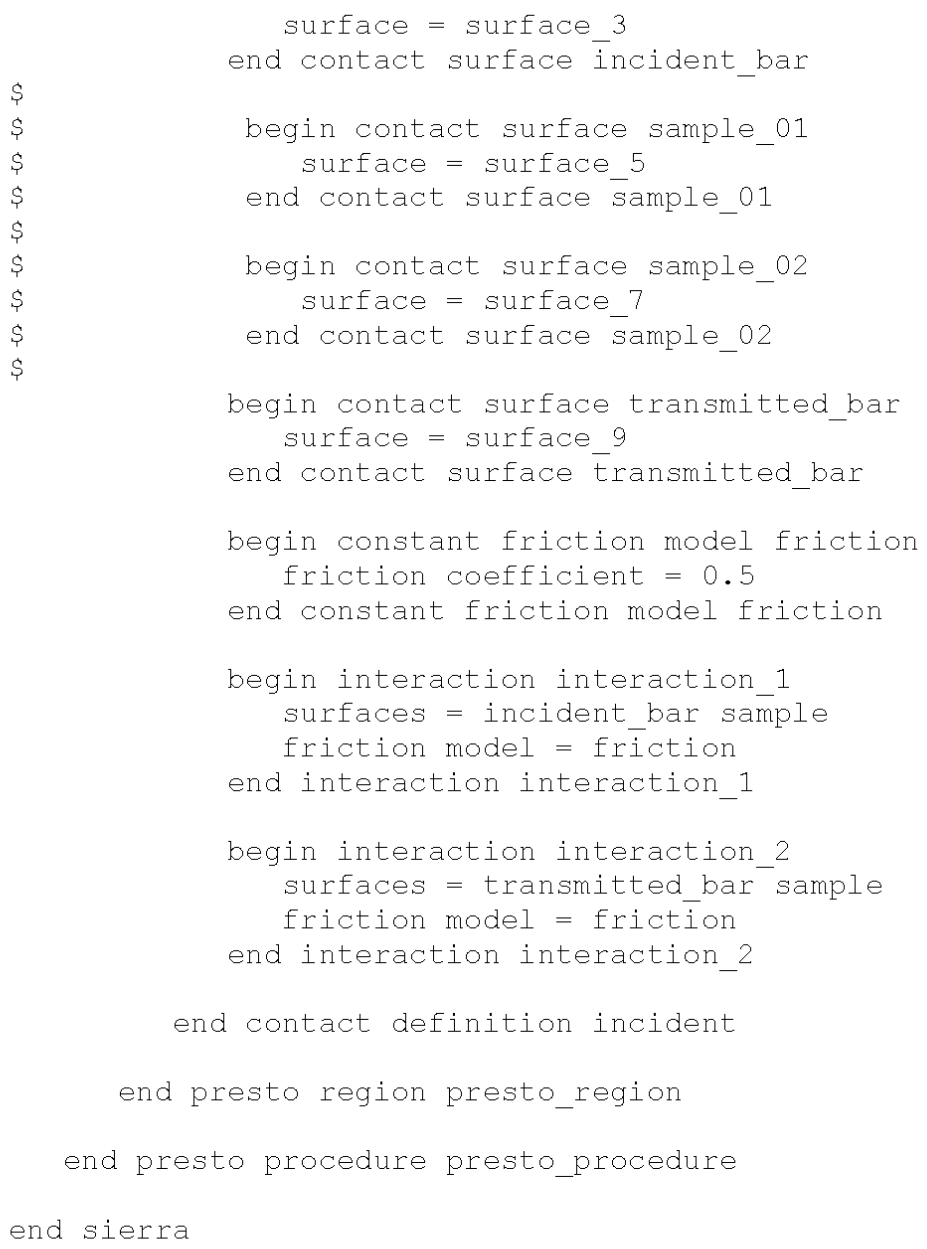




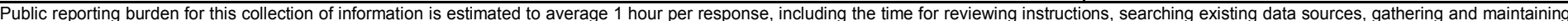

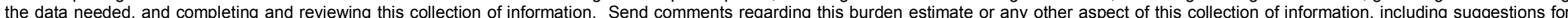

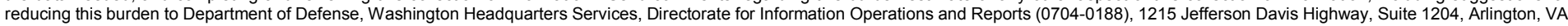

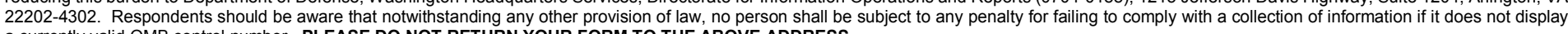
a currently valid OMB control number. PLEASE DO NOT RETURN YOUR FORM TO THE ABOVE ADDRESS.
1. REPORT DATE (DD-MM-YYYY)
June 2017

\section{TITLE AND SUBTITLE}

Effects of Thermally Induced Microcracking on the Quasi-Static and Dynamic Response of Salem Limestone

\section{DATES COVERED (From - To)}

5a. CONTRACT NUMBER

5b. GRANT NUMBER

5c. PROGRAM ELEMENT NUMBER

5d. PROJECT NUMBER

P2 331691

5e. TASK NUMBER

5f. WORK UNIT NUMBER

\section{PERFORMING ORGANIZATION NAME(S) AND ADDRESS(ES)}

Geotechnical and Structures Laboratory

U.S. Army Engineer Research and Development Center

3909 Halls Ferry Road

Vicksburg, MS 39180-6199

\section{SPONSORING / MONITORING AGENCY NAME(S) AND ADDRESS(ES)}

U.S. Army Engineer Research and Development Center

Vicksburg, MS
8. PERFORMING ORGANIZATION REPORT NUMBER

ERDC/GSL TR-17-15
10. SPONSOR/MONITOR'S ACRONYM(S)

USACE

11. SPONSOR/MONITOR'S REPORT NUMBER(S)

\section{DISTRIBUTION / AVAILABILITY STATEMENT}

Approved for public release; distribution is unlimited.

\section{SUPPLEMENTARY NOTES}

\section{ABSTRACT}

The effects of microcracking on the mechanical properties of Salem limestone were investigated in three phases: introduction of quantifiable levels of microcracks by thermal treating, mechanical testing of limestone samples with varying levels of microcracks, and modification of a numerical model to incorporate the measured effects. Computed tomography scanning, scanning electron microscopy, and optical microscopy (OM) were used to observe microstructural changes caused by the heat treatments. Mechanical testing was performed to characterize the mechanical response of the intact and damaged limestone. Quasi-static tests included uniaxial compression, triaxial compression, hydrostatic compression, and uniaxial strain / constant volume tests. Microcracking did not affect the limestone's strength at pressures greater than $10 \mathrm{MPa}$. Dynamic tests were performed using a modified split Hopkinson pressure bar.

The results of the mechanical tests were used to modify the HJC model. Modifications were made to account for shear modulus degradation and failure surface changes. The original and modified HJC models were used in a numerical analysis of the mechanical tests performed in this work. The modified HJC provided better results for damaged material when compared with the quasi-static and dynamic experiments. This work demonstrated that this approach is useful for examination of the effects of microcracking on quasi-brittle materials and can be used to improve the predictive capabilities of material models.

15. SUBJECT TERMS (see reverse)

\begin{tabular}{|l|l|l|l|l|l|}
\hline \multicolumn{2}{|l|}{ 16. SECURITY CLASSIFICATION OF: } & $\begin{array}{l}\text { 17. LIMITATION } \\
\text { OF ABSTRACT }\end{array}$ & $\begin{array}{l}\text { 18. NUMBER } \\
\text { OF PAGES }\end{array}$ & $\begin{array}{l}\text { 19a. NAME OF RESPONSIBLE } \\
\text { PERSON }\end{array}$ \\
\hline \begin{tabular}{c|c} 
a. REPORT \\
Unclassified
\end{tabular} & $\begin{array}{c}\text { b. ABSTRACT } \\
\text { Unclassified }\end{array}$ & $\begin{array}{c}\text { c. THIS PAGE } \\
\text { Unclassified }\end{array}$ & SAR & $\begin{array}{l}\text { 19b. TELEPHONE NUMBER (include } \\
\text { area code) }\end{array}$ \\
\hline
\end{tabular}


15. SUBJECT TERMS (concluded)

Quasi-static testing

Dynamic testing

Limestone - Cracking

Split Hopkinson Pressure Bar (SHPB)

Damage model

Microcracking

Thermal effects

Materials - Mechanical properties

Microstructure

Fracture mechanics

Brittleness

Numerical analysis 